\title{
Frank Golczewski
}

\section{Polen}

Die Gebiete des 1939 von Deutschland überfallenen polnischen Staates nehmen im Hinblick auf den Völkermord an den Juden eine Sonderstellung ein, die nur mit der der besetzten sowjetischen Gebiete vergleichbar ist." Zum einen lebten in Polen 1939 mehr Juden als in irgendeinem anderen europäischen Staat, zum anderen brachten die Deutschen auf ehemals polnischem Territorium diejenigen Einrichtungen unter, deren unfaßbare Grausamkeit noch auf lange Zeit ein unbefangenes Herangehen an die deutsche Geschichte jener Jahre unmöglich machen wird: In den Ghettos, den Konzentrations- und Vernichtungslagern sowie in zahllosen Arbeitslagern wurde zwischen 1939 und 1945 die Mehrzahl der europäischen Juden umgebracht - zuvor fanden aus ganz Europa Transporte in das ehemalige Polen statt.

Um die Vorbehalte, die allen konkreten Angaben über die als jüdisch eingeordneten Opfer des Nationalsozialismus gegenüber angebracht sind, zu erlāutern, wollen wir zunāchst die Hauptprobleme benennen und die Wege umreißen, die gewāhlt wurden, um sie zu bewāltigen. Daß diese nicht immer optimal sind, ist dem Verfasser klar andererseits sah er sich aber der Notwendigkeit gegenüber, zu nachvollziehbaren Ergebnissen auf der Basis der vorliegenden Forschungsarbeiten zu gelangen, und so scheint das Offenlegen der möglichen Fehlerquellen zumindest eine Z $\mathbf{Z}$ wischenbilanz zu ermöglichen, von der aus spāter einmal eine höhere Genauigkeit erzielende Forschungsarbeiten möglich sein sollten.

Problematisch ist bereits die territoriale Abgrenzung des bearbeiteten Territoriums: Der polnische Vorkriegsstaat ist mit demjenigen der Zeit nach 1945 territorial nicht identisch, also lassen sich auch die quantitativen Angaben zur Bevölkerung Polens nicht ohne weiteres vergleichen. Aber auch in den Jahren des $Z$ weiten Weltkriegs selber gab es keine territoriale Einheit, die mit dem Vor- oder Nachkriegspolen gleichzusetzen oder auch nur mühelos zu vergleichen wäre: Im Westen wurden kleinere Teile verwaltungsmāßig vollstāndig dem Reich „eingegliedert“ (Danzig, Ostoberschlesien), andere wiederum zwar formell annektiert, aber durch eine ${ }_{n}$ Polizeigrenze ${ }^{\text {u abgeriegelt }}$ und damit mit einer eigenen Qualitāt versehen (Wartheland, Reg.Bez. Zichenau, Dombrowa-Gebiet) oder als eine Art Zwischengebiet verwaltet (Bezirk Bialystok ab 1941). Andere Teile Polens gehörten zeitweise zu Litauen bzw. zur UdSSR, und nach dem Uberfall auf die Sowjetunion wurden auch diese zunächst außerhalb des deutschen Einflußbereichs gelegenen Landesteile zwischen den Reichskommissariaten Ostland und Ukraine (Wolhynien) und dem bereits im Oktober 1939 errichteten Generalgouvemement mit der Hauptstadt Krakau aufgeteilt.

\footnotetext{
- Für die Hilfe bei der Materialerfassung danke ich Frau Susanne Hassen und Frau Dr. Gertrud Pickhan.
} 
Im Zusammenhang damit ergeben sich die Quantifizierungsschwierigkeiten von selber; es kann hier nur versucht werden, sie im Rahmen der vorhandenen Möglichkeiten zu überwinden, wobei ein nicht geringer Rest an Zweifelhaftem sicherlich verbleiben wird. In diesem Beitrag wird auf die eingehende Behandlung der nach 1941 den Reichskommissariaten zugeteilten Gebieten verzichtet: $W$ ir beschrānken uns da-

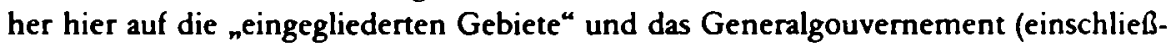
lich des Distrikts Galizien), wāhrend die übrigen ehemals polnischen Territorien im Zusammenhang mit dem Beitrag über die UdSSR bearbeitet werden. Dabei darf nicht übersehen werden, daß freiwillige und zwangsweise Migrationen sich nicht an diesen willkürlich gezogenen Grenzen aufgehalten haben.

Eine zweite, nicht zu unterschātzende Schwierigkeit liegt in der Unzuverlāssigkeit der quantitativen Angaben zur Nationalitāten-Zusammensetzung des früheren polnischen Staates, die ja als Ausgangsbasis dienen müssen. Weder die Zahlen der Volkszählungen von 1921 und 1931, noch die darauf basierenden Fortschreibungen bis 1939 kōnnen vorbehaltlos übernommen werden. Die polnische Staatsführung hatte stets die politische Absicht, den polnischen Staat als dem nationalstaatlichen Ideal möglichst weit entsprechend darzustellen und auf dieser Grundlage die nationalen Minderheiten quantitativ weitestgehend zu reduzieren. In bezug auf die Juden bedeutete dies nicht nur, daß man nach den jeweiligen Kategorisierungen (nach selbstempfundener Nationalität 1921 bzw. nach Muttersprache und Religion 1931) zu unterschiedlichen Ergebnissen kam, sondern auch, daß ganz offensichtlich Zählungsverfälschungen vorkamen, so daß man den Anteil der nationalen Minderheiten an der Bevölkerung Polens in nicht politisch motivierten Kreisen stets erheblich über den Zensus-Angaben ansetzte. ${ }^{1}$ So kamen in den Statistiken der Vorkriegszeit polnisch bzw. deutsch (Oberschlesien, Posen) assimilierte Juden nicht eindeutig vor, obgleich sie die Verfolgung nach den Prinzipien der deutschen Rassegesetzgebung ebenso traf wie die gar nicht seltenen "Rassejuden“, die bereits zum Christentum konvertiert waren.

Aber auch die quantitativen Angaben zur jüdischen Bevölkerungslage in Polen im Zweiten Weltkrieg sind problematisch. Die weitverbreiteten Vorstellungen von einer funktionierenden deutschen Erfassung der jüdischen Bevölkerung entsprechen zum Teil nicht der Realitāt. Zwar gab es Zāhlungen, auch wurde z.B. in einigen Arbeitsund Konzentrationslagern über die beschäftigten bzw. eingelieferten Juden so genau Buch geführt, daß Einzelschicksale nachvollzogen werden können, in einigen wenigen Ghettos (z.B. Lódź/Litzmannstadt) wurde an Statistiken gearbeitet, zu Beginn der Kriegszeit gab es noch Erhebungen von Hilfsorganisationen, andererseits fanden jedoch Massenmorde und Judentransporte in die Vernichtungslager auch ohne weitergehenden Nachweis statt (oder der Nachweis wurde spāter vernichtet), so daß im Ergebnis wiederum eine abgesicherte Quantifizienung unmöglich ist. Hāufig ist nur die Zahl der Transporte überliefert, so daß die Forschung auf der Basis der Durchschnittszahlen vorging. Die dauernde Fluktuation der jüdischen Bevölkerung erhöhte daneben die Gefahr von Doppelzählungen, auf die bereits die erste, 1943 erschienene Arbeit über Bevölkerungsverschiebungen in Europa hinweist. ${ }^{2}$ Czeslaw Madajczyk hat

1 Vgl. Jörg K. Hoensch, Geschichte Polens, Stuttgart 1983, S. 263.

2 Eugene M. Kulisher, The Displacement of Population in Europe, Montreal 1943, S. 163. 
1972 betont, daß kriegerische Handlungen die administrative Durchführung größerer Umsiedlungen im allgemeinen verhindert haben - in der umgekehrten Realitāt des Zweiten Weltkriegs sieht er eines der Spezifika dieses Krieges. Er ordnet die Bevölkerungsumsiedlung der Lebensraum- und Genozid-Politik der Deutschen zu und erkennt in der Fluktuation damit ein wesentliches Element des Zweiten Weltkriegs in Osteuropa. ${ }^{3}$ Das allgemeinere Problem der schlechten Aktenlage wird zusātzlich durch die Verschleierungsversuche der deutschen Dienststellen verschärft; aber auch dort, wo diese nicht erfolgreich waren, diente die Zeitlage nicht der Uberlieferung. Auch wo sie nicht planmäßig vernichtet wurden, blieben Akten im Zuge der Evakuierung der Lager, die zumeist überstürzt geschah, nicht immer erhalten. 4 Zahlreiche Angaben in der Forschungsliteratur stammen aus kaum kontrollierbaren Schātzungen von Zeitzeugen.

Wir haben versucht, die jeweilige Quelle einer Zahl möglichst genau nachzuprüfen, um so eine Beurteilung ihres Wahrscheinlichkeitswertes zu ermöglichen. Dennoch wird in zahlreichen Fällen nur auf Sekundärliteratur verwiesen - deren umfassende Nachweise anzugeben, verbietet die räumliche Begrenzung dieses Beitrags. Im Arbeitsverfahren zur Erschließung einer Endziffer haben wir uns meist an der jeweils kleinsten gesicherten Zahl bzw. an realistisch erscheinenden Berechnungen orientiert, wobei uns das Ziel vorschwebte, eine unbezweifelbare Minimalzahl zu erhalten, die die Quantität derjenigen polnischen Juden angibt, die zweifellos von den deutschen Nationalsozialisten ermordet wurden. Für die moralische Einschātzung der Täter und ihres Staates ist die Zahl irrelevant. Gleichzeitig kann nicht deutlich genug gesagt werden, daß es darüber hinaus eine nur ungenau abzusteckende Grauzone von Morden gibt, die dokumentarisch nicht eindeutig belegt werden kōnnen.

Anders als in westeuropäischen Staaten, in denen die Juden verhältnismäßig rasch nach der deutschen Besetzung erfaßt und geordnet ${ }^{\star}$ deportiert wurden, anders als etwa auch in Ungarn und Italien, wo sie noch relativ lange ein den Umständen entsprechend normales Leben führen konnten, waren die Lebensverhältnisse sowohl der polnischen als auch der aus anderen europäischen Staaten eingesiedelten Juden in Polen vom Beginn des Krieges an extrem schlecht - sie waren von ungenügender Emährung, Zusammenschließung in hygienisch untragbaren Ghettos und zahlreichen Epidemien gekennzeichnet, die als unmittelbare Folgen der Verfolgung zu bezeichnen sind, auch wenn es dabei noch nicht um eine gewaltsame Tōtung ging. Die sich hier ergebende Sterbeziffer, die sich aus der Berechnung der faktischen Sterbefälle abzüglich der normalen Mortalitāt in Friedenszeiten ergibt, gehört gleichfalls in den Bereich der Verfolgungstodesfälle, auch wenn es hierbei um eine nur in Ansätzen nachvollziehbare statistische Erfassung der so verstorbenen Juden gehen kann.

In Einzelfallen wird auf weitere Fehlerquoten hingewiesen werden: die obigen Angaben mögen bereits darauf vorbereiten, daß es bei den folgenden Zahlen stets nur um Annāherungswerte auf mōglichst solider Basis des gegenwärtigen Forschungsstandes gehen kann. Dieser Forschungsstand ist nicht ganz einfach zu beschreiben. Zwar ist

${ }^{3}$ Czeslaw Madajczyk, Otwarcie obrad, in: Przesiedlenia ludności przez III Rzeszę i jej sojuszników podczas II wojny światowej. Międzynanodowe Kolokwium. Zamość 17.-20.10.1972, Lublin 1974, S. 7.

4 So gingen z.B. die Akten des Abeitslagers Szebnie bei der Räumung des Lagers Plaszów verloren, wohin man sie verbracht hatte (Vgl. St. Zabierowski, Szebnie, Rzeszów 1985, S. 7). Angesichts der nahenden Front wurden Archivbestände planmälig vernichtet (Vgl. Michal Grynberg, Żydzi $\$$ rejencji ciechanowskiej 1939-1942, Warszawa 1984, S. 6 . 
die Zahl der Holocaust-Publikationen Legion, sehr hāufig handelt es sich dabei jedoch um ungenaue Handlungsbeschreibungen, die zwar zum Verständnis der Verfolgungssituation beitragen, aber hinsichtlich exakter Angaben recht unergiebig sind.

In den ersten Nachkriegsmonaten wurde durch das Institut für Nationales Gedenken (Instytut Pamięci Narodowej) erstmals versucht, auf der Basis von Fragebögen, die den Bürgermeistem aller polnischen Gemeinden zugingen, rasch ermittelbare Daten über Einzelexekutionen und Massenmorde zu erhalten, die außerhalb des Umfelds der diversen Lager begangen wurden. Daneben gab es einige Schätzungsversuche von Kommissionen, deren Werte meist weiter verwendet werden; die Ergebnisse der Enqueten lagen erst Anfang der 1960er Jahre publiziert vor. Diese Zahlenangaben waren nicht nur damals nur mit größter Vorsicht zu verwenden: Zum einen bestand keinerlei Kontrolle über die Richtigkeit der Ergebnisse, zum anderen haben unter den so kurz nach Kriegsende in Polen herrschenden Bedingungen wohl auch nicht alle angeschriebenen Stellen der Wahrheit entsprechende Angaben gemacht. Über- und Untertreibungen dürfen vorgekommen sein. Die großen Städte wurden nicht oder nur ungenügend erfaßt. Erst langsam erschließt sich, in welchem Maße das Leben in Polen in den ersten Nachkriegsjahren von unterschiedlich motiviertem Antisemitismus geprägt war; eine Vielzahl von Ereignissen mag auch ganz einfach der Erinnerung der Zeitgenossen entwichen sein. Dieser Tatbestand - zudem noch beachtet werden muß, daß naturgemäß die polnischen Ostgebiete nicht erfaßt werden konnten - wird inzwischen allgemein in Polen anerkannt, obwohl mangels anderer Daten die damals ermittelten Ergebnisse nicht selten weiterhin kolportiert werden. Auch die Ende der 1940er/Anfang der 1950er Jahre unternommenen Informationssammlungsversuche des Jüdischen Historischen Instituts in Warschau erbrachten kein einheitliches, einfach auszuwertendes Material. Erst etwa seit den 1960er Jahren, und damit vielfach zu spät, findet in Polen in größerem Umfang eine solide quantitative Forschung in der uns interessierenden Richtung statt, wobei das Jüdische Historische Institut in Warschau weiterhin eines ihrer Zentren ist. Die dort publizierten Ergebnisse werden in den letzten Jahren zunehmend durch allgemeine demographische Arbeiten ergänzt und in Einzeluntersuchungen zu Kreisen, Gemeinden und Einzelereignissen bestātigt bzw. korrigiert.

Wenig ergiebig waren die bisherigen Erkenntnisse des Yad-Vashem-Archivs in Jerusalem, dessen Schwerpunkt auf der Sammlung von Erinnerungen aus einzelnen Gemeinden beruht, welche nur in Einzelfällen wissenschaftlichen Ansprüchen genügen. Die Nachrichten über Einzelschicksale, die eine unschātzbare Quelle für die Aufarbeitung der Ereignisse selber darstellen, lassen jedoch kaum quantitative Schlüsse zu. Shmuel Krakowski, der Leiter des Archivs, stützt sich demgemäß auch bei seinen eigenen Arbeiten zu quantitativen Fragen kaum auf die eigenen Bestände.

\section{Ausgangslage}

Wieviele Juden lebten am 1. September 1939 in Polen? Bereits diese recht simpel klingende Frage lāßt sich nicht ohne einschrānkende Bemerkungen beantworten, und entsprechend sind die Zahlen, die in der Literatur genannt werden, auch Schwankungen unterworfen, je nachdem, welcher Maßstab angelegt wird. 
Die unterschiedlichen Zahlen beruhen zum einen auf den verschiedenen, politisch motivierten Erfassungsmodalitāten der polnischen statistischen Ämter, zum anderen aber auch darauf, daß die deutliche Bestimmung der jüdischen Bevölkerungsgruppe auch so kein unproblematisches Unterfangen ist. Der Unterschied zwischen "Glaubens-“ und "Rassejuden " ist aus der deutschen Geschichte der NS-Zeit bekannt. Während jedoch im Deutschen Reich bei der relativ geringen Gesamtzahl auch recht zuverlässige Zählungen statufanden, die die Abschätzung einer Relation zwischen den angegebenen Kategorien zulassen, gab es derartige Unterlagen in Polen nicht. Die Volkszählungen der Zwischenkriegszeit helfen nur scheinbar.

Der Zensus vom 30. September 1921, in dem nach der Nationalitāt gefragt wurde, ermittelte für das Staatsgebiet Polens etwa 2110000 Personen, die sich zur jüdischen Nationalitāt bekannten - in bezug auf die Gesamtbevölkerungszahl von damals 27177000 (in anderen Grenzen als 1931) ergibt dies einen Satz von 7,8\%.5

Dabei wurde eine nicht genauer zu ermittelnde Gruppe von Personen nicht erfaßt, die sich - obgleich jüdischer Religion - einer anderen Nationalitāt zugehörig fühlte und das Judentum ausschließlich als konfessionelle Kategorie ohne nationale Bedeutung auffaßte. Hierbei fallt insbesondere die Gruppe von „Polen mosaischen Bekenntnisses “ ins Gewicht, die in der Geschichte der polnischen Juden vor dem Anwachsen der Bedeutung des jüdischen Nationalismus eine nicht unwichtige Rolle gespielt hatte. In den ehemals preußischen Teilen Polens (Posen, Westpreußen) bekannte sich ein wichtiger Anteil der dort allerdings insgesamt nicht allzu zahlreichen Juden zur deutschen Nationalität. Oberschlesien, wo dies ebenfalls der Fall war, gehörte zum Zeitpunkt der Volkszāhlung noch nicht zum polnischen Staatsgebiet.

Auch die zweite und vor dem Krieg letzte Volkszählung im unabhängigen Polen vom 9. Dezember 1931 lieferte keine besseren Resultate: Diesmal wurde zunāchst nach der Muttersprache gefragt - das heißt nach der Sprache, , in welcher die befragte Person denkt und derer sie sich in ihrer Familie bedient ${ }^{\star}$. Die eindeutig als Juden auszumachenden Gruppen ergaben hier 6 :

\begin{tabular}{|c|c|c|}
\hline $\begin{array}{l}\text { für } \\
\text { und für }\end{array}$ & $\begin{array}{l}\text { Jiddisch } \\
\text { Hebräisch }\end{array}$ & $\begin{aligned} 2489034 & =7,8 \% \text { der Bev. } \\
243539 & =0,76 \% \text { der Bev. }\end{aligned}$ \\
\hline & & $2732573=8,56 \%$ der Bev. \\
\hline
\end{tabular}

Aber auch bei Juden, die sich zur jüdischen Nationalitāt bekannten, brauchte nicht unbedingt eine der beiden jüdischen Sprachen die Umgangssprache zu sein. Das Jiddische hatte ungeachtet einer sich entwickelnden Literatur den Ruch des "Jargons", als welcher es von Antisemiten, aber auch teilweise von Zionisten pejorisiert wurde die angebliche „Sprache der jüdischen Gasse“ besaß insbesondere für assimilationsorientierte Aufsteiger wenig Attraktivitāt. Hebräisch hatte als wiederbelebte Sprache der Zionisten noch kaum die Breitenwirkung, die wir aus dem heutigen Staat Israel kennen, und wurde sicherlich häufig eher aus politischen, denn aus faktischen Gründen angegeben. Dagegen war die Polonisierung der polnischen Juden - nicht zuletzt durch die ungenügende Dichte des jiddischen Schulnetzes - weit fortgeschritten, so

5 Nach Rocznik statystyczny 1925/26, Tab. 5; zit. nach Osteuropa-Handbuch Polen, Köln 1959, S. 37.

6 Drugi Powszechny Spis Ludnosci z dn. 9. XIl. 1931 r.; Statystyka Polski, Seria C, Zeszyt 94a, Warszawa 1938, Tab. 10, S. 15 . 
daß die Zahl der nach nationalsozialistischen Prinzipien als Juden anzusehenden Menschen weitaus höher angesetzt werden muß.

Die Zugehörigkeit zur jüdischen Religionsgemeinschaft, die ebenfalls Erhebungsobjekt war, ergibt, auf die Sprachgruppen aufgeteilt, das folgende Bild?

\begin{tabular}{lrcr}
\hline Muttersprache & "Mosaische“ & Konfessionszugehörigkeit & insgesamt \\
\hline Polnisch & 371821 & $1,7 \%$ von & 21933444 \\
Ukrainisch & 547 & $0,01 \%$ & 4441622 \\
"Hiesige“ & 75 & $0,01 \%$ & 707088 \\
Weißrussisch & 200 & $0,02 \%$ & 989852 \\
Jiddisch & 2487844 & $99,95 \%$ & 2489036 \\
Hebräisch & 243527 & $99,99 \%$ & 243539 \\
Deutsch & 6827 & $0,92 \%$ & 740992 \\
Russisch & 444 & $0,32 \%$ & 138713 \\
Litauisch & 18 & $0,02 \%$ & 83116 \\
Tschechisch & 95 & $0,25 \%$ & 38097 \\
Andere & 454 & $4,08 \%$ & 11119 \\
Ohne Angabe & 2081 & $5,31 \%$ & 39163 \\
\hline insgesamt & 3113933 & & \\
\hline
\end{tabular}

Wenn man die Angaben über den Stand der jüdischen Bevölkerung gemāß den deutschen rassistischen Kriterien ermitteln will (und das waren schließlich diejenigen, die dann zur Richtlinie der Verfolgung wurden), wird ein Zuschlag zur oben gegebenen Gesamtzahl erforderlich, der ohne weiteres nicht bezifferbar ist, da hierzu jegliche Unterlagen fehlen und die interessenorientierten Angaben aus der Vorkriegszeit einander widersprechen. Ein weiterer Zuschlag mag dadurch erforderlich werden, daß Korrekturen der Zahlen zur Bestātigung eines größeren Anteils ethnisch polnischer Staatsangehöriger nicht ausgeschlossen werden können. In diesem Zusammenhang muß erwāhnt werden, daß die antijüdische Politik des polnischen Staates vor 1939 keinen deutlichen Abstand zu den deutschen Nationalsozialisten einhielt. Der Leiter des Jüdischen Historischen Instituts in Warschau schrieb darüber: „Die Tatsachen bestātigen, daß (die polnische Sanacja-Regierung) in den Umbruch-Monaten nach dem Münchner Abkommen offen die Methoden der ,Lōsung der Judenfrage durch die faschistischen Staaten unterstützte. Hier gibt es quasi ein Zusammengehen der Innenund Außenpolitik der Sanacja-Regierung mit der Politik des Dritten Reiches ... Eine Plattform der Zusammenarbeit zwischen der Sanacja-Regierung Polens und den Hitleristen war auch der Antisemitismus. "8 Artur Eisenbach geht sogar soweit zu schreiben, die antijüdische Haltung polnischer Regierungskreise habe „in gewissem Maße das Schicksal der jüdischen Bevölkerung in Polen mitbeeinflußt ${ }^{4} .9$

7 Ebenda.

8 Artur Eisenbach, Hitlerowska polityka zaglady Zydów, Warszawa 1961, S. 115.

9 Ebenda, S. 128. Neuere Forschungen bestätigen diese Sätze. Piotr Nehring (Polityka Rządu RP wobec Żydów - obywąteli polskich mieszkających w Niemczech w latach 1933-1939, Phil. Diss. Warszawa 1989) ermittelt trotz anfanglicher Interventionen polnischer Diplomaten zugunsten von in $\mathrm{KZ}$ eingelieferten polnischen Juden (S. 45) zwei Maximen polnischer Politik: einerseits war die Rückkehr ehemals polnischer Juden nach Polen unerwünscht (S. 34, 72), andererseits war die Vetbesserung der deutsch-polnischen Beziehungen das Hauptanliegen polnischer Bestrebungen zwischen 1938 und Anfang 1939 (S. 101). Die Einstellung der Interventionen 1938 nennt selbst Nehring "nicht allzu elegante Methoden " (S. 104). - Auch Yisrael Gutman und Shmuel Krakowski (Unequal Victims, New York 1986, S. 18) beschreiben den Wandel von 1934 mit den Worten: a close relationship between the two countries developed in many areas." Daß Lipski, der polnische dipl. Vertreter in Berlin, im September 1938 Hitler ankündigte, man werde im Herzen Warschaus ein 
Für die Zeit nach 1931 liegen keine empirisch gesicherten Zahlenangaben mehr vor. Wir stützen uns auf die Schätzungen des Statistischen Hauptamtes (Glówny Urząd Statystyczny), wenn wir für das Jahr 1939 auf der Basis der Fortschreibung der Zensuszahlen unter Berücksichtigung von natürlichem Zuwachs und Emigration für den Polnischen Staat eine Gesamtbevölkerung von 35100000 Personen annehmen ${ }^{10}$, wobei darin der Anteil der Juden auf $3446000^{11}$ geschātzt wird. Noch einmal: diese Zahlen sind nicht gesichert. 12 Weder können wir bei der reinen Fortschreibung davon ausgehen, daß auch die ,irregulären “ Bevōlkerungszuwächse berücksichtigt (etwa die 13000 - 17000 polnischen Juden ${ }^{13}$, die im Herbst 1938 durch die Deutschen aus dem Reich nach Polen deportiert wurden und nach einem lāngeren qualvollen $Z$ wischenaufenthalt in provisorischen Zwischenlagern in Zbaszyn, Kattowitz, Chojnice, und Gdingen nach Polen unter der Bedingung eingelassen wurden, sich möglichst bald um eine Emigration zu bemühen), noch daß die Grenzgänger erfaßt wurden. Die Gesamtgrößen, mit denen man es in Polen zu tun hat, und der unklare Quellenstand bei den Massenmorden lassen diese $Z$ weifel allerdings wieder fast irrelevant erscheinen.

Wir lassen es daher bei dieser Schātzungszahl bewenden: eine 1946 eingesetzte britisch-amerikanische Kommission ${ }^{14}$ operierte mit der Zahl von 3350000 Juden, Shmuel Krakowski geht bei seinen Berechnungen von der von Philip Friedman eingeführten Zahl von 3500000 in Polen aus. ${ }^{15}$ Die Zahl der polnischen Juden selber sagt

schōnes Denkmal zu seinen Ehren errichten, wenn er die Judenfrage durch Emigration lösen würde, ist mehr als ein geschmackloses Bonmot (Lipskj an Beck, 20.9.1938, Dok. 99, in: W. Jedrzeje wicz, Diplomat in Berlin 1933-1939, London 1968, S. 411).

$10 \mathrm{Vgl}$. Henryk Kopeć, Straty $\mathbf{w}$ ludności poniesione przez Polske $w$ II Wojnie Swiatowej/Gutachten vom 7.12.1946/, in: Ekspertyzy i orzeczenia pred Najwyiszym Trybunalem Narodowym. Bd. 9, Warszawa 1982, S. $148-155$, S. 149.

11 Vgl. ebenda, S. 152.

12 Zu dieser Problematik vgl. auch Grynberg. Zydzi, S. 8 f.

13 Nach Klaus Drobisch/Rudi Goguel/Wemer Müller, Juden unterm Hakenkreuz, Frankfurt a.M. 1973, S. 186. - Martin Gilbert (Die Endlösung, Frankfurt a.M. 1984) gibt die Gesamtzahl mit 15000 an, Eisenbach (Polityka, S. 121) mit 17000, während die neuesten Forschungen 18-19000 von den Deportationen Betroffene (insbesondere Familienoberhäupter) und noch einmal 5-6000 nachreisende Frauen und Kinder nennen (Sybil Milton, The Expulsion of Polish Jews from Germany, October 1938 to July 1939, in: Yearbook of the Leo Baeck Institute 29 (1984), S. 169-199, S. 169-172). Die Zahl von 17000 (zwischen dem 27. und 29. Oktober 1938) stützt sich auf eine Mitteilung Heydrichs an den Chef der Reichskanzlei vom 2.12.1938 (ADAP 1918-1945. Serie D, Bd. 5, Baden-Beden 1953, S. 115, Dok. 107); Emanuel Melzer (Relations between Poland and Germany and their Impact on the Jewish Problem in Poland 1935-1938, in: Yad Yashem Studies 12 (1977) S. 193-229) spannt die Bandbreite von 15000 bis 20000 und setat die Anzahl der insgesamt von den Bestimmungen Betroffenen mit 20000 in Osterreich und 50000 in Deutschland an (S. 216). Nach dem Abschluß der „Familienzusammenführung" hätten in Deutschland noch 3-4000 Frauen und Kinder auf polnische Visa gewartet (S. 222). Auch diese Angaben lassen sich dadurch erginzen, daß bis zu 8000 polnische Juden in Deutschland und dem annektierten Osterreich verblieben (S. 172 t.). Es wire zu überiegen, ob diese Personen, die allem Anschein nach mit den Deportationen der deutschen Juden das Reichsgebiet vertießen, den polnischen oder den deutschen Juden zuzurechnen wiren. Auch die von Milton angegebenen Zahlen für die Durchgangsstellen sind unter Vorbehalt zu übernehmen, was der Leistung der Verfasserin keinen Abbruch tut - im Dokumentaranhang wird ein Bericht des US-Botschafters in Warschau an den Außenminister Condell Hull vom 5.11 .1938 abgedruckt, in dem für Chojnice 7000 Umsiedler genannt werden (Milton schreibt von 1500) und für Zbęszyn (für das Milton über $\mathbf{8 0 0 0}$ angibt) ebenfalls 7000 (Melzer, Relations, S. 185). Die polnischen Konsulate wiesen 13000 Ausgewiesene für 1938 nach (Nehring, Polityka, S. 127), während 1939 noch 11000 polnische Juden in Deutschland gewesen sein sollen (S. 217). Alle diese Zahlen sind jedoch unsichet.

14 Stanislaw Waszak, Bilans walki narodowościowej rądów Greisera, Poznań 1946, S. 507.

15 Shmuel Krakowski, Avedot Yehudei Polin BaShoe, in: Dapim icheker tkufat HaShoa, Sammlung 2, Tel Aviv 1982/83, S. 232. 
jedoch nichts über die Anzahl derjenigen aus, die nach dem 1. September 1939 tatsāchlich im deutschen Machtbereich lebten. Krakowski nimmt an, daß von den 3500000 Juden, die seinen Uberlegungen zugrunde liegen,

2350000 im späteren deutschen und

1150000 im späteren sowjetischen Teil

des ehemaligen polnischen Staatsgebiets wohnten. ${ }^{16}$ Die Zahl der Juden innerhalb des deutschen Operationsgebiets im September 1939 läßt sich durch eine weitere Schātzung dergestalt ermitteln, daß man die Zensus-Angaben für die neuen Verwaltungsgrenzen fortschreibt, wobei die Fehlergefahr sicher nicht gering ist. Danach sollte die jüdische Bevōlkerung Anfang der 1930er Jahre in den spāter eingegliederten Gebieten $637000^{17}$, im späteren Generalgouvernement (ohne den erst 1941 hinzugekommenen Distrikt Galizien) 1269000 betragen haben.18

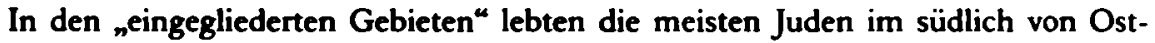
preußen gelegenen Bezirk Ciechanów (Zichenau) und im sog. Wartheland, wo mit ca. 233000 Juden die Industriestadt Lódź (Litzmannstadt) den höchsten jüdischen Bevōlkerungsanteil hatte. Als realistischen Ausgangswert für die als Reichsgau Wartheland zusammengefaßten Gebiete darf man die Zahl 385000 ansetzen, die den Hochrechnungen 19 am nächsten kommt, auch wenn manchmal von bis zu $\mathbf{4 0 0 0 0 0}$ Juden die Rede ist. ${ }^{20}$ Im Regierungsbezirk Zichenau lebten bis 1939 ca. 80000 Juden. ${ }^{21}$

Die Stadt mit der größten jüdischen Bevölkerung im späteren Generalgouvernement war die polnische Hauptstadt Warschau,

$\begin{array}{lll}\text { in der } & 1931 & 352689, \\ \text { Anfang } & 1938 & 368394 \\ \text { und im September } & 1938 & 380567 \text { Juden }\end{array}$

lebten.22 Im ganzen Distrikt Warschau gab es ca. 600000 Juden $^{23}$, im Distrikt Krakau ca. 250000, im Distrikt Lublin um 250000 und im Distrikt Radom etwa 395000.24 Dabei geben diese Zahlen Berechnungen auf der Basis der späteren deutschen Verwal-

16 Ebenda

17 Kulisher (Displacement, S. 99) rechnet für 1939 mit 670000; Malcolm Proudfoot (European Refugees 1939-1952, London 1957, S. 322f.) gibt die Zahl für die eingegliederten Gebiete mit 400000 an, 200000 seien aus dem Westen Polens in den sowjetisch besetzten Teil geflohen, im Generalgouvernement habe es 1362000 gegeben. Insgesamt hätten danach also 19401762000 polnische Juden unter deutscher Herrschaft gelebt.

18 Vgl. Peter-Heinz Seraphim, Die Judenfrage im Generalgouvernement als Bevōlkerungsproblem, in: Die Burg 1 (1940), S. 58.

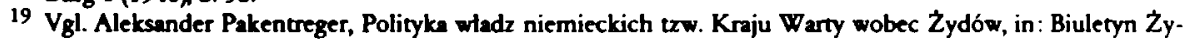
dowskiego Instytutu Historycznego (BZIH) 4/104 (1977), S. 34; Edward Serwański, Obóz zaglady w Chelmnie nad Nerem 1941-1945, Poznań 1964, S. 20; Eisenbach, Polityka, S. 154.

20 Vgl. D. Dapbrowske, Zaglada skupisk żydowskich "Kraju Warty" okresie okupacji hitlerowskiej, in: BZIH 13/14 (1955), S. 122; Waszak, Bilans, S. 505.

21 Vgl. Grynberg, Zydzi, S. 18.

22 Vgl. T. Berenstein/A. Rutkowski, Liczba ludności żydowskiej i obszar przez nią zamieszkiwany w Warszawie $\mathbf{w}$ latach okupacji hitlerowskiej, in: BZIH 26 (1958), S. 75.

$23 \mathrm{Vgl}$. Tatiana Brustin-Berenstein, Deportacje i zaglada skupisk żydowskich w dystrykcie warszawskim, in: BZIH 1/3 (1952), S. 83.

24 Vgl. E. Podhorizer-Sandel, O zagładzie Zydów w dystrykcie krakowskim, in: BZIH 30 (1959), S. 87 f.; Adam Rutkowski, Martyrologia, walka i zagłada ludności żydowskiej w dystrykcie radomskim podczas okupacji hitlerowskiej, in: BZIH 15/16 (1955), S. 77; Tatiana Berenstein, Martyrologia, opór i zagłada ludności żydowskiej $w$ dystrykcie lubelskim, in: BZIH 21 (1957), S. 22. 
tungsgrenzen an. Für Ostgalizien werden 573000 jüdische Einwohner ${ }^{25}$, davon etwa 100000 in Lemberg ${ }^{26}$ angenommen, für die Kreise des zunāchst zur Sowjetunion geschlagenen spāteren Bezirks Bialystok für das Jahr 1939240000.27

Damit ergibt sich für das hier behandelte Territorium als Ausgangswert mit dem Stichdatum 31. August 1939 die nachfolgende jüdische Bevölkerungszahl:

\begin{tabular}{lcc} 
& nach Seraphim & nach Krakowski \\
Deutsch besetzte Gebiete & 1906000 & 2350000 \\
Bezirk Bialystok 1939 & 240000 & 240000 \\
Ostgalizien & 573000 & 573000 \\
\cline { 2 - 3 } & 2719000 & 3163000
\end{tabular}

\begin{tabular}{lr} 
nach Kulisher/Proudfoot & nach Dabro \\
2032000 & 1829000 \\
240000 & 240000 \\
573000 & 573000 \\
\hline 2845000 & 2642000
\end{tabular}

Da es bei den Intentionen diese Bandes um die Ermittlung einer sicheren Minimalzahl geht, wird der geringere Wert angesetzt, wobei eine Unrichtigkeit des höheren dadurch keineswegs unterstellt werden soll.

\section{Polenfeldzug und Militärverwaltung}

Die Tötung polnischer Juden setzte bereits in den ersten Tagen nach dem Uberfall auf Polen ein. Dabei sind zwei Vorgehensweisen auseinanderzuhalten, wenngleich für die Betroffenen die Folgen und Umstānde letztlich gleich bleiben. Polnische Juden starben an den Folgen der regulären Kriegsereignisse. Im polnischen Militär konnten zwar Juden nur in wenigen Einzelfällen vorgesetzte Dienstränge erreichen, es bestand jedoch auch für die jüdische Bevölkerung die allgemeine Wehrpflicht, so daß im polnischen Militār etwa 120000 Juden gedient haben dürften. ${ }^{28}$ Die Schātzungen der im Verlauf der Kämpfe auf polnischer Seite gefallenen Juden bewegen sich zwischen $6000^{29}$ und $36000^{30}$, wobei auch hier sowohl die Kategorisierung, die sich so nirgendwo in amtlichen Unterlagen nachvollziehen läßt, als auch die Beurteilung der

25 Vgl. Filip Fridman, Der Umkum fun di Idn in Mizrah-Galizie, Fun leztn hurbn, München 4 (März 1947) S. 2.

26 Vgl. Lucy S. Dawidowicz, The War against the Jews 1933-1945, London 1975, S. 197.

27 Vgl. Srymon Datner, Eksterminacja ludnosci żydowskiej w okry̧gu bialostockim. Struktura administracyjna okręgu bialostockiego, in: BZIH 60 (1966), S. 7.

28 Vgl. Bernard Mark, Zycie i walka mlodzieży w gettach w okresie okupacji hitlerowskiej (1939-1944), Warszawa 1961, S. 21.

29 Vgl. Gilbert, Endlösung, S. 35.

30 Vgl. Mart, Zycie, S. 21 . - Nora Levin ( The Holocaust The Destruction of Polish Jewry 1933-1945, New York 1978, S. 170) zitiert eine Verlautbarung des polnischen Generalstabes, die sie nicht näher ertäutert wonach 1939 insgesamt 31216 Juden gefallen seien, Friedman gibt die Zahl mit 32216 wieder (Schreiblehler?), was jedoch nach Szymon Damer (Zbrojne wystapienia Żydów polskich w gettach i obozach śmierci $w$ II wojnie swiatowej, in: BZIH 4/125 (1983), S. 11) der Uberprüfung bedarf. 
Gruppe der „Gefallenen“ Schwierigkeiten bereitet: Berichte Uberlebender wissen insbesondere über von den den Vormarsch begleitenden SS- und Polizeieinheiten begangenen Morden an Kriegsgefangenen zu berichten. So erschossen z.B. in Biała Podlaska SS-Leute etwa 600 polnisch-jüdische Gefangene. ${ }^{31}$

In Gefangenschaft gerieten schließlich etwa $\mathbf{4 0 0 0 0 0}$ polnische Soldaten ${ }^{32}$, von denen Madajczyk schreibt, man habe sich ihnen gegenüber in den Gefangenenlagern in der Regel recht korrekt verhalten ".33 Ungeachtet dessen, daß dies nicht immer zutreffend war, betraf es nur zu einem geringeren Teil die ca. 61000 jüdischen Soldaten ${ }^{34}$. die mit der polnischen Armee in deutsche Kriegsgefangenschaft gerieten. Krakowski gibt an, daß etwa 20-25000 von ihnen in den Lagern starben. ${ }^{35}$ Die Gesamtverluste der jüdischen Bevölkerung Polens infolge der kriegerischen Ereignisse von 1939 (Gefallene, Tote in Kriegsgefangenenlagern, Verluste innerhalb der Zivilbevölkerung) beziffert er ungesichert und vermutlich überhöht auf ca. 100000.36

Die jüdischen Soldaten wurden wie die polnischen im Laufe ihrer Gefangenschaft zu diversen Arbeitseinsātzen (etwa in der Landwirtschaft) geführt. Aus Westpreußen besitzen wir Berichte, daß sich Bauem weigerten, Juden als Erntehelfer einzusetzen. Wenn Juden aus der Gefangenschaft entkamen oder um die Jahreswende 1939/40 entlassen wurden, dann führte diese Entlassung nicht in die Freiheit - im Gegenteil kamen die dem Lager Entronnenen in die keineswegs angenehmeren Ghettos, Arbeits- und schließlich Vernichtungslager, aus denen es nur für die wenigsten ein Entkommen gab. 37

Neben den "regulären“ Kriegstoten kam es auch im Septemberfeldzug bereits zu gezielten Judenmorden, die die Einsatzgruppen der SS, aber auch reguläre Wehrmachtseinheiten begingen. Die Tatsache, daß der Befehlshaber der 14. Armee, General Wilhelm List, in seinem Befehl vom 18. September 1939 ausdrücklich die ErschieBung von Juden neben anderen Ausschreitungen verbot ${ }^{38}$, läßt den Schluß zu, daß zu diesem Befehl ein auch den Führungsstellen bekannter Grund vorlag. Versicherungen militārischer Führer (von Brauchitsch, Blaskowitz), den polnischen Juden werde nichts geschehen, die deutschen Truppen hielten sich an die Grundsātze des Kriegsvölkerrechts, waren von Anfang an wirkungslos; sie zielten gegen den Konkurrenten SS, wurden jedoch kaum umgesetzt.

Bei der Besetzung Warschaus sollen Juden umgebracht worden sein ${ }^{39}$, in Przemyśl in einer gezielten Aktion gegen die Intelligenz etwa 500 Juden.40 Nahezu unzählbar sind die Einzeltaten der SS. In einem von Hilberg angeführten Fall wurden ein SSSturmmann und ein Polizeiwachtmeister vor Gericht gestellt, weil sie in einer Ort-

31 Vgl. Berenstein, Martyrologia, S. 32.

32 Vgl. Czeslaw Madajczyk, Polityka III Rzeszy w okupowanej Polsce. Bd. 1, Warszawa 1970, S. 29.

33 Ebenda.

34 Vgl. Mark, Zycie, S. 21 ; Gilbert, Endlōsung, S. 35.

35 Vgl. Krakowski, Avedot, S. 232.

36 Vgl. ebenda.

37 Gracjan Bojar-Fijalkowski, Losy jeńców wojennych na Pomorzu Zachodnim i w Meklemburgii 1939-1945, Warszawa 1979, S. 207.

38 Nbg. Dok. NOKW-1621, zit. bei Raul Hilberg, Die Vemichtung der europäischen Juden. Die Gesamtgeschichte des Holocaust, Berlin 1982, S. 138. Hilberg interpretiert diese "Einzelaktionen" als bewußt inszenierte vorbereitende Aktivitäten, die dem Vorgehen in Deutschland und Osterreich entsprächen.

39 Dawidowica (War, S. 189) spricht von 20000, die Zahl scheint jedoch erheblich zu hoch zu sein.

$40 \mathrm{Vgl}$. Gilbert, Endlösung, S. 37; It. Podhorizer-Sandel (O zagładzie, S. 93) etwa 600. 
schaft 50 Personen ermordet hatten. Die ausgesprochenen Strafen ourden dann mit verschiedenen Begründungen herabgesetzt, bis die Gesamtstrafe drei Jahre betrug. Es war einer der wenigen Fälle, in denen wenigstens noch versucht wurde, „Recht“ zu sprechen. ${ }^{41}$ In den ersten Tagen kam es manchmal noch zu jüdischen Hilfsdiensten für die Deutschen. Wie aus der Zeit des Ersten Weltkriegs gibt es Berichte über die Dolmetschertātigkeit der jiddischsprachigen Bewohner Ostpolens. 42 Das Gesamtbild ist alles andere als einheitlich. Die Rivalitāt zwischen Wehrmacht und SS führte dazu, daß einzelne Wehrmachtsstellen gezielte Angaben über SS-Massaker sammelten, um den Rivalen zu diffamieren. Gerade dadurch besitzen wir Daten, die aber weit davon entfernt sind, das ganze Ausmaß der Mordaktionen zu umreißen. In Mogilno wurde die Synagoge gesprengt, wobei zehn Juden umkamen 43 , nach deutschen Angaben wurden im Kreis Sępolno 49 Juden in den letzten Monaten des Jahres 1939 ermordet. 44 In Dynów in der Wojewodschaft Rzeszów wurden im September 1939 etwa 150 Juden im Wald von Zurawiec von der SS erschosssen. ${ }^{45}$ Die Zerstörung jüdischer Kultstātten folgte dem Modell des deutschen November-Pogroms von 1938: In Przeworsk wurde am 12. September 1939 die Synagoge gesprengt, als man im Keller eine noch aus dem Ersten Weltkrieg stammende Munitionspackung gefunden hatte. Hier war die Gestapo aus Jarosław aktiv. 46

Aber auch das Schuldkonto des regulären Militārs ist beachtlich. Wehrmachtsangehörige haben in Żarki am 4. September 193990 Juden und 12 Polen exekutiert. In diesem Fall wurden alle Opfer identifiziert, eine Kartothek befindet sich im Schlesischen Wissenschaftlichen Institut in Kattowitz. 47 In Tschenstochau wurden im Zuge einer großangelegten Aktion gegen die der Unterstützung der polnischen Armee beschuldigte Zivilbevölkerung neben 205 Polen auch 22 Juden erschossen. Dieser Vorgang ist u.a. dadurch zu belegen, daß der deutsche Stadthauptmann eine Exhumierung der eilig vergrabenen Leichen anordnete. ${ }^{48}$

Diese Mordaktionen geschahen öffentlich; sie waren nur zum Teil gegen Juden als solche gerichtet. In den ersten Wochen des Krieges wurden unter dem Vorwand der „Reaktion auf polnische Terrorakte gegenüber Deutschen “ in hoher Zahl Erschießungen vorgenommen, von denen die christlichen Polen in gleicher Weise betroffen waren wie die Juden. Da die Aufzeichnungen darüber höchst lückenhaft sind und auch nicht zwischen den beiden Personenkreisen differenzieren, ist eine genaue Ermittlung

41 Gemeint sein kann hier die doppelte Exekution in der kleinen Ortschaft Piạtek, bei der nach Zeugenaussagen 61 Personen erschossen wurden, davon 15 Juden. Vgl. Hilberg, Vernichtung, S. 138; Karol Marian Pospieszalski, Z masowych egzekucji we wrześniu 1939 r., in: Przegląd Zachodni 11 (1955), S. 230.

$42 \mathrm{Vgl}$. Jozef Benbenek, Martyrologia mieszkańców Przeworska w czasie II wojny światowej, Rzeszów 1978, S. 23, 118.

43 Vgl. Pakentreger, Polityka, S. 33.

$44 \mathrm{Vgl}$. Barbara Bojarska, Obozy zniszczenia na terenie powiatu şpoleńskiego w pierwszych miesiącach okupacji hitlerowskiej, in: Przeglad Zachodni 21 (1965), S. 134.

45 Vgl. Sunislaw Zabierowski, Rzeszowskie pod okupacją hitlerowskg, Warszawa 1975, S. 29.

$46 \mathrm{Vgl}$. Benbenek, Martyrologia, S. 118.

$47 \mathrm{Vgl}$. Andrzej Szeler, Zbrodnie Wehmachtu na ludności cywilnej w powiatach kłobuckim, czȩstochowskim i myszkowskim w pierwszych dniach września 1939 r, in: Zamaie Sląskie 23 (1969), S. 453.

$48 \mathrm{Vgl}$. ebenda, S. 454. Vgl. auch Srymon Datner, 55 dni Wehrmachtu w Polsce. Zbrodnie dokonane na polskiej ludności cywilnej w okresie 1.DX.-25X1939 roku, Warszawa 1967, S. 216; Jan Pietrzykowski, W obliczu śmierci, Katowice 1966, S. 65. Uber die Exhumierung berichten die Akten des Bezirksgerichts Częstochowa IIK.98/47, nach Jan Pietrzykowski, Hitlerowcy w Częstochowie w latach 1939-1945, Poznań 1959, S. 13. - Gilbert (Endlōsung, S. 33) gibt für Tschenstochau/Czȩstochowa 180 getötete jüdische Zivilisten an. 
der jüdischen Opfer nicht möglich - wie etwa im Falle von Sieradz, wo am 4. und 5. September 1939 etwa 200 polnische und jüdische Flüchtlinge getötet wurden ${ }^{49} \mathrm{Er}$ wähnenswert ist in diesem Zusammenhang, daß zur Vorspiegelung angeblicher jüdischer Terrorakte in Kalisz Polen und Juden festgenommen und wochenlang zu Propagandazwecken im Reich unter einem Transparent vorgeführt worden sein sollen, auf

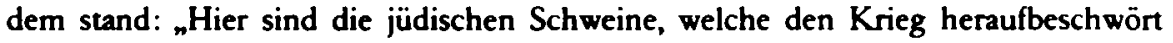
und auf deutsche Soldaten geschossen haben ${ }^{30}$ Die sicherlich gröBten Massaker dieser Art geschahen in Będzin im Dombrowa-Revier, wo am 9. September 1939 die Synagoge und 56 Hāuser niedergebrannt wurden. Der späteren Enquete zufolge sollen etwa 500 jüdische Einwohner dabei den Tod gefunden haben. 51 Bei Gilbert ${ }^{52}$, dessen Quellenbasis jedoch durchweg umstritten ist und der keine eigenen Grundlagenforschungen unternommen hat, liegt die Gesamtzahl „nur ${ }^{\mu}$ bei 13 für den 4. September 1939. Mit Problemen dieser Art wird man bei diesen Einzelaktionen dauernd konfrontiert. Für den Reg.Bez. Zichenau ermittelte Grynberg mindestens 450 allein im September 1939 getötete Zivilisten und Kriegsgefangene.53 Kennzeichnend ist, daß es kaum ein Gebiet des besetzten Polen gab, wo die noch verhältnismäßig vereinzelten Mordaktionen nicht stattgefunden hätten: im westlichen Tschenstochau ebenso wie in den deutsch besetzten Teilen der Wojewodschaft Bialystok 54 oder in Strzyziów und Gorlice in Galizien. 55

Plünderungen verlassener jüdischer Wohnungen durch Deutsche und Polen waren an der Tagesordnung. ${ }^{56}$ Aus manchen Orten wurden die Juden auf Anweisung der Militärbehörden vertrieben. Dies geschah am 26. September 1939 in Pultusk, aber auch in Mlawa und Wloclawek. ${ }^{57}$ Zeitweise hatte man wohl vor, auf diese Weise improvisiert einen „polen- und judenreinen " Grenzstreifen zu schaffen, wie er bereits im Ersten Weltkrieg in deutschen Planungen aufgetaucht war. ${ }^{58}$ Diese ersten Vertreibungen erfolgten dezentral auf Veranlassung lokaler Machthaber. In Nowy Dwór und Ostrolęka (Woj. Warschau; Reg.Bez. Zichenau) ordnete der Stadtkommandant der Wehrmacht den Auszug der Juden an. In Zichenau/Ciechanów versuchte die Wehrmacht, die Juden zum „freiwilligen “ Abzug mit der Drohung zu verleiten, die nachfolgende Gestapo werde mit den Juden "nicht mehr sprechen“. Am 6. September 1939 versuchte die SS in Goworowo (Kreis Ostrolęka) die Juden in der Synagoge zu verbrennen - dem Eingreifen eines Wehrmachtsoffiziers ist es zu verdanken, daß sie dann doch ${ }_{n}$ nur $^{4}$ vertrieben wurden. ${ }^{59}$ Aus Ostrolęka wurde überwiegend in sowjetisch besetztes Gebiet vertrieben, aufgegriffene Zurückgekehrte wurden erschossen.

49 Vgl. Mirostaw Cygáski, Powiat sieradzki w latach okupacji hitlerowskiej 1939-1945, in: Rocznik Lódzki 14 (1970) S. 84; bei Gilbert (Endlōsung, S. 33) erscheint unter Sieradz nur eine Angabe von 33 am 20.9.1939 Getöteten.

so Zit. nach Aleksander Pakentreger, Dzieje Zydów Kalisza i powiatu kaliskiego w okresie okupacji hitlerowskiej, in: BZIH 3/111 (1979), S. 79 f.

51 Vgl. Pospieszalski, Z masowych, S. 231.

$\$ 2$ Gilber, Endlösung. S. 33.

$\$ 3$ Vgl. Grynberg, Zydzi, S. 152-159.

34 Vil. Jozef Kowalczyk, Zbrodnie Wehrmachtu w regionie bialostockim w latach 1939-1945, in: Biuletyn Glównej Komisji Badania Zbrodni Hitlerowskich w Polsce (GKBZHwP) 31 (1982), S. 89 ff.

55 Vgl. S. Cynarski/J. Garbacik, Jaslo oskaria, Warszawa 1973, S. 176 f.

36 Vgl. Pakentreger, Dzieje, S. 60; Benbenek, Martyrologia, S. 119.

57 Vgl. Chaim Kaplan, Buch der Agonie, Frankfurt 2.M. 1967, S. 67f, 78.

58 Vgl. dazu Imanuel Geiss, Der polnische Grenzstreifen 1914-1918, Lübeck 1960, passim.

39 Vgl. Grynberg, Żydzi, S. 28 f. - nach in Israel publizierten Erinnerungsbüchem jüdischer Gemeinden. 
Von den Pultusker Juden durften nur Frauen und Kinder die Narew-Brücke benutzen, Mānner mußten schwimmen. Einige ertranken dabei, andere wurden von Soldaten von der Brücke aus erschossen. 60

Man darf nicht übersehen, daß in den ersten Monaten der deutschen Herrschaft polnische antisemitische Gruppen und eine plünderungswillige Unterschicht die deutschen Maßnahmen erleichterten.61 Die Gründung von pro-deutschen Kollaborationsorganen scheiterte an der nationalsozialistischen Programmatik - gleichberechtigte polnische Gruppen entsprachen weder der deutschen Großraumpolitik noch der rassistischen Hybris. Ein Potential erschließt sich jedoch aus den u.a. von Emmanuel Ringelblum berichteten polnischen antijüdischen Ausschreitungen, die eine gewaltsame Fortsetzung und Folge der noch gewaltlosen antijüdischen Politik der polnischen Vorkriegsregierung darstellten. Erwähnt seien hier die pogromāhnlichen Exzesse in Warschau im März 1940.62

Von Anfang an zogen deutsche Soldaten und zivile Stellen Juden zu Zwangsarbeiten heran, bei denen sie hāufig verhōhnt und kōrperlich gequält wurden. Man schnitt orthodoxen Juden die Bārte ab, zwang sie zu lācherlichen Hüpftānzen oder ließ sie mit der eigenen Kleidung Straßen und Fußböden reinigen, um sie dann als „Schweine hinstellen zu kōnnen.

Im September 1939 fielen in Verhandlungen zwischen dem Oberkommando des Heeres und dem Chef der Sicherheitspolizei Reinhard Heydrich die ersten Entscheidungen über das künftige Vorgehen gegenüber den polnischen Juden. Der Chef des Generalstabs des Heeres Franz Halder notierte unter dem 20. September in seinem Kriegstagebuch:, Gbetto-Gedanke besteht im großen; im einzelnen noch nicht klarliegend. Berücksichtigung der Wirtschaftsbelange vorweg. "63 Nāhere Einzelheiten sind aus dem Schnellbrief ersichtlich, den Heydrich am 21. September 1939 an die Einsatzgruppen der Sicherheitspolizei sandte: Darin wird zwischen einem „Endziel (welches längere Fristen beansprucht) und ... den Abschnitten der Erfüllung dieses Endzieles (welche kurzfristig durchgeführt werden) 4 unterschieden. 64

Das „Endziel“ war hier noch nicht die berüchtigte „Endlösung“, sondern die Errichtung eines Judenreservats ${ }^{\mu}$ zwischen dem Osten Krakaus und der neuen deutsch-so-

$60 \mathrm{Vgl}$. ebenda, S. 30.

61 Nach Kaplan (Buch, S. 69) wurden die aus Pultusk vertricbenen Juden aul dem anderen Narew-Ufer überfallen und der Rabbiner ausgernubt.

62 Vgl. Ruta Sakowska (Hrsg.), Archiwum Ringelbluma Getto warszawskie, Lipiec 1942- styczeń 1943, Warszawa 1980; Bemard Goldstein, Die Steme sind Zeugen, Hamburg 1950, S. 59 ff.; Kaplan, Buch, S. 160 f.; Adam Czerniaków, Im Warschauer Getto, München 1986, S. S4ff.; Emmanuel Ringelblum, Polish-Jewish Relations during the Second World War /geschrieben 1943/. Jerusalem 1974, S. 51. - Der Arbeitsrwang für die jüdische Bevōlkerung wurde am ersten Tag des Bestehens des Generalgouvernements eingeführt (Verordnungsblatt des Generalgouvemeurs für die besetzten polnischen Gebiete (VOBIGG 1/26.10.1939, S. 6f.) Im Unterschied zu den Polen, für die nur eine „Arbeitspflicht“ galt, waren Juden prinzipiell in $Z$ wangsarbeitertrupps“ zusammenzufassen. In der zweiten Durchführungsvorschrift zu dieser Verordnung vom 12.12.1939, die als „Erfassungsvorschrift“ bezeichnet wurde, hieß es: „Die Dauer dieses Arbeitszwanges beträgt in der Regel zwei Jahre; sie wird verlangert, wenn innerhalb dieser Zeit ihr erzieherischer Wert nicht erreicht sein sollte. ... Die Zwangsarbeitspflichtigen werden zur Auswertung ihrer Arbeitskraft, nach Möglichkeit entsprechend etwa erlemter Benufe, bei lagermäliger Unterbringung zur Arbeit eingesetzt. Nicht voll Arbeitsfähige finden ihrem Arbeitsvermögen entsprechend Verwendung." NOBIGG 14/23.12.1939, S. 246 (f.).

63 Generaloberst Franx Halder, Kriegstagebuch. Bd. 1, Stuttgart 1962, S. 82.

64 Nbg. Dok. PS-3363; auch abgednuckt in: Ursachen und Folgen. Vom deutschen Zusammenbruch 1918 und 1945 bis zur stantlichen Neuordnung Deutschlands in der Gegenwart. Bd. 14, Bertin 0.J. S. 159-163, Dok. 28812 
wjetischen Demarkationslinie. Als unmittelbare Verfügung enthält der Schnellbrief die Anweisung, die ${ }_{n}$ eingegliederten Gebiete ${ }^{\text { }}$ von Juden frei" zu machen, zum mindesten (soll) aber dahin gezielt werden, nur wenige Konzentrierungsstādte zu bilden“. Auch im restlichen besetzten Gebiet sollten Juden konzentriert werden: „Jüdische Gemeinden mit unter 500 Köpfen (seien) aufzulōsen und der nāchstliegenden Konzentrierungsstadt zuzuführen." Die Konzentrierungsstādte sollten mōglichst an Bahnlinien liegen, ,so daß die spāteren Maßnahmen erleichtert werden“. Daneben enthielt der Schnellbrief Anweisungen zur Bildung jüdischer "Ältestenrāte" aus den „zurückgebliebenen maßgeblichen Personen und Rabbinern", die für die „exakte und termingemäße Durchführung aller ergangenen oder noch zu ergehenden Weisungen “ verantwortlich zu machen waren. Die Ausführung der Deportation der Juden aus den eingegliederten Gebieten wurde bis nach der Errichtung der Zivilverwaltung im ehemaligen Polen ausgesetzt.65

Damit waren die Schritte der deutschen Instanzen für die nāchsten Monate festgelegt. Ungeachtet der bis Anfang Oktober 1939 noch in Erwägung gezogenen Reststaat-Pläne 66 waren die Gebiete umrissen worden, aus denen die Juden unter allen Umstānden ausgesiedelt werden sollten: dabei handelte es sich nicht allein um die eingegliederten Gebiete (wobei beachtet werden muß, daß im übrigen Reichsgebiet Deportationen staatsangehöriger Juden bis 1939 nicht vorgekommen waren), sondern - abgesehen von dem ${ }_{n}$ Reservat ${ }^{4}$ - auch um das spätere Generalgouvernement. Die Ghettoisierung, die Bildung der Judenräte war also von Anfang an nur als vorübergehende Zwischenlōsung geplant, der provisorische Charakter der Ghettos (Konzentrierungsstädte) deutlich geworden. ${ }^{67}$

In bezug auf die Bevölkerungsverānderungen sind für die ersten Monate des Zweiten Weltkriegs jedoch noch andere Erscheinungen von Bedeutung. Aus den grenznahen Gebieten (Ostoberschlesien, Zichenau, Posen) flohen Juden gemeinsam mit der einheimischen polnischen Bevōlkerung in spāter nicht "eingegliederte" Gebiete. Grynberg führt etwa Chorzele in der Wojewodschaft Warschau an, wo von den 2400 Juden kein einziger die deutsche Besatzung abgewartet haben soll. Allerdings kamen die meisten von ihnen nach dem Ende der Kampfhandlungen wieder in ihre Heimatorte zurück. In Warschau registrierte man 1939 dennoch z.B. 450 Flüchtlinge aus dem oben genannten Chorzele.68

$65 \mathrm{Vgl}$. auch Halder, Kriegstagebuch. Bd. 1, S. 79, Eintragung vom 19.9.1939. Danach forderte Heydrich eine "Flubereinigung", die „Judentum, Intelligenz, Geistlichkeit, Adel" betreffen sollte; demgegenüber stellte das Heer die "Fordenung", daß die "Bereinigung", über die man sich wohl keinen Illusionen hingab, "nach dem Herausziehen des Heeres und nach Ubergabe an stabile Zivilverwaltung" erfolgen sollte. - Die "Verordnung über die Einsetzung von Judenraten " erging am 28.11.1939 (VOBIGG 9/6.12.1939, S. 72f.). Ihr Par. 5 lautete: „Der Judenrat ist verpflichtet, durch seinen Obmann oder durch seinen Stellvertreter die Befehle deutscher Dienststellen entgegenzunehmen. Er haftet für ihre gewissenhafte Durchführung in vollem Umfange. Den Weisungen, die er zum Vollzuge dieser deutschen Anordnungen erläßt, haben samtliche Juden und Jüdinnen zu gehorchen."

66 Vgl. Martin Broszat, Nationalsozialistische Polenpolitik 1939-1945, Stuttgart 1961, S. 16 f.

67 Der israelische Historiker Yisrael Gutman schreibt dazu: Natürlich hatte das Getto den Zweck, die Juden von anderen Volksgruppen völlig zu isolieren. Trotzdem betrachtete man das Getto vermutlich nur als Durchgangsetappe und nicht als endgültige $\mathrm{Ma}$ nahme. Man beabsichtigte, die Juden zu deportieren nach Madageskar oder sonstwohin. Uber eine endgültige Lösung würde man später entscheiden" (l. Gutman, Vorwort, in: Czemiaków, Getto, S. XVII).

$68 \mathrm{Vgl}$. Grynberg, Żydzi, S. 27 f. 
Vor dem Einmarsch der Deutschen konnten sich nach realistischen Schātzungen etwa 200000 polnische Juden in das seit dem 17. September 1939 sowjetisch besetzte Gebiet in Sicherheit bringen.69 In einer zweiten "Welle ${ }^{\omega}$ gelangen in der ersten Zeit noch Grenzübertritte in die sowjetischen Gebiete; dazu kamen die bisher noch nicht umfassend dargestellten, zahlreiche Opfer fordemden Vertreibungsaktionen der Deutschen, die etwa zwischen dem 20. und dem 27. Oktober 19392000 Juden aus Kattowitz in die UdSSR deportierten. ${ }^{70}$ Ende September 1939 wurden die jüdischen Bewohner Przeworsks (1939: 1472) mit Ausnahme der Familie des Bäckers Kohm, der für den deutschen Bedarf buk, über den San vertrieben. ${ }^{71}$ Im November 1939 wurden 2000 Juden aus Warschau über die Grenze geschickt ${ }^{72}$, im Osten des Generalgouvernements wurden die jüdischen Einwohner Tarnobrzegs nach Ostgalizien vertrieben ${ }^{73}$, und im Dezember 1939 fand der berüchtigte "Todesmarsch" aus Chelm über Hrubieszów an den Bug statt, bei dem diejenigen, die den Gewaltmarsch überstanden und nicht in dem winterkalten Fluß ertranken, sich an das sowjetische Ufer retten konnten $^{74}$, wo sie z.T. von sowjetischen Soldaten am Verlassen des Flusses gehindert wurden.

Insgesarnt mōgen bis 1941 etwa 300000 Juden aus den deutsch besetzten Gebieten (einschließlich der 200000 Flüchtlinge) in Sowjetisch-Polen angekommen sein - davon ca. 150000-180000 in Ostgalizien.75 Die Hauptsammelpunkte waren Lemberg, Białystok, Wilna und Minsk.

In den deutsch besetzten Territorien fand eine allgemeine Ostverschiebung der Juden statt. Vor den Deutschen hatten sich bis zu 60000 Juden $^{76}$ aus den westlichen Grenzgebieten nach Kempolen in trügerische Sicherheit bringen wollen. Eine Schātzung für den spāteren Distrikt Krakau ergibt eine Abwanderung von dort nach Osten

$69 \mathrm{Vgl}$. Krakowski, Avedot, S. 232; Levin, Holocaust, S. 270; Elizbieta Homowa, Powrót Zydów polstich z ZSRR oraz dzialalnost opiekuńcza Centralnego Komitetu Zydów w Polsce, in: BZIH 1-2/133-134 (1985), S. 106. - Hierzu gehōren auch die polnischen Juden, die durch die Ubergabe Wilnas an Lituren durch die Sowjetunion am 10. Oktober 1939 in den litauischen Stant gelangten (s. Beitrag Robel). Wahrend amtliche litauische Angaben von 70000 sprechen, gibt das American Jewish Year Book nur 15000 an (nach Kulisher, Displacement, S. 50)

$70 \mathrm{Vgl}$. Aleksander Pakentreger, Statystyka Zydów m. Kalisza, ocalalych po II wojnie światowej, in: BZIH 96 (1976), S. 83.

71 Vgl. Benbenek, Martyrologia, S. 119 f.

72 Vgl. Berenstein/Rutkowski, Liczba, S. 77.

73 Vgl. Gazeta Zydowska 5/6.8.1940, nach Marian Fuks, Male Judenraty w swietle "Gazety Zydowskiej" 1940-42, in: BZIH 4/128 (1983), S. 114 .

74 Vgl. Krakowski, Avedoc, S. 232; It. Gilbert (Endlösung, S. 37) übertebten nur 400 von den 1800, die aufgebrochen waren.

75 Vereinzelt anzutreffende Werte von bis zu 500000 jüdischen Menschen dürften überhöht sein. Sie entstammen einer fehlerhaften Auswertung der vom Internationalen Arbeitsamt bestellten Arbeit von Eugene M. Kulisher, The Displacement of Population in Europe, Montreal 1943. - Kulisher gibt die Zahl von 500000 Juden an, die aus den sowjetisch besetzten Gebieten Polens ins Innere der Sowjetunion deportiert worden seien; aus dem deutsch besetzten Polen seien 215000 Juden bis 1941 in den sowjetischen Mechtbereich gelangt, die meisten von ihnen seien wiederum in der oben genannten Zahl von 500000 enthalten (S. 114). Proudfoot (Refugees, S. 59) nennt die Zahl von $\mathbf{4 0 0 0 0 0}$ Juden, die sich vor den Deutschen in Sicherheit gebracht hätten. Etwa 18000 seien im Laufe des Krieges in andere Länder weitergezogen. Für Robert Ginesy (La Seconde Guerre Mondiale et les Déplacements de Populations, Paris 1948, S. 18) flohen im September 193960000 in den sowjetischen Machtbereich; ihnen seien bis 1941500000 weitere gefolgt: 200000 nach Ostpolen und 300000 ins Innere des Landes. Die Doppelzählung ist offensichtlich, darüber hinaus kommen bei Ginesy zahlreiche andere Fehler vor.

76 Lt. Kulisher, Displacement, S. 99. 
von 35000 bis 40000 Juden 77 , von denen etwa 5000 bis 6000 aus der Stadt Krakau selber kamen. Aus noch westlicheren Teilen Polens wanderten hier bis Oktober 1939 etwa 20000 Juden zu. ${ }^{78}$ Aus dem dicht an der Demarkationslinie gelegenen Kreis Ostrów Maz. floh die Mehrzahl der Juden (ca. 7000) in die nahen sowjetischen Gebiete. Die Zurückgebliebenen wurden Anfang November 1939 größtenteils erschossen - deren Zahl wird auf 500 geschātzt. 79

In Warschau führte das Statistische Büro des dortigen Judenrats die erste Zählung der jüdischen Einwohner am 28. Oktober 1939 durch. Sie ergab 350827 Juden, was etwa 28\% der Bevōlkerung der Stadt ausmachte. ${ }^{80}$ Für Krakau und einige Nachbargemeinden fand im November 1939 eine Judenregistrierung durch die jüdische Gemeinde auf Anweisung des Kommandos der Sicherheitspolizei statt. Man ermittelte 68482 "einheimische " Juden, davon 19732 Kinder unter 16 Jahren. Nicht erfaßt wurden Juden, die vor dem Krieg oder den Deutschen aus anderen Gegenden nach Krakau geflohen waren. ${ }^{81}$ Eine demographische Publikation aus dem Jahre 1940 schreibt ohne Berücksichtigung der Kriegsereignisse für den Dezember 1939 schlicht die Vorkriegszensusergebnisse weiter fort ${ }^{82}$

Nimmt man die Zahl der Juden in den deutsch besetzten Gebieten mit 2053000 an und zieht davon die Kriegstoten und im Vorgriff auch die in der Gefangenschaft Umgekommenen ab (67000), desweiteren die in den ersten Monaten Ermordeten $(5000)^{83}$ und die in den sowjetischen Teil, nach Rumānien, Ungarn und Litauen Geflohenen 300000, dann verblieben zum Zeitpunkt der Einrichtung des Generalgouvernements etwa 1681000 polnische Juden im deutschen Einflußbereich. ${ }^{84} \mathrm{Am}$ Rande muß erwāhnt werden, daß bereits am 17. September 1939 das erste Konzentrationslager eingerichtet wurde - und $2 w a r$ auf dem Territorium der ehemaligen Freien Stadt Danzig in Stutthof. Etwa 300 Danziger Juden wurden zunāchst eingeliefert ${ }^{85}$, es folgten ihnen bald 150 Juden aus Warschau und Bialystok. ${ }^{86}$ Der polnische Historiker Krzysztof Dunin-Wąsowicz, der selber Stutthof-Häftling war, bezeugt, daß nahezu alle bis 1942 auf die eine oder andere Weise den Tod gefunden hatten. ${ }^{87}$

\section{Die Deportationen aus den eingegliederten Gebieten}

Nachdem die Hoffnungen auf eine Beendigung des Kriegszustandes im Westen aufgegeben worden waren, im Osten mit der UdSSR im Freundschaftsvertrag eine Regu-

77 V 1 . Podhorizer-Sandel, O zagladzic, S. 88.

78 Vil ebenda.

79 Vgl. Tatiana Brustin-Berenstein, Deporacje i zagiada skupisk żydowskich $w$ dystrykcie warszawskim, in: BZIH 1/3 (1952), S. 84.

80 Nach Akten des Judenrates im Jüdischen Historischen Institut in Warschau, zit. nach Berenstein/Rutkowski, Liczba, S. 76.

81 Vgi. Aleksander Bieberstein, Zagłada Zydów w Krakowie, Kraków 1986, S. 14.

82 V 1 . Fritz Arts, Ubersicht über die Bevölkerungsverhältnisse im Generalgouvernement, Krakau 1940, S. 16.

83 Nach Gilbert (Endlösung, S. 33) ergibt sich dieser Anteil von insgesamt 16336 Zivilisten, die in den ersten Kriegswochen an 714 Orten hingerichtet wurden.

84 Nach Gilbert, Endlōsung, S. 36: 1139000 im Generalgouvernement und 678000 in den eingegliederten Gebieten; zusammen also 1817000 .

85 Vgl. Krzysztof Dunin-Wagsowicz, Zydowscy wiȩźniowie KL Stutthof, in: BZIH 63 (1967) S. 6.

86 Vgl. Krzysztof Dunin-Wąsowicz, Obóz koncentracyjny Stutthof, Gdynia 1966, S. 97.

87 Vgl. ebenda, S. 42,97. 
lierung von Demarkationslinien und Interessensphären (28. September 1939) erreicht worden war und die UdSSR das von ihr besetzte Wilna-Gebiet an die Republik Litauen abgetreten hatte (10. Oktober 1939), konnte man an die Konsolidierung des $\mathrm{Zu}$ standes und die verwaltungsmäßige Neuordnung der polnischen besetzten Gebiete gehen. Zwischen dem sowjetisch besetzten Polen und den in das Reich „eingegliederten Gebieten " entstand am 26. Oktober 1939 das „Generalgouvernement für die besetzten polnischen Gebiete“ (GG) - wobei die letzten Worte später gestrichen wurden, als die

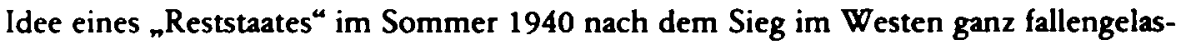
sen wurde.

Zum „Generalgouverneur für die besetzten polnischen Gebiete " wurde Hans Frank bestellt. Sein Amtssitz war zunāchst (vor der Ausrufung des staatsāhnlichen Gebildes) in Posen, dann in Lódź - erst am 6. November 1939 siedelte er nach Krakau über, wo auf dem nunmehr "Burg" genannten Wawel die "Regierung des Generalgouvernements ${ }^{\star}$ untergebracht wurde. Die Regierung unterstand formell ausschließlich Adolf Hitler persönlich, allerdings ist die gesamte Geschichte des Generalgouvernements auch von Kompetenzstreitigkeiten zwischen ihr, unterschiedlichen Instanzen der Reichsregierung, dem Militär und den verschiedenen Ebenen von SS und SD geprägt, auf die detailliert einzugehen sich hier verbietet.

Das Generalgouvernement bestand bis 1941 aus vier Distrikten (Krakau, Radom, Lublin, Warschau), deren Chefs unmittelbar dem Generalgouverneur unterstanden. Die Hauptstadt war nach Krakau verlegt worden, weil Warschau sehr dicht an der Grenze zwischen dem Generalgouvernement und den „eingegliederten Gebieten “ lag und man dem dort stärker vermuteten polnischen Nationalismus ausweichen wollte. 1939 bestand das Generalgouvernement aus Gebieten mit einer Fläche von 96559 $\mathrm{km}^{2}$ und wurde von etwa 12000000 Menschen bewohnt ${ }^{88}$

In der Geschichte des nationalsozialistischen Deutschland spielte das Generalgouvemement insofern eine große Rolle, als es der Hauptaustragungsort für die Realisierung der deutschen rassistischen Konzeptionen wurde: in rascher Folge gelangten hier die deutschen Plāne ansatzweise bzw. in ihrem ganzen grausigen Ausmaß zur Realisierung. Nachdem anfangs noch von einer temporären Heimstätte des polnischen Volkes

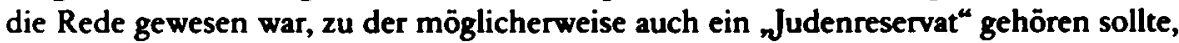
wurde das "Nebenland des Reiches" schon bald zum Ort unverhüllter Verfolgungen. Die nGettoisierung ${ }^{\star}$ der jüdischen Bevōlkerung wurde durchgeführt; ab 1941 deportierte man hierher die Masse der europäischen Juden zur Ermordung. ${ }^{89}$

Eine Lagerwelt wurde geschaffen, die sich bis auf den heutigen Tag einer zusammenfassenden genauen Aufarbeitung im Westen entzogen hat 90 Neben Arbeits- und Konzentrationslagern entstand die Kategorie der "Vernichtungslager", in denen der

88 Für die improvisierende Willkürherrschaft illustrierend ist die Tatsache, daß im Generalgouvernement zunächst keine verbindliche Definition des Begriffes Jude" galt. Ein von den sog. Nürnberger Gesetzen nicht abweichender Eriaß für des Generalgouvernement erging erst in der ${ }_{n}$ Verordnung über die Bestimmung des Begriffs Jude“ im Generalgouvemement“ vom 24.7.1940 (VOBIGG 48/1.8.1940, Teil I, S. 231 f); für die "eingegliederten Gebiete“ galten die deutschen Rassegesetze gar erst vom 31. Mai 1941 an (RGBl vom 4.6.1941). Dies behinderte die antijūdischen Aktivitäten jedoch überhaupt nicht.

B9 Andere Deportationsziele waren Lód́́, Theresienstadt in Bōhmen und Māhren sowie die Ghettos des Reichskommissariats Ostland.

90 In Polen liegt ein erster enzyklopadischer Versuch vor. Die GKBZHwP hat eine eindrucksvolle Gesamtübersicht herausgegeben: Obozy hitlerowskie na ziemiach polskich 1939-1945. Informator encyklopedyczny, Warszawa 1979. 
Massenmord an Menschen in bis dahin unbekannter Art industrialisiert worden ist. Parallel dazu gab es wechselnde Konzepte der Behandlung von nicht-jüdischen Polen, die von wirtschaftlicher Ausbeutung, Germanisierung und sogar der pragmatischen Förderung eines rudimentären polnischen Nationalismus gegen Kriegsende bis hin zur Einkerkerung, Geiselnahme und willkürlichen Erschießung ohne ersichtlichen Grund reichten. Es darf als sicher angenommen werden, daß zahlreichen deutschen Machthabem eine Vemichtung der ethnischen Polen nach dem Abschluß der Judenvernichtung vorschwebte. Im Generalgouvernement fand der Hauptteil des Massenmordes an den europäischen Juden statt - daher wird ihm im weiteren die besondere Aufmerksamkeit gewidmet werden müssen.

Der erste organisierte Abschnitt des Vorhabens war mit dem Heydrich-Plan vom 21. September 1939 umrissen worden. Als sich nach dem 26. Oktober 1939 die Militärbehörden aus dem Generalgouvernement zurückzogen und im Osten Kampfruhe eingetreten war, erließ Heinrich Himmler am 30. Oktober 1939 die Anweisung, die Juden aus den „eingegliederten Gebieten “ ins Generalgouvernement zu deportieren. 91 Als Termin sah der Himmler-Befehl die Zeit zwischen November 1939 und Februar 1940 vor, wobei gleichzeitig auch die „besonders feindlich eingestellte polnische Bevōlkerung“ aus den "eingegliederten Gebieten“ entfernt werden sollte.

Von Anfang an traf diese Vertreibungsaktion auf den Widerstand der Regierung des Generalgouvernements, die hier zum ersten Male in einen Streit mit der SS geriet. Zum einen ergab sich die Notwendigkeit, im Generalgouvernement Unterkünfte für die Eingesiedelten zu beschaffen, zum anderen stelite sich die Nahrungsmittelfrage; hinzu trat ein auch in anderen Zusammenhāngen erkennbares Bestreben Franks, das eigene Gebiet zu einem ngut funktionierenden Musterstaat" umzugestalten, um so die eigenen Fähigkeiten unter Beweis zu stellen.

Nachdem zunāchst beschlossen worden war, bis Frühjahr 19401000000 Polen und Juden ins Generalgouvernement abzuschieben ${ }^{92}$, und ein leitender Beamter sofort angemerkt hatte, die dann 16000000 Menschen starke Bevölkerung sei nicht mehr $2 u$ ernāhren (man operierte mit willkürlichen Zahlen, um die eigenen Argumente zu stützen), liefen die Deportationen Anfang Dezember 1939 planmäßig an, nachdem man bereits im November z.B. in Kalisz versucht hatte, durch schlechte Behandlung möglichst viele Juden zum „freiwilligen “ Abzug ins Generalgouvernement zu bewegen.93 Vom 12. Dezember 1939 an wurden die Posener Juden deportiert - ihr Ziel lag wie das vieler anderer Transporte in der Lubliner Umgebung, wo eine Art Judenreservat" geplant schien. Für die Deportation ungeeignete Personen durften zurückbleiben, sie wurden spāter umgebracht.94 In Kalisz internierten die Deutschen am 20. November 193910000 Juden unter unmenschlichen Bedingungen in der Markthalle, wo sie bis Dezember bleiben mußten. Zwischen dem 2. und dem 14. Dezember 1939 ver-

91 Das Dokument wird als Dok. 246 im Archiv der GKBZHwP katalogisiert; vgl. Brustin-Berenstein, Deportacje, S. 85.

92 Sitzung der Distriktchefs und Amtsleiter des Generalgouvemements vom 8.11.1939; vgl. Wemer Präg/ Wolfgang Jacobmeyer (Hrsg.), Das Diensttagebuch des deutschen Generalgouverneurs in Polen 1939-1945. Stuttgart 1975 (im folgenden: Diensttagebuch), S. 60.

$93 \mathrm{Vgl}$. Pakentreger, Dzieje, S. 88 f.; vgl. hierzu auch die noch früheren Versuche gleicher Art im Reg.Bez. Zi. chenau (Grynberg, Zydzi, S. 28 t.).

94 Vgl. Jerzy Marczewski, Eksterninacja fizyczna ludnosci w Poznaniu (1939-1945), in: Przeglạd Zachodni 28 (1972), S. 58. 
ließen zehn Transportzüge die Stadt in Richtung Lublin, Sandomierz, Rzeszów, Krakau usw. Etwa 16000 Kaliszer Juden wurden so ins Generalgouvernement deportiert. $^{95}$ - Aus Kalisz ist aus jenen Tagen die Beschwerde eines Kaliszer deutschen stādtischen Beamten über eine Gruppe von Wehrmachtsoffizieren überliefert, die versucht hatte, sich für die Juden einzusetzen. 96 Im Ergebnis dieser ersten Umsiedlungswelle wurden die westlichen Kreise des Warthegaus ,judenrein“.97 Nach dem „Ersten Nahplan" vom 12. November 1939 sollten nur aus Posen, Gnesen und Hohensalza (Inowrocław) sofort alle Juden deportiert werden, aber SS-Gruppenführer Wilhelm Koppe übererfülite sein Soll. Statt der vorgesehenen 80000 meldete er am 18. Dezember 1939 dem RSHA über 87883 „evakuierte“ Polen und Juden.98

Zwischen Dezember 1939 und April 1940 wurden nach Dąbrowska ca. $140000 \mathrm{Ju}$ den aus den eingegliederten Gebieten ins Generalgouvernement deportiert. Allerdings kommt Dạbrowska zu dieser Zahl anhand des Vergleichs der Vorkriegszahl (ca. 400000 ) mit einer Zählung der Juden, die sich zu jener Zeit noch in Konzentrationspunkten befanden, die das American Joint Distribution Committee - eine amerikanische jüdische Wohlfahrtsorganisation - im Juni 1940 vorgenommen hat.99 Von dieser Zahl sind etwa 20-60000 abzuziehen, die vor dem November aus den polnischen Westprovinzen geflohen waren. Die Rechnung nach Transporten ist ebenfalls unzulänglich, selbst wenn sie quellenmäßig möglich wäre. Daneben ist von einer nicht näher bestimmbaren, aber nicht allzu gering anzusetzenden Zahl von Juden auszugehen ${ }^{100}$, die während der Umsiedlungszeit auf eigene Faust, d.h. nicht mit einem organisierten Bahntransport, ins Generalgouvernement gezogen waren.

Eine andere Rechnung ist von den Generalgouvernement-Gebieten aus mōglich: Für die Stadt Warschau besitzen wir für diese Zeit eine Angabe über 90000 Zugewanderte ${ }^{101}$, in den Distrikt Lublin kamen bis Ende 1939 etwa 11200 Juden ${ }^{102}$ mit den Transporten. Aus den eingegliederten Gebieten sollen etwa 16500 in den Distrikt Krakau deportiert worden sein, der Wert für den Distrikt Radom ist nicht bekannt.

Unzweifelhaft sind die meisten Juden aus den eingegliederten Gebieten nach Warschau gekommen - ungeachtet der "Judenreservat-Idee", die jedoch ab Februar 1940 zunehmend obsolet geworden war. ${ }^{103}$ Die Zahl 90000 für Warschau dürfte dennoch

95 Vgl. Pakentreger, Dzieje, S. $91 \mathrm{ff}$.

96 Vgl. ebenda, S. 94.

97 Vgl. Dabrowska, Zagtada, S. 128.

98 Vgl. Pakentreger, Dzieje, S. 94.

99 Akten des American Joint Distribution Committee (AJDC) im Archiv des Jüdischen Historischen Instituts Warschau (AZIH), Nr. 414, nach Dębrowska, Zagtada, S. $126 \mathrm{f}$.

$100 \mathrm{Vgl}$. ebends, S. 127

$101 V_{g l}$. Ruta Sakowska, Ludzie z dzielnicy zamkniçtej. Zydzi w Warszawie w okresie hitlerowskiej okupacji. Paidziernik 1939 - Marzec 1943, Warszawa 1975, S. 55.

102 Vgl. Eisenbach, Polityka, S. 157. Zu Krakau vgl. Podhorizer-Sandel, O zagladzie, S. 90.

103 Bereits im Frühjahr hatte man den ursprünglichen Lublin-Plan fallengelassen. Hans Frank sprach von Madagaskar als Ausweichort, aber diese Diskussion war letztlich akodemisch; der bereits 1938 einmal anvisierte Zielort hatte trotz der Hoffnungen auf Vichy-Frankreich keinen Realitātswert mehr. Vgl. dazu Philip Friedman, The Lublin Reservation and the Madagascar Plan: Two Aspects of Nazi Jewish Policy during the Second World War (verfaßt 1953) in: ders., Roads to Extinction. Essays on the Holocaust, New York 1980, S. 34-58; Eisenbach, Polityka, S. 80, 165-182; L. Yahil, Madagascar - Phantom of a solution for the Jewish Question, in: B. Vago/G. Mosse (Hrsg-) Jews and Non-Jews in Eastern Europe 1918-1945, New York 1974, S. 315-324. - 1940 sollten die Deutschen noch aus dem Lubliner Gebiet ausgesiedelt werden, das „für das Judenreservat bestimmt ist" (Heinrich Himmler aul der Karinhall-Konferenz vom 12.2.1940, Nbg. Dok. EC-305). Nach dem Beginn der Judenvernichtung machte dic Planung eine Wendung um 180 Grad: Im Gebiet des „Judenreservats" sollte nun nach einem zwischen November 1942 und Sommer 1943 


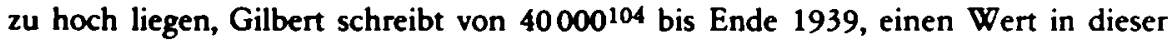
Höhe ergab die Zāhlung der jüdischen Gemeinde im April 1940. Es dürfte daher realistisch sein, für die Gesamtdeportationen eine Zahl von etwa 80 - 90000 Juden anzunehmen. Eisenbach ${ }^{105}$ nennt keine eigenen Schätzungen, und eine sorgfăltige polnische Arbeit ${ }^{106}$ spricht von neinigen - zig Tausend“.107

Als Ergebnis dieses Winters dürfte anzunehmen sein, daß sich groß angelegte Deportationen als praktikabel erwiesen hatten und daß diese Maßnahmen irgendwann einmal auch auf das Generalgouvernement anzuwenden sein würden; und nur soweit interessierte Frank das Ergebnis. Er begrüßte es jedenfalls, daß Göring am 23. März 1940 die Einstellung sämtlicher Evakuierungen aus den eingegliederten Gebieten anordnete. Himmler setzte die Anweisung in einen Befehl um, und der Höhere SS- und Polizeiführer Wilhelm Koppe verfügte daraufhin die Aussetzung der Transporte. ${ }^{108}$

Das unmittelbare Ergebnis der Einstellung der Evakuierungen ins Generalgouvernement war der Beginn der Einrichtung von Ghettos in den „eingegliederten Gebie-

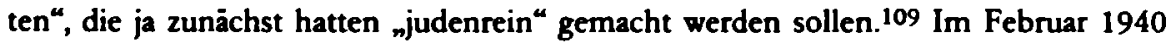
wurde aus zahlreichen kleineren Orten im Wartheland die jüdische Bevölkerung nach Lódź (1939: 162000 Juden), aber auch nach Pabianice (ca. 8500), Zduńska Wola (10000), Ozorków (4700), Belchatów (5500), Kutno (7000), Zelów (4500), Włoclawek $(4000)$ und Wieluń (4000) deportiert. Die jüdischen Bevölkerungszahlen der dadurch betroffenen Orte erhōhten sich entsprechend.

Die Entstehung des "offenen Ghettos“ in Koźminek ist ein deutliches Beispiel der deutschen Judenverfolgung: Nach den Dezemberdeportationen waren in Kalisz etwas über 600 Juden zurückgeblieben. Die Markthalle wurde nun vom 20. Dezember an mit Juden aus den kleineren umliegenden Orten (Blaszki, Chocz, Zbiersk, Iwanowice, Opatówek) gefüllt. Am 13. Januar 1940 kamen 800 Juden aus Stawiszyn dazu. Mit der Hālfte der verbliebenen Kaliszer schickte man diese Leute in einem Zug nach Lódź.

aktuellen Plan das erste DEUTSCHE Kolonisationsgebiet im Generalgouvernement eingerichtet werden. $\mathrm{C}_{2} 100000$ Polen wurden zu diesem Zweck vertrieben, etwa 10000 Volksdeutsche angesiedelt, bis die Aktion wegen der Kriegsentwicklung und der Verstärkung der Partisanentätigkeit bis "nach dem Krieg" ausgesetzt wurde. Vgl. Zygmunt Mańkowski, Hitlerowska akcja wysiedleń i osadnictwa na Zamojszczyźnie, in: Przesiedlenia, S. 15-34.

104 Vil. Gilbert, Endlösung, S. 42.

$105 \mathrm{Vgl}$. Eisenbach, Polityke, S. 165.

106 Vgl. Czeslaw Luczak, Polityka ludnościowa i ekonomiczna hitlerowskich Niemiec w okupowanej Polsce, Poznań 1979, S. 128.

107 Peter-Heinz Seraphim schätzte 1940 die Zahl auf 330000 (Judenfrage, S. 61), Kulisher (Displacement, S. 99) nimmt ebenfalls einen viel zu hohen Wert von „über $330000^{\prime \prime}$ an. Dies dürfte die Gesamtzahl der ausgesiedelten Polen und Juden sein. Zu den Quantifizierungs- und Klassifizierungsschwierigkeiten vgl. Czeslaw Luczak, Wysiedlenia hitlerowskie na tak zwanych Ziemiach Wschodnich wcielonych do Rzeszy, in: Przesiedlenia S. 178-182. - Der Chef der Sicherheitspolizei und des SD in Berlin nannte am 15.11.1940 303 Polen-Transporte mit zusammen 294336 POLEN (Ubersicht über die durchgefūhrten Evakuierungen, Nbg. Dok. NO-5150, zit. bei Eisenbach, Polityka, S. 165).

$108 \mathrm{~V}_{\mathrm{g}}$. Eisenbach, Polityka, S. 163.

109 Das "Planziel" für die Zeit von Mär bis Dezember 1940 war die Umsiedlung von 450000 Juden, bis zu 35000 Zigeunem und 120000 Polen. Die Umsiedlung der Juden wurde jedoch nach dem Mär 1940 eingestellt. Artur Eisenbach (Przesiedlenia ludności żydowskiej w okresie II wojny światowej, in: Przesiedlenia, S. 288) nennt die Karinhall-Konferenz, auf der die Gefahr der Schwāchung der Wirtschaftskraft der Ostgebiete durch die Deportationen zum Thema gemacht wurde, als Auslöser der Transporteinstellung. Göring habe aufgrund dessen dann eine entsprechende Anweisung gegeben. In seinem früheren Buch hatte Eisenbach die Konferenz Hōherer SS- und Polizeiführer in Bertin vom 30.1.1940 als Basis der vorübergehenden Aussetzung von Judendeportationen genannt (Nbg. Dok. NO-5322-2; Eisenbach, Polityka, S. $157 \mathrm{ft}$.). 
Dort weigerte sich der Judenrat, sie aufzunehmen. Also brachte man sie am 28. Januar 1940 wieder in die Markthalle von Kalisz zurück - und am 23. Februar nach Koźminek, wo dann vorübergehend für 1312 Juden ein Ghetto eingerichtet wurde. ${ }^{110} \mathrm{Im}$ Juni 1940 lieferte man etwa 50 Juden aus Ostrów Kaliski ein. Entlassene Kriegsgefangene und Wechsel zwischen Kalisz (wo es ein Krankenhaus gab) und Koźminek brachten die Zahlen auf 700 in Kalisz bzw. 1300 in Koźminek.111

Das Krankenhaus von Kalisz ist von besonderer Bedeutung, weil hier lange vor dem Rußlandfeldzug Abgas-Lkws zum Judenmord eingesetzt wurden. ${ }^{112}$ Am 27., 28. und 30. Oktober 1940 holte ein schwarzer, abgedichteter Lkw 290 jüdische Patienten aus dem Krankenhaus ab, fuhr mit ihnen in den acht Kilometer entfernten Ort Biernatki, wo die Patienten ermordet ankamen und die Leichen begraben wurden. 1946 wurden sie exhumiert und auf dem jüdischen Friedhof in Kalisz beigesetzt. ${ }^{113}$ Dieser

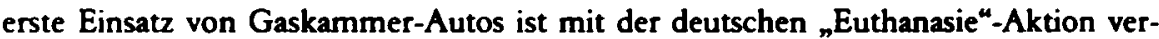
knüpft. 1941 machte es in Polen keine Schwierigkeiten, auf diese „Erfahrungen“ zurückzukommen. ${ }^{114}$

Die Ermordung Geisteskranker und Pflegebedürftiger fand (wiederum im Zusammenhang mit den deutschen "Euthanasie“-Morden) auch im Reg.Bez. Zichenau in größerem Umfang statt. In Mackeim/Maków Mazowiecki richtete man im Februar 1940 in einem Schulgelände ein Schein-Krankenhaus ein, dessen ca. 500 polnische und jüdische Insassen im nahen Wald von Sewerynowo durch Gestapo, SS und Beihilfe leistende Volksdeutsche erschossen, begraben - und im Mai 1944 exhumiert wurden. Ähnliches geschah in Zichenau/Ciechanów, Sichelberg/Sierpc und Pieńki Borowe (Kr. Ostrolęka/Scharfenwiese). In Schröttersburg/Plock traf es im Januar 1940 neun jüdische (und 27 christliche) Bewohner eines katholischen Pflegeheims, Ende des Jahres die 40 Bewohner des jüdischen Altersheims. 115

Nach den Deportationen verblieben in den „eingegliederten Gebieten " etwa 600000 Juden, davon ca. 400000 im Gau Wartheland ${ }^{116}$, etwa 100000 im Dombrowa-Gebiet und etwa 80000 im zu Ostpreußen geschlagenen Nordteil der Woje-

110 Vgl. Aleksander Pakentreger, Losy Zydów missta Kalisza i powiatu kaliskiego w okresie okupacji hitlerowskiej. Martyrologia i zaglade, in: BZIH 2-3/114-5 (1980), S. 4 f.

111 Vgl. ebenda, S.9.

112 Pakentregers Hinweis, man habe hier eine Generalprobe für Lódź unternommen, ist nicht schlüssig, weil die von ihm zitierten Dokumente entstellt wiedergegeben sind - hier ist weitere Forschung vonnöten.

113 Vgl. ebenda, S. 12 f. - Eine weitere Vergasungsaktion fand im Kreis Kalisz am 18.11.1941 statt: 127 Personen, darunter 15 Kinder aus dem Waisenhaus, wurden mit Gaskammer-Autos in einen Waid bei Jedlec, Kreis Jarocin gefahren und dor verscharrt. Zwischen dem 28.11. und dem 1.12.1941 folgten ihnen 100 Personen aus Kalisz und 600 aus dem Ghetto Koźminek. Die fünf Massengriber wurden durch die Anpflanzung von Bāumen getamt. In Kelisz blieben nur mehr 150 Juden übrig (vgl. ebende, S. $18 \mathrm{f}$.). Da Himmler im Sommer 1941 in Minsk dem Chef der Einsatzgruppe B Nebe eine humanere" Tötungsmethode als die Massenerschießung zu suchen befohlen hatte, experimentierte dieser mit Sprengungen und Autoabgasen herum. Hierin sieht Helmut Krausnick (vgl. Diskussionsbeitrag in: Eberhand Jäckel/Jürgen Rohwer (Hrsg.), Der Mord an den Juden im Zweiten Weltkrieg. Entschlußbildung und Verwirdlichung, Stuttgart 1985, S. 140) die Vorläufer der Vergasungsentscheidung. Vom 3.9.1941 an fanden in Auschwitz Vergasungsversuche zunächst an sowjetischen Kriegsgefangenen statt.

114 Vgl. Diskussionsbeitrag Hilberg, in: Jäckel/Rohwer, Mord, S. 142.

115 Vgl. Grynberg, Zydzi, S. $41 \mathrm{f}$.

116 Wir vemachlässigen hier die etwa 1800 Juden des neuen Gaus Danzig-Westpreußen. Die Angaben stammen von Gauleiter Greiser. Sitzung über Ostragen unter dem Vorsitz des Ministerpräsidenten Generalfeldmarschall Göring, 12.2.1940, in: Der Prozeß gegen die Hauptkriegsverbrecher vor dem Internationalen Militärgerichtshof Nümberg, 14. November 1945 - 1. Oktober 1946. Nürnberg 1947-1949, Bd. 36, S. 303, Dokument 305-EC. 
wodschaft Warschau (Reg.Bez. Zichenau). ${ }^{117} \mathrm{Daß}$ sich in der gleichen Zeit die Zahl der Juden im Generalgouvernement um etwa 350000 erhöht haben kann ${ }^{118}$, ist dennoch kein unbedingter Widerspruch. Der Kategorisierungsbegriff „Juden“ war nach rassistischen Kriterien verändert worden und umfaßte einen deutlich größeren Personenkreis. Daneben kamen in dieser Zeit bereits Transporte aus nicht-polnischen Gebieten an. Im Februar 1940 wurden etwa 1000 Stettiner Juden nach Lublin deportiert - abgesehen von der 1938er Deportation war dies die erste organisierte Vertreibung aus Deutschland. Auch aus Österreich und dem Protektorat Bōhmen und Māhren wurden bereits 1939/1940 Juden in das geplante Judenreservat" abgeschoben. Zu erwāhnen wäre auch der natürliche Zuwachs, der so wenige Monate nach Kriegsausbruch noch „Friedensniveau“ gehabt haben dürfte, auch wenn die Sāuglingssterblichkeit vermutlich deutlich zunahm.

Eine Zählung des Judenrates in Warschau, auf deren Basis die Lebensmittelkarten ausgegeben wurden und die deshalb allgemein als leicht überhöht angesehen wurde, ergab im April 1940395025 Juden, darunter 40000 Zugänge aus dem Gau Wartheland und dem Regierungsbezirk Zichenau. ${ }^{119}$ Für Częstochowa/Tschenstochau stiegen die Zahlen zwischen Januar 1940 und Januar 1941 von 31758 auf $33921^{120}$, andere Angaben sprechen für 1941 sogar von 35653 jüdischen Einwohnern Tschenstochaus. ${ }^{121}$ Insgesamt stieg durch die Deportationen ${ }^{122}$ die Zahl der jüdischen Bewohner des Generalgouvemements leicht an, wāhrend für die „eingegliederten Gebiete“ eine Abnahme registriert werden muß.

Vom 1. Dezember 1939 an galt für die Juden des Generalgouvernements der Kennzeichnungszwang. Gleichzeitig trat eine Anordnung in Kraft, die Konten von Juden sperrte, wenig spāter eine Verordnung „über die Pflicht zur Anmeldung jüdischen Vermögens“ - dies waren erste Hinweise auf die Aussonderung und Beraubung der Juden nun auch in dem Gebiet, in das sie zu dieser Zeit noch massenweise transportiert wurden. Vom 1. Januar 1940 an war der eigenmächtige Wechsel des Wohnsitzes untersagt: im Generalgouvernement begann die „Ghettoisierung ${ }^{\text {. }}{ }^{123}$

\footnotetext{
117 Vgl. Michał Grynberg, Getta w rejencji ciechanowskiej, in: BZIH 4/116(1980), S. 57.

118 Vgl. Karol Marian Pospieszalski, Hitlerowskie „prawo" okupacyjne w Polsce. Bd. 2, Poznań 1958, S. 521.

119 Vgl. Berenstein/Rutkowski, Liczbe, S. 75 ff.

120 Vgl. L. Brener, O pracy przymusowej ludności żydowskiej w Częstochowie w okresie okupacji hitlerowskiej, in: BZIH 22 (1957), S. 48.

121 Vgl. Jan Pietrzykowski, Hitlerowcy w Częstochowie w latach 1939-45, Poznań 1959. S. 178.

122 Die Zahl derjenigen, die auf dem Transport umkamen, kann nicht ermittelt werden; die Deportationen fanden im Winter in ungeheizten Waggons statt.

123 Gemäß der „Verordnung über die Kennzeichnung von Juden und Jüdinnen im Generalgouvemement vom 23.11.1939" (VOBIGG 8/30.11.1939, S. 61). In den eingegliederten Gebieten war die Kennzeichnungsplicht bereits früher eingeführt worden, in Sichelberg/Sierpc am 12.10.1939, in Leslau/Wloctawek am 24.10.1939 (Vgl. Grynberg, Zydzi, S. 37); der Kompetenzwirrwart führte zu unterschiedlichen Kennzeichnungsformen in den einzelnen Distrikten und Kreisen. - Jüdische Konten wurden mit der Anordnung Nr. 4 des Leiters der Abteilung Devisen im Amte des Generalgouvemeurs vom 20.11.1939 gesperrt (VOBIGG 7/20.11.1939, S. 57f.). Die Wohnsitzbindung erfolgte durch die Erste Durchfühnungsvorschrift zur Verordnung vom 26.10.1939 über die Einführung des Arbeitszwanges vom 11.12.1939 (VOBIGG 13/21.12.1939, S. 231 f.). Die Verondnung über die Pflicht zur Anmeldung jūdischen Vermōgens im Generalgouvemement vom 24.1.1940 (VOBIGG 7/29.1.1940, S. 31-35) sah eine Erfassung aller Gegenstände und Forderungen von einigermaßen fafbarem Wert bis hinunter zu "Einrichtungsgegenständen" und "persōnlichen Gebrauchsgegenständen“ vor.
} 


\section{Die Ghettoisierung}

Die "Konzentration" der Juden in Orten, die nach Möglichkeit entlang von Bahnlinien gelegen sein sollten, war bereits ein Hinweis darauf, daß alle diese Umsiedlungen provisorischen Charakter hatten, daß es sich letzten Endes um $Z$ wischenstationen auf einem Weg handelte, dessen Endpunkt aber zu dieser Zeit noch nicht endgültig formuliert worden war. Uberhaupt zeichnete sich nach außen kein eigentlicher Umriß einer zielgerichteten Politik ab. Scheinbar auf Dauer angelegte Maßnahmen kontrastierten scharf mit hektischen Umsiedlungen, die auch innerhalb des Generalgouvernements stattfanden und keine einheitliche Planung verrieten.

In einer Abteilungsleitersitzung am 12. April 1940 vekündete Hans Frank den Plan,

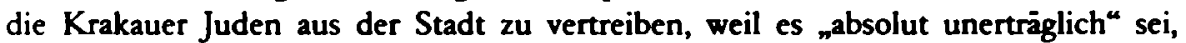
„wenn in einer Stadt, der der Führer die hohe Ehre zuteil werden lasse, der Sitz einer hohen Reichsbehörde zu sein, Tausende und Abertausende von Juden herumschlichen und Wohnungen innehātten“.124 Zum 1. November 1940 sollte Krakau "soweit irgend möglich, judenfrei“ sein. Seit September 1939 hatte sich die Zahl der jüdischen Einwohner Krakaus infolge der Deportationen aus den neingegliederten Gebieten " erhöht - hatte sie vorher über 56000 betragen, so lag sie Anfang 1940 zwischen 60000 und 80000. Im März/April 1940 erfolgte in Krakau auf Anweisung des "Amtes des Hōheren SS- und Polizeiführers“ eine Régistrierung der arbeitsfähigen Mānner zwischen 12 und 60 Jahren: man ermittelte 21105 Personen. Da Bieberstein ${ }^{125}$ diese Zahl als $73,3 \%$ der mānnlichen jüdischen Bevölkerung charakterisiert, erhält man etwa 60000 als Gesamtzahl für Krakau. Allerdings dürfte sich manch einer der Registrierung entzogen haben, so daß die faktische Zahl vermutlich höher anzusetzen ist. Aufgrund der Kennzeichnungsverordnung für Juden über 12 Jahren verteilte die jüdische Gemeinde 53828 Armbinden mit dem Davidstem ${ }^{126}$ - setzt man ein āhnliches Verhāltnis wie oben ein, ergibt sich eine Gesamtzahl von 70000. Bis Mitte August 1940 wurde die "freiwillige“ Abreise der Juden aus Krakau den Betroffenen über den Judenrat nahegelegt, wobei als Anreiz dienen sollte, daß die so die Stadt Verlassenden ohne Einschränkungen ihren Besitz mitnehmen dürften. Nach der Verordnung des Stadthauptmanns vom 18. Mai 1940 sollten am 15. August 1940 nur mehr 15000 aus wirtschaftlichen Gründen erforderliche Juden und ihre Familien in Krakau wohnen. ${ }^{127}$ Es kann anhand der amtlichen deutschen Angaben davon ausgegangen werden, daß etwa 23000 Juden im Zuge dieser Aktion Krakau verließen.128 Die Wohlfahrtsorganisation American Joint Distribution Committee registrierte im Juni 1940 noch etwa 67000 Juden in Krakau. ${ }^{129}$ Die Abreise aus der Stadt, für die bereits Passierscheine und Sondererlaubnisse erforderlich waren, organisierte der Judenrat. Hierzu muß angemerkt werden, daß bis in den Sommer 1940 hinein die jüdischen

124 Diensttagebuch, S. 165.

125 Vgl. Bieberstein, Zagtada, S. 14, 25.

126 Vgl. ebenda, S. 22.

127 Vil. ebenda S. 32.

128 Vgl. Krakauer Zeitung 31.12.1940/1.1.1941, nach Hiberg, Vernichtung, S. 152.

$129 \mathrm{~V}$ l. Rechenschaftsbericht der Abteilung des AJDC im Distrikt Krakau vom 4.7.1940, AZIH, Akte AJDC 354, nach Podhorizer-Sandel, O zagtadzie, S. 89. 
Gemeinden im Generalgouvernement die Arbeitsfähigen selber registrierten. In Krakau ging am 1. April 1940 diese Kompetenz an das deutsche Arbeitsamt über. ${ }^{130}$

Im September 1940 wurden weitere 9000 Juden zwangsweise aus der Stadt vertrieben, indem der Judenrat ihnen entsprechende Reisebefehle zuschickte. Ob damit aber die in den deutschen Unterlagen auftauchende Gesamtzahl von 32000 Abgewanderten bis Ende 1940 stimmt ${ }^{131}$, ob die vom Judenrat im Bericht für die Zeit vom 13. September 1939 bis zum 30. September 1940 genannte Zahl von $29610^{132}$ zutriff, die wohl eine Abgrenzung nach unten darstellt, oder ob ca. 35000 Juden, wie in den Generalgouvernement-Dokumenten ebenfalls ermittelt wird ${ }^{133}$, bis Anfang Oktober die Stadt verließen, wird wohl unbekannt bleiben - wobei beachtet werden muß, daß, abgesehen von der forcierten Abreise, auch eine solche außerhalb der Regie des Judenrates stattfand. Etwa 15000 Krakauer Juden gelangten bis Oktober 1940 in den Kreis Miechów, 5000 nach Dzialoszyce, 3000 nach Wolbrom, jeweils mehr als 1000 nach Slomniki, Proszowice, Skalbmierz und in die Stadt Miechów. ${ }^{134}$ Auf Personen, die nicht im Besitz der vom Judenrat ausgegebenen, zum Bleiben berechtigenden Ausweise waren, fanden im November 1940 erstmals Razzien statt, in deren Verlauf weitere 11000 Personen die Stadt zu verlassen hatten. ${ }^{135}$ Die restlichen Juden wurden in einem Judenwohnbezirk " in dem wenig attraktiven Stadtviertel Podgórze zusammengespert, wo 1939 etwa 3000 Menschen gelebt hatten.

Das am 21. Mărz aufgrund einer Anordnung vom 3. Mārz 1941 eingerichtete Ghetto besaß nur mehr 15000 Einwohner. Offiziell wurden 12000 Kennkarten ausgestellt, Bieberstein ${ }^{136}$ rechnet mit etwa 3000 zusātzlichen „illegalen“ Bewohnern. Etwa 15 - 20000 weitere mußten die Stadt verlassen, nachdem der Distriktchef Wächter am 25. November 1940 alle bisherigen Bescheinigungen für ungültig erklärt hatte und in nochmals reduziertem Umfang neue Kennkarten ausgeben ließ. Die Akten der Distrikte Lublin und Krakau im Archiv des Jüdischen Historischen Instituts in Warschau weisen 80 Transporte mit Umsiedlern aus, die zwischen dem 29. November 1940 und dem 2. April 1941 Krakau in östlicher Richtung verließen. ${ }^{137}$ Die von den Deutschen kontrollierte Presse für die Juden förderte die Umzugsbereitschaft. Man berichtete etwa aus dem Kreis Chelm, dort stānde ausreichender Wohnraum zur Verfügung und die ländliche Umgebung ,erlaube den Juden die Durchführung der von ihnen heißersehnten landwirtschaftlichen Umschulung ${ }^{\text {“. }}{ }^{138}$

Die verhältnismäßig ausführliche Behandlung Krakaus bezweckt mehreres: Zum einen soll gezeigt werden, daß auch in den relativ ,ruhigen ${ }^{*}$ Zeiten zwischen den ersten Deportationen und dem Beginn der Massenvernichtung dauemd ein Umschlag von Juden zwischen verschiedenen Wohngebieten stattgefunden hat, der mit den üblichen Mitteln des Historikers in diesem Rahmen auch nicht annāhernd erfaßt werden

\footnotetext{
130 Vgl. Bieberstein, Zagtada, S. 26.

131 Vgl. Krakauer Zeitung, 31.12.1940, nach Hilberg, Vernichtung, S. 152.

132 Vgl. Podhorizer-Sandel, $O$ zagladzic, S. 91.

133 Vgl. ebenda.

134 Vgl. Gazeta Zydowska 28/7.10.1940, nach Fuks, Male Judenraty, S. 198.

135 Vgl. Hilberg, Vemichtung, S. 152.

136 Vgl. Bieberstein, Zegtade, S. 48.

137 Vgl. ebenda, S. 40; Podhorizer-Sandel, O zagladzic, S. 91.

138 Gazeta Zydowska 12/10.2.1941, zit nach Fuks, Male Judenraty, S. 108. Zur Charakterisierung der Gazeta Zydowska vgL. Tadeusz Cieślak, Z historii niemieckiej prasy w języku polskim, in: Rocznik Historii Crasopiśmiennictwa Polskiego 8 (1969), S. 579-588.
} 
kann. Über die Verschickungen fehlen z.T. Unterlagen, andererseits wird mit Zahlen operiert, die nur angenäherte Schātzwerte sein kōnnen. Vielfach entgehen Deportationen der Aufmerksamkeit der Forscher - so erscheinen z.B. die quantitativ nicht ganz unbedeutenden Abschiebungen zwischen November 1940 und Frühjahr 1941 im grundlegenden Buch Hilbergs nicht, obwohl dort Krakau sonst viel Beachtung geschenkt wird. Andererseits dokumentiert die Krakauer Vertreibung, daß „Aussiedlungen “ eine der regulären Maßnahmen der deutschen Herrschaft in Polen waren, über die auch noch in der zensurierten Presse positiv berichtet wurde; dies wiederum bietet einen Hinweis darauf, warum spāter die als „Aussiedlungen“ ausgegebenen Deportationen in die Mordmaschinerien der Vernichtungslager zunāchst nur wenig Verdacht erregten.

Die Mitteilungen über Deportationen aus der Hauptstadt des Generalgouvernements sind zu ergänzen durch die Erwähnung von Judendeportationen aus anderen lokal begrenzten Gebieten. Bereits 1939 wurden etwa 900 Juden aus Wielopole Skrzyńskie im Kreis Dębica vertrieben, wo die Wehrmacht einen Truppenübungsplatz einrichten wollte. ${ }^{139}$ Im Mārz 1940 hatten alle Juden die Orte Krzeszowice und Swoszowice zu verlassen, wo die Sommerresidenz des Generalgouverneurs errichtet wurde, und im Sommer 1940 wurde das Gebiet von Zakopane zum Erholungsgebiet für Deutsche erklārt und für Juden gesperrt. Im Juni 1941 wurde dieses Sperrgebiet bis Nowy Targ erweitert.140 Im November 1940 war den Juden das Betreten des Kurgebiets von Krynica verboten worden. ${ }^{141}$

Die Bevölkerungsverschiebungen im Winter 1940/41 scheinen am wenigsten erforscht zu sein. Sie waren der "Konzentrationsbewegung “ gegenläufig - ihr Sinn ist nicht in allen Fällen schlüssig zu bestimmen. Aus der Stadt Radom wurden im Dezember 1940 Juden ,aufs Land“ geschickt. Etwa 500 blieben in Chmielnik, Kreis Busko, 225 in Nowy Korczyn - eine nicht genannte Zahl verteilte sich auf andere Orte des Kreises. ${ }^{142}$ Aus Jedrzejów, Distr. Krakau wurden 1941600 Juden nach Wodzisław (300), Szczekociny (150), Sobków (100) und Sędziszów (50) umgesiedelt ${ }^{143}$ Wie in Krakau wurde in Lublin - die Plāne für ein „Reservat" waren längst ad acta gelegt - ein Großteil der jüdischen städtischen Bevölkerung in die umliegenden Kreise ausgesiedelt - im dann eingerichteten Ghetto lebten anfangs 30-40000 Menschen. ${ }^{144}$

Die Judenumsiedlungen führten dennoch hauptsächlich in die grōßeren Stādte hinein, in denen die verwaltungsmäßige Erfassung der Juden einfacher erschien. Zu diesem Zweck waren bereits aufgrund der Heydrichschen Anweisung vom 21. September 1939 Judenräte gebildet worden, die als einzige Verbindung zwischen den die jeweilige Stadt bewohnenden Juden und den diversen deutschen Stellen zu dienen hatten. Für die Deutschen brachte dies neben der Vereinfachung ihrer Verwaltung auch einen möglichst reduzierten persōnlichen Kontakt mit der jüdischen Bevölkerung mit sich, was zum einen wegen der Furcht vor Seuchen positiv erschien, die zu-

139 Vgl. AZIH, Akte Jüdische Selbsthilfe JUS 553, nach Podhorizer-Sandel, O zagładzie, S. 90.

$140 \mathrm{~V}_{\text {gl }}$. Rechenschaftsbericht des Kreishauptmanns von Neumarkt/Nowy Targ für die Zeit vom 17.9.1939 bis zum 31.5.1941, nach Podhorizer-Sandel, O zagladzie, S. 90.

141 Vgl. Eisenbach, Polityka, S. 223.

142 Vgl. Gazeta Zydowska 4/14.1.1941, nach Fuks, Male Judenraty, S. 187.

143 Vgl. Gazeta Zydowska 12/11.2.1941, nach Fulks, Male Judennaty, S. 192.

144 Vgl. Eisenbach, Polityke, S. 222; R Moszyński/L Polichs, Lublin w okresie okupacji (1939-1944), Lublin 1948, S. 72; Berenstein, Martyrologia, S. 29 f. 
mindest zeitweise subjektiv nicht nur vorgeschoben gewesen sein mag, zum anderen aber eine Gefahr der Fraternisierung möglichst gering hielt, die den deutschen Stellen nach den Erfahrungen im Ersten Weltkrieg nicht ganz unmōglich erscheinen mußte. ${ }^{145}$

Die „Einsiedlung“ in die großen Städte stieß jedoch auf den Widerstand der davon betroffenen deutschen Stadt- und Kreishauptleute, so daß gleichzeitig auch andere Zwischenjösungen gesucht wurden. So mußten zwar die meisten Juden die Dörfer verlassen - man hat sie jedoch nicht gleich in den Städten untergebracht. Ein Beispiel ist die Anweisung an die in Dōrfern des Kreises Sochaczew-Blonie, Distr. Warschau lebenden Juden, im Januar 1941 in den jüdischen Wohnbezirk von Żyrardów umzuziehen. ${ }^{146}$ Noch im selben Jahr mußten dann alle Juden Żyrardóws ins Warschauer Ghetto gehen. Zwischen Ende 1939 und 1941 entstanden so letztlich unsystematisch auf dem Territorium des Generalgouvernements und in den östlichen Teilen der „ein-

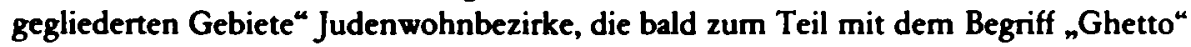
belegt wurden. Der Ghetto-Begriff sollte implizieren, daß diese mittelalterlich-frühneuzeitliche Lebensform eine den Juden gemäße sei. Er trägt eindeutig beschönigende Merkmale, die die inhumane Realitāt der Wohnbezirke ebensowenig abbildet wie der Satz im offiziösen GG-Handbuch du Prels: „Die jüdischen Wohnbezirke sind größtenteils von Mauern umgeben, sodaß die Juden völlig unter sich leben. ${ }^{147}$

Bereits 1939 waren jüdische Stadtteile im Westen Polens abgesteckt worden. Im Oktober entstand der erste in Petrikau/Piotrków, im Dezember folgten Puławy und Radomsko. ${ }^{148}$ In den ersten Monaten des Jahres 1940 wurden Judenviertel in weiteren westpolnischen Stādten gebildet, dabei auch im $\mathbf{W}$ arthegau, nachdem die Deportation ins Generalgouvernement eingestellt worden war. Es seien hier nur Pabianice, Warta und Lódź genannt. Im April 1940 wurde das Ghetto Brzeziny, im Juni 1940 dasjenige von Kutno eingerichtet. ${ }^{149}$ Im Reg.Bez. Zichenau, in dem es 19 jüdische Bezirke gab, entstand das erste Ghetto Anfang 1940 in Sichelberg/Sierpc ${ }^{150}$; aus der Stadt waren zuvor $90 \%$ der Juden vertrieben worden. Gegen Ende des Jahres erfaßte die Abgrenzung der jüdischen Wohnbereiche von denjenigen der nicht-jüdischen Polen auch die mittleren Gebiete des besetzten Landes. Im Oktober 1940 wurde ein Ghetto in Mińsk Mazowiecki bei Warschau geschaffen ${ }^{151}$, zu Anfang 1941 war der Abschluß der Umsiedlung innerhalb von Otwock angeordnet. In Otwock wurde ein getrenntes „Kur-

145 Zur Problematik der Judenrite und der jüdischen Hilfspolizei, die auch von dem Vorwurf der Kollaboration nicht ausgenommen wurden, vgl. u.2 die massive Kritik Hannah Arendts (Eichmann in Jerusalem. Ein Bericht von der Banalitāt des Bösen, München 1986', S. 151-166) sowie das grundlegende Werk von Isaiah Trunk, Judennat. The Jewish Councils in Eastem Europe under Nazi Occupation, New York 1972. Einzelschriften Philip Friedmans über die Lage in Lódź, Sosnowiec/Sosnowitz und Wilna s. in: ders., Roads, S. 333-380.

146 Vgl. Gazeta Zydowska 11/7.2.1941, nach Fuks, Male Judenraty, S. 99.

147 Max Freiherr du Prel, Das Generalgouvernement, Würburg 1942, S. XVII. Vgl. hingegen die einleitenden Säze aus dem Stroop-Bericht über die Niederschlagung des Warschauer-Ghetto-Aufstands (s. Anm. 382): "Die Bildung jüdischer Wohnbezirke und die Auferlegung von Aufenthalts- und Wirtschaftsbeschränkungen für die Juden sind in der Geschichte des Ostens nicht neu. Ihre Anfänge gehen weit bis ins Mittelalter zurück und waren auch noch im Verlaufe der letzten Jahrhunderte immer wieder zu beobachten. Diese Beschrinkungen erfolgten aus dem Gesichtspunkt, die arische Bevölkerung vor den Juden zu schützen" (Nbg. Dok. 1061-PS, S. 632 f.).

148 Vgl. Eisenbach, Polityka, S. 218.

149 Vgl. ebenda; Dąbrowske, Zaglada, S. 131.

150 Vgl. Grynberg, Zydzi, S. 47.

151 Vgl. Eisenbach, Polityka, S. 221 f. 
Ghetto" für Kranke und Schwache eingerichtet, das zunāchst positiv bewertet wurde. ${ }^{152}$ Bald sollte man jedoch erkennen, daß Nicht-Arbeitsfähige als erste ermordet wurden. Im Distrikt Lublin entstand im Oktober 1940 das Ghetto Chetm. ${ }^{153}$ Aus dem Zentrum von Krasnystaw wurden die Juden im Juli 1940 vertrieben. Sie durften nur noch jenseits des Flusses Wieprz leben, wo auch vor der Emanzipation im 19. Jahrhundert das Judenghetto gewesen war. ${ }^{154}$ Im März 1941 wurde das Leben außerhalb der festgelegten Bezirke in Krakau (21. März 1941), Lublin (24. Mărz 1941) und Bochnia (15. März 1941) untersagt. Zum 7. April 1941 wurde angeordnet, in Tschenstochau einen geschlossenen jüdischen Wohnbezirk“ einzurichten. ${ }^{155}$ Aber auch im Zichenauer Bezirk entstanden noch im November 1941 neue Ghettos in Strzegowo (Kr. Mława) und Nowe Miasto (Kr. Płońsk). ${ }^{156}$

Bereits wāhrend der Konsolidierungsphase des Ghettos kam es zu Improvisation und Willkür. Úber den Reg.Bez. Zichenau etwa berichtet Grynberg, daß in Plock das Ghetto im September 1940 eingerichtet, jedoch bereits im März 1941 wieder aufgelöst wurde. ${ }^{157}$ Angeblich wollte die deutsche Stadtverwaltung möglichst rasch und ungehindert über einen Fonds verfügen, in den die arbeitenden Juden $50 \%$ ihrer Verdienste einzuzahlen hatten. Bereits Mitte 1941 wurden kleinere Ghettos in Czerwińsk, Wyszogród und Zakroczym aufgelōst und deren Bewohner nach Nowy Dwór „eingesiedelt".158 Eine Sonderrolle nahm das Ghetto im Fort Pomiechówek bei Nowy Dwór (Reg.Bez. Zichenau) ein. Nachdem hier Juden konzentriert worden waren, die man als Illegale im Regierungsbezirk aufgegriffen hatte, wurde das Fort von Mai bis September 1941 als "normales" Ghetto mit einer Bevōlkerung von über 6000 geführt. Im September 1941 wurden 2500 hier noch lebende Juden an die Grenze des Generalgouvernements eskortiert und laufen gelassen. ${ }^{159}$ Bis zum Kriegsende war Pomiechówek ein Gestapo-Gefāngnis. Zuletzt wurden die Ghettos im Kreis Rzeszów errichtet. Kreishauptmann Ehaus gab am 17. Dezember 1941 einen entsprechenden Erlaß aus, woraufhin Umzüge stattfanden und in Rzeszów am 10. Januar 1942, in anderen Orten des Kreises am 1. Februar 1942 die jüdischen Wohnbezirke von der Außenwelt abgeschlossen wurden. 160

Die Ghettoorganisation war keineswegs einheitlich. Zahlreiche Ghettos waren zunächst offen - was bedeutete, daß ihre Bewohner sich in der gesamten Ortschaft frei bewegen durften und nur im Ghetto wohnen mußten. Solche offenen Ghettos befanden sich meist nicht in größeren Orten, sondem in Kleinstädten wie Sieradz (Anfang 1941, 2000 Personen) ${ }^{161}$ oder Zduńska Wola (Mai 1940, 8500 Personen). ${ }^{162}$ Daneben entstanden im Warthegau auch sog. Dorfghettos, bei denen die gesamte polnische Bevölkerung eines Dorfes ausgesiedelt wurde, um aus ihrem Dorf ein Ghetto werden zu

\footnotetext{
152 Vgl. Gazeta Zydowska 35/19.11.1940, nach Fuks, Maje Judennaty, S. 102.

153 Vgl. Eisenbach, Polityka, S. 222.

154 Vgl. Gazeta Zydowska 12/10.2.1941, nach Fuks, Male Judenraty, S. 195.

155 Vgl. Pietrzykowski, Hitlerowcy $\approx$ Częstochowie, S. 176.

156 Vgl. Grynberg, Zydzi, S. 47 ff.

157 Vgl. Grynberg, Getta, S. 60.

$158 \mathrm{Vgl}$. ebende, S. 59.

159 Vgl. Michal Grynberg, Obozy w rejencji ciechanowskiej, in: BZIH 1/117 (1981), S. 50f, 57.

160 Vgl. Stanislaw Poradowski, Zaglada Zydów rzeszowskich, in: BZIH 3-4/135-6 (1985), S. 80.

161 Vgl. Cygański, Powiat, S. 86.

162 Vgl. ebenda.
} 
lassen. Dies geschah z.B. in zwei Dörfern der Gemeinde Lubotyń, Kreis Kolo: 150 Fa. milien aus Kolo und 50 Familien aus Babiak wurden am 2. Oktober 1940 in den Bauernhāusern von Bugaj und Nowiny Brdowskie untergebracht. ${ }^{163}$ In anderen Fällen hier geht es um Dörfer der Gemeinde Grodziec (2000 Juden) und Rzgów bei Konin (1000 Juden) ${ }^{164}$ - wurden die Juden in Nebengebäuden von Bauernhöfen einquartiert.

Das größte Ghetto entstand in der ehemaligen polnischen Hauptstadt Warschau. Nach der Lebensmittelkartenzählung lebten in der Stadt, deren Judenrat von dem Ingenieur Adam Czemiaków geführt wurde, im Mai 1940396041 Juden. ${ }^{165}$ Czerniaków hinterließ ein Tagebuch, das zusammen mit den vom Historiker Emmanuel Ringelblum gesammelten Dokumenten einen unschätzbaren Einblick in die Herrschaftspraxis der Deutschen und das tägliche Leben im Warschauer Ghetto bietet. ${ }^{166}$ Wāhrend die Quellenlage zu den großen Ghettos (Warschau, Krakau, Lódź) so ist, daß man sich ein recht genaues Bild von den Lebensumstānden darin und von der Ghettogeschichte machen kann, sind die Nachrichten über die zahlreichen kleineren Orte spärlich. Da dort die Anzahl der Uberlebenden und die Zahl der an einer Úberlieferung Interessierten geringer waren, müssen diesbezügliche Informationen sehr mühsam erschlossen werden. In vielen Fällen erweist sich ein solcher Versuch bereits heute als unmöglich. 167

Ab Anfang April 1940 wurden die von den Juden bewohnten Warschauer Viertel mit einer Mauer umgeben. Offizielle Begründung war die Seuchengefahr - es waren in der Tat Typhusfälle aufgetreten. Aber es gab auch die nicht als absurd aufgenommene Behauptung, die Mauem seien dafür da, die jüdischen Einwohner vor Exzessen (der Polen) zu schützen. ${ }^{168}$ Im April 1940 hatte ein polnischer Mob drei Tage lang pogromāhnlich jüdische Hāuser verwüstet. Das Ghetto entstand in den Stadtvierteln, die bereits vor dem Krieg den hōchsten Anteil an jüdischer Bevōlkerung hatten - dennoch waren im Zusammenhang mit der Segregation der jüdischen Einwohner Umsiedlungen von 138000 Juden und 113000 polnischen Nichtjuden innerhalb des Stadtgebiets erforderlich. ${ }^{169}$ Im November 1940 wurde das Ghetto Warschau geschlossen. Es war von da an Juden untersagt, sich ohne besondere Erlaubnisscheine außerhalb seiner Mauern aufzuhalten. Die Verlautbarung des Distriktchefs erschien am 14. Oktober, am 15. Oktober erfolgte die Verkündung durch Lautsprecher, Ausführungsverordnungen publizierte man am 17. Oktober 1940, die endgültigen Abwicklungsmaßnahmen zogen sich noch eine gewisse Zeit hin. ${ }^{170}$

163 AZIH, Akte Ring. II/303, nach Dagbrowske, Zaglada, S. 132 f.

164 AZIH, Akte AJDC 332, nach ebenda, S. 132.

165 Vgl. Berenstein/Rutkowski, Liczba, S. 75.

166 S. Anm. 62. - Vgl. hierzu Yisrael Gutman, Adam Czemiakow - the man and his diary, in: Yisrael Gutman/ Livia Rothkirchen (Hrsg.) The Catastrophe of European Jewry. Antecedents - History - Reflections, Jerusalem 1976, S. 451-489; Marian Fuks, Das Problem der Judenräte und Adam Czerniakóws Amtstätigkeit, in: Steffi Jersch-Wenzel (Hrsg-h, Deutsche - Polen - Juden, Berlin 1987, S. 229-239.

167 Vgl. dazu die Materialsammlung in Fuks, Male Judenraty.- Zu Krakau vgl. auch Roman Kielkowski, ... zlikwidować na miejscu! Kraków 1981.

168 Vgl. dazu Czemiaków, Im Warschauer Getto, S. 58. - Später trug der Warschauer Gouvemeur Ludwig Fischer abweichende Gründe vor: Es sei darum gegangen, „den Einfluß der Juden auf die polnische Bevölkerung auszuschalten", weiter auch um Gründe "wirtschaftlicher und hygienischer Natur ${ }^{4}$ (Besprechung vom 3.4.1941, Diensttagebuch, S. 343).

169 Vgl. Madajcryk, Polityke, Bd. 1, S. 282.

170 Vgl. Czerniaków, Im $\mathbb{W}$ arschauer Getto, S. 122 f; Henryk Makower, Pamiętnik z getta warszawskiego, Wroctaw 1987, S. 8. 
Die Zahl der Juden im Warschauer Ghetto erhöhte sich weiter bis in die Mitte des Jahres 1941. Es zogen Juden aus den „eingegliederten Gebieten“ und aus Krakau (etwa 20000), etwa 50000 aus dem Regierungsbezirk Zichenau, andere aus dem Westen des Warschauer Distrikts, der Anfang 1941 ,judenfrei“ sein sollte und aus anderen Gegenden des Generalgouvernements zu. ${ }^{171}$ Für März 1941 nahm der Judenrat in einer Schātzung 445000 Ghetto-Bewohner an ${ }^{172}$, deutsche Schätzungen schwanken für diese Zeit zwischen $\mathbf{4 7 0 0 0 0}$ und $\mathbf{4 9 0 0 0 0 . 1 7 3}$ Krakowski setzt für den Zeitpunkt der Ghetto-Schließung (16. November 1940) eine ursprüngliche Einwohnerzahl von über 400000 an, zu der er 68500 Zugezogene und 3500 Neu-Geburten rechnet, wodurch er eine Gesamtzahl von 490000 erhält ${ }^{174}$, die den höchsten deutschen Schātzungen entspricht. Im Herbst 1941 wurde die Umsiedlung von Juden aus den östlich von Warschau gelegenen dörflichen und halbstädtischen Regionen fortgesetzt. Obwohl einige 10000 Juden in dieser Zeit neu in das Ghetto eingeliefert worden sein dürtten ${ }^{175}$, nahmen die absoluten Einwohnerzahlen (nach den LebensmittelkartenDaten) von April 1941 an dauernd ab: im Mai 1941 lebten noch 442 337, im September 1941 nur mehr 404300 offiziell registrierte Juden im Warschauer Ghetto. 176 Emil Apfelbaum gibt für das Jahr $1941^{177}$ allein 11000 Hungertote an - 1940 waren es nur ${ }^{\text {" }} 91$ gewesen.

Bemerkbar macht sich zum einen die rapide zurückgehende Geburtenzahl, während andererseits - auch wenn es nur vereinzelt zu gewaltsamen Tötungen kam - die Todesrate anstieg. Nur vorübergehend wurde die Lebensmittelversorgung verbessert, um bessere Arbeitsergebnisse zu erzielen. Bald wurden die Emāhrungsverhältnisse unerträglich. Im Sommer 1941 betrug die Todesrate in den Ghettos von Warschau und Lódź um $1 \%$ im Monat. ${ }^{178}$ Die miserablen Lebensverhältnisse, unzureichende Ernāhrung und medizinische Versorgung, das Fehlen jeglicher Vorsorge gegen Krankheiten forderten auch ohne aktive Mitwirkung der Okkupationsmacht ihren Zoll. ${ }^{179}$ Die Todesfälle sind - zieht man von ihnen die natürliche Sterberate in Friedenszeiten ab - ebenfalls der nationalsozialistischen Judenverfolgung anzulasten.

Auch die anderen Ghettos wurden im Laufe der nächsten Monate „geschlossen": Tschenstochau am 7. April 1941 - Umsiedlungen durften bis zum 17. April 1941 durchgeführt werden. ${ }^{180}$ Am 19. April 1941 zählte man in Tschenstochau $35663 \mathrm{Ju}$ den. ${ }^{181}$ Das Lubliner Ghetto wurde am 24. Mäz 1941 geschlossen ${ }^{182}$, das Krakauer

171 Vgl. Berenstein/Rutkowski, Liczba, S. 75-78; Sakowska, Ludzie, S. 25; zu den umfangreichen Umsiedlun-

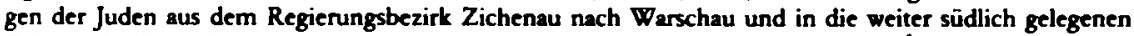
Gebiete des Generalgouvernements vgl. die sorgfältigen Ermittlungen bei Grynberg, Zydzi, S. 99-105.

172 Vgl. Berenstein/Rutkowski, Liczba, S. 75.

$173 \mathrm{Vgl}$. ebenda, S. 78.

174 Vgl. Krakowski, Avedot, S. 234.

$175 \mathrm{~V}$ gl. Brustin-Berenstein, Deportacje, S. 87

$176 \mathrm{Vgl}$. Berenstein/Rutkowski, Liczba, S. 75.

177 Nach Dewidowicz, War, S. 214.

178 Vgl. Hilberg, in: Jäckel/Rohwer, Mord, S. 126. - Vgl. Myron Winick (Hrsg.h Hunger Disease. Studies by the Jewish Physicians in the Warsaw Ghetto, New York 1979.

179 Marian Marek Drozdowski nennt in seinem Diskussionsbeitrag (Przesiedlenia, S. 216) allein für Warschau 96000 Tote aufgrund der wirtschaftlichen, gesundheidlichen und sozialen Situation".

$180 \mathrm{Vg}$. Pietrzykowski, Hitlerowcy w Częstochowic, S. 176.

$181 V_{g}$. Jan Pietrzykowski, Hitlerowcy w powiecie częstochowskim 1939-1945, Katowice 1972, S. 115.

$182 \mathrm{Vgl}$. Berenstein, Martyrologia, S. 29. 
Podgórze-Ghetto, dessen Bewohner sich zunāchst etwas weitergehender Freizügigkeit erfreuen durften, wurde im Oktober $1941^{183}$ von der Außenwelt abgeriegelt.

Entsprechend der Einsiedlung der Umlandbewohner nach Warschau erfolgte die Konzentrierung der Juden des "eingegliederten “ Warthegaues - sofern sie nicht im Winter 1939/40 ins Generalgouvernement deportiert worden waren - im großen Ghetto der von den Deutschen in Litzmannstadt umbenannten Stadt Lódź. Waren zunāchst neben den dörflichen Ghettos hier noch kleinere Judenwohnbezirke in Kolo (Dezember 1940), Lęczyca (Februar 1941) und Uniejów (Juni 1941) ${ }^{184}$ eingerichtet worden, so erging nun der Beschluß (3. Juni 1941), in Litzmannstadt ein Gau-Ghetto einzurichten ${ }^{185}$, in das sämtliche Juden aus den anderen Orten des Gaus eingeliefert werden sollten, soweit sie nicht anderswo in der Produktion gebraucht wurden. Der Beschluß wurde dergestalt ausgeführt, daß man in der Praxis nur gesunde, arbeitsfãhige Juden nach Litzmannstadt deportierte und die Arbeitsunfāhigen meist sofort in den ursprünglichen Heimatorten umbrachte. ${ }^{186}$ Am 1. Mai 1940 gab es in Lódź 157306 Juden, bis zum 1. Februar 1941 hatte sich diese Zahl auf 153995 Personen verringert ${ }^{187}$ Nun erfolgten jedoch die „Einsiedlungen“: Im Oktober 1941 kamen etwa 3100 Juden aus Leslau/Wloclawek, in den nächsten Wochen aber auch Transporte von Juden aus dem Deutschen Reich, bzw. aus anderen europäischen Gebieten, die inzwischen dem Reich einverleibt worden waren - sie werden mit etwa 20000 angegeben. 188

Der Plan eines Gaughettos wurde nun aber doch nicht verwirklicht. Man ließ die meisten der neugeschaffenen kleineren Judenbezirke zunāchst fortbestehen, weil sich gegen Ende 1941 eine andere Methode abzeichnete, wie die Deutschen vorgehen wollten: es begann - zunāchst mit Hilfe von Autoabgasen - der industriell betriebene Massenmord an den polnischen Juden.

Nicht erst nach der Wannsee-Konferenz, schon viel eher erkennt man im Osten die Absicht, die Juden nicht den Zweiten Weltkrieg überleben zu lassen. Dazu mußten die Juden verfügbar gehalten werden; die anfänglich noch gewāhrte Freizügigkeit sollte nach Möglichkeit reduziert werden. Anfang 1941 ergingen Anweisungen, die das Reisen ohne besondere Genehmigungen unmöglich machten. Daß dies für die hāufig vom Handel lebenden osteuropäischen Juden eine Unterbindung aller Erwerbsmöglichkeiten bedeutete, sei nur am Rande erwähnt. Die Ziele waren bereits viel weitergreifend. Bei den ersten Beschränkungen der Freizügigkeit ging es pro forma noch um die Verhinderung von Schmuggel: So stellte der Lubliner Distriktchef Zörner seinen lokalen Untergebenen Anfang 1941 noch frei, das Aufenthaltsrecht der Juden einzuschränken, um so den Schmuggel wirksam zu bekämpfen.189 Die Einschränkungen wurden dann immer drastischer, bis mit der dritten Verordnung über

183 Vgl. Podhorizer-Sandel, O zagiadzie, S. 90; Bieberstein, Zaglada, S. 52.

184 Vgl. Dąrowske, Zagiade, S. $131 \mathrm{f}$.

185 Vgl. ebenda, S. 134.

186 Vgl. ebenda; Abraham Heltzin, Przyczynek do znajomosci stosunków demograficznych wśród ludności ży. dowskiej wodzi, Krakowie i Lublinie podczas okupacji niemieckiej, Lódź 1946, S. 11.

187 Vgl. Chronicle, S. 22.

188 Vgl. Danuta Dąbrowska, Wsiedleni Zydzi zachodnioeuropejscy w getcie lódzkim, in: BZIH 65/66 (1968), S. 105; Heltzin, Przyczynek, S. 58.

189 Dienstsitzung des Distrikts Lublin, 17.1.1941, Archiv der GKBZHwP, Akten des Bühler-Prozesses. Bd. 34, Bl. 125; nach Berenstein, Martyrologia, S. 29. 
Aufenthaltsbeschrānkungen im Generalgouvernement vom 15. Oktober $1941^{190}$ der unerlaubte Aufenthalt außerhalb des Ghettos ebenso wie das Verstecken von Juden mit der Todesstrafe bedroht wurde.

Dabei darf die Funktion des Úberfalls auf die Sowjetunion nicht unterschātzt werden. Die Einsatzgruppen, die mit den vorrückenden Truppen in das sowjetisch besetzte Gebiet eindrangen, begingen Massenmorde an der jüdischen Bevölkenung, die möglicherweise einige der moralischen oder pragmatischen Barrieren einrissen, die in den ersten Kriegsjahren noch bestanden haben mochten und wenigstens zeitweise den Juden eine Úberlebenshoffnung vorgegaukelt hatten. Auch die Einrichtung der die Massentötung erst ermöglichenden Vernichtungsstätten hängt partiell mit diesem Kriegsausbruch zusammen. Am 20. Juli 1941 wurde der Befehl erteilt, bei Lublin ein großes Kriegsgefangenenlager einzurichten ${ }^{191}$, dessen bloßer Name - Majdanek - später ein Synonym des Grauens werden sollte. Im Dezember 1941 trafen hier vor den Toren der Stadt die ersten Juden aus Lublin ein, die mit der Errichtung des Lagers begannen. ${ }^{192}$ Der Feldzug gegen die Sowjetunion veränderte die politischen Perspektiven der deutschen Führung recht deutlich. Nicht allein, daß in einer weiteren Richtung die Grenzen des deutschen Machtbereichs von einer Front gesāumt wurden, der Krieg brachte mit sich, daß größere materielle Anstrengungen zu leisten waren und

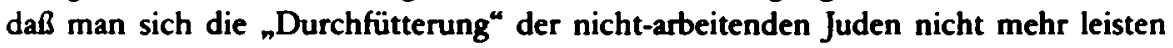
wollte. Die "Erfolge" der Einsatzgruppen, die im Osten hunderttausende von Juden erschossen, brachten Heinrich Himmler auf den Gedanken, am 2. Oktober 1941 Hitler vorzuschlagen, die deutschen und westeuropäischen Juden nach Riga, Reval und Minsk zu verlagern, wo der Massenmord bereits in vollem Gange war. ${ }^{193}$

Sehr schlüssig setzt Yehuda Bauer für den Sommer 1941 den Ubergang von selektiven Massenmorden zur immer umfassender praktizierten Totalvernichtung der europäischen Juden an. 194 Die entsprechenden Maßnahmen auf der Leitungsebene, das Vorgehen der Einsatzgruppen in der eroberten Sowjetunion, die Deportationen aus dem Westen und der Beginn der Einrichtung mechanisierter Vergasungsstātten markieren damit einen neuen Abschnitt einer teuflischen Eskalation - der „Endlösung“.

\section{Der Feldzug gegen die Sowjetunion}

Nach dem Uberfall auf die UdSSR am 22. Juni 1941 kamen mit den westlichen Teilen der Sowjetunion Gebiete unter deutsche Herrschaft, die vor dem Krieg zum polnischen Territorium gehört hatten und eine nicht unbeträchtliche jüdische Einwohnerzahl aufwiesen. Da wir uns für die Zwecke dieser Untersuchung an der deutschen Verwaltungsstruktur orientieren, beschränken wir uns im folgenden auf die bis 1941 sowjetischen Gebiete, die nicht zu den Reichskommissariaten Ostland und Ukraine

190 VOBIGG 99/25.10.1941, S. 595.

191 Vgl. Tatiana Berenstein/Adam Rutkowski, Zydzi w obozie koncentracyjnym Majdanek (1941-1944), in: BZIH 58 (1966), S. 4. - Ob die geplante Errichtung eines Kriegsgetangenenlagers ein Vorwand war (wie Alfred Streim meint) muß fraglich bleiben.

192 Vgl. ebenda, S. 7. - Zunächst waren es als Zivilgefangene gehaltene ehemalige jüdische Soldaten der polnischen Armee, bald bei Razzien festgenommene Lubliner.

193 Vgl. Hilberg, in: Jackel/Rohwer, Mord, S. 126

$194 \mathrm{Vgl}$. Bauer, in : Jackel/Rohwer, Mord, S. $169 \mathrm{ff}$. 
kamen, d.h. auf den dem Generalgouvernement angeschlossenen sog. Distrikt Galizien - (Früher Ost-Galizien oder West-Ukraine) - und den „Bezirk Bialystok“, der von Ostpreußen aus verwaltet wurde und eine $Z$ wischenstellung zwischen Reichs- und Okkupationsgebiet einnahm. ${ }^{195}$

Systematisch, also anders als dies im Polenfeldzug der Fall gewesen war, erfolgte während der Besetzung der westlichen Sowjetunion durch die Wehrmacht eine umfassende Ermordungsaktion von Juden durch die nEinsatzgruppen der Sicherheitspolizei und des $\mathrm{SD}^{\mu}{ }_{196}$ Diskrepanzen herrschen in bezug auf die Zahlen der seitens der „Einsatzgruppen ${ }^{\text {" durchgeführten Judenmorde dadurch, daß die „Ereignismeldungen }}$ der Einsatzgruppen nicht immer zuverlässig sind und daß in den Tötungszahlenangaben nicht zwischen Juden und anderen getöteten Menschen ausreichend differenziert wurde.

Im Rahmen unserer territorialen Abgrenzung sind für uns die Einsatzgruppe B, die sich Anfang Juli 1941 eine Zeitlang in Bialystok aufhielt ${ }^{197}$, und die Einsatzgruppe $C$ von Bedeutung, die den Einmarsch in die Westukraine mitmachte. Da nur die Tātigkeit der Einsatzgruppe $A$ von Wilhelm genauer quellenkritisch erforscht ist, konnten wir für diese Zusammenfassung keine nāheren Angaben aus den noch nicht ausgewerteten Einsatzgruppen-Berichten gewinnen. Die früheren Schātzungen beliefen sich für das gesamte sowjetische Staatsgebiet von 1941 auf eine Zahl von 1300000 getöteten Juden, davon 600000 auf dem früher polnischen Territorium. ${ }^{198} \mathrm{Krausnick} / W$ ilhelm kommen auf 2200000 , wobei sie dabei den Einsatzgruppen selber etwa ein Viertel der „Sonderbehandelten “ - so die Einsatzgruppen-Bezeichnung für die Ermordeten - anlasten. ${ }^{199} \mathrm{Da}$ aber auch diese Zahl nicht geographisch differenziert wird, lassen wir sie hier außer Betracht und überlassen ihre Diskussion dem UdSSR-Beitrag. Schwierigkeiten bereitet vor allem die Frage, wieviele der in den westlichen Gebieten der UdSSR lebenden Juden den Deutschen bei ihrem Vormarsch in die Hānde gefallen sind. Da es keine zuverlässigen Unterlagen dazu gibt und die Úberlegungen, in welchem Umfang Menschen die Rettung durch Evakuierung gelang, ebenfalls ohne ausreichende Quellenbasis angestellt werden, bewegen sich die diesbezüglichen Angaben im Bereich des Hypothetischen. ${ }^{200}$ Kaum ein Wert ist so unzuverlāssig wie die Schātzungen der in die Sowjetunion gelangten polnischen Juden. So wie die Gesamtzahlen für polnische Staatsangehörige insgesamt schwanken:

$\begin{array}{lr}\text { Związek Patriotów Polskich } & 500-700000 \\ \text { Krystyna Kersten (Repatriacja, S. 34) } & 1200000 \\ \text { Elżbieta Hornowa („Powrót “, S. 108) } & 1694000 \\ \text { Eugene Kulisher (Displacement) } & 2000000\end{array}$

195 Die übrigen Teile des besetzten Gebietes der Sowjetunion werden, auch wenn es sich um ehemals polnisches Territorium handelt, im Zusammenhang mit den Judenmorden in der Sowjetunion abgehandelt.

196 Die Truppe des Weltanschauungskrieges, Stuttgart 1981.

197 Vgl. Krausnick/Wilhelm, Truppe des Weltanschauungskrieges, S. 181.

198 Nach ebenda, S. 621.

199 Ebenda, S. 622.

200 Aus diesem Grund gehen wir hier nicht näher auf die Argumente der frühen Polemik zwischen Gerald Reitlinger (Die Endlösung. Berlin 1956) und Solomon S. Schwarz (The Jews in the Soviet Union, Syracuse 1951) ein, die sowohl bei Hilberg als auch bei Krausnick/Wilhelm wiedergegeben wird. 
so vage sind auch die Schātzungen für den Anteil der Juden:

Gerald Reitlinger (Die Endlösung, S. 569) 700000

Eugene Kulisher (Displacement) 600000

Malcolm Proudfoot (Refugees) $\quad 400000$

Registrierung der Botschaft der polnischen Exilregierung in

Moskau von 1941

106602

(Krystyna Kersten, Repatriacja, S. 36)

Die Schātzungen des American Joint Distribution Committee für die Jahre 1939 und 1940 nahmen für das sowjetisch besetzte polnische Gebiet eine jüdische Einwohnerzahl von 1350000 an.201 Krakowski202 geht von 1150000 aus, während die deutschen Angaben für die Gebiete Ostgalizien und Bialystok, also ohne Wolhynien, Polesien und Mittellitauen 813000 ergeben.203 Gilbert schreibt von 1309000 Juden, die 1939 in den sowjetisch besetzten Gebieten gelebt hätten, zu diesen seien weitere 250000 gekommen, die sich vor den Deutschen über die deutsch-sowjetische Demarkationslinie retten konnten. ${ }^{204}$ Diese Zahl von 1559000 reduziert sich um die Zahl derjenigen, die evakuiert werden konnten. Wenn Gilbert ${ }^{205}$ von 300000 evakuierten Juden schreibt, dann meint er damit ${ }^{206}$ alle Gebiete, die bis Stalingrad und zum Elbrus von den Deutschen besetzt wurden - in spāteren Phasen des Krieges konnte die Evakuierung aber wohl um vieles effizienter sein als im Augenblick des Uberfalls selber, als man in der Sowjetunion keinerlei Vorkehrungen für diesen Fall getroffen hatte. Setzen wir die Zahl der vor dem Einmarsch Geflohenen also mit etwa 150000 an 207 und berücksichtigen wir auch noch etwa 250000 polnische Juden, die ab 1940 von den sowjetischen Behörden, weil sie nicht die sowjetische Staatsbürgerschaft akzeptierten oder aus anderen Gründen, nach Sibirien deportiert wurden ${ }^{208}$, dann gelangen wir zu 900000 nach Gilbert ${ }^{209}$ oder zu den 1150000 , von denen bei Krakowski die Rede ist. 210

Addieren wir einen Mittelwert von 1000000 zu den oben angegebenen Werten für die bis 1941 deutsch besetzten Gebiete (um die 2000000), kommen wir auf ca. 3000000 Juden aus dem ehemaligen Polen, die insgesamt unter deutsche Herrschaft gerieten.

Wichtig ist zunāchst die Zahl der Juden, die zur Zeit der Invasion in den oben umrissenen Gebieten lebten. Von diesen kamen viele durch die Aktionen der Einsatzgruppen ums Leben, daneben kam es in den ersten Monaten der deutschen Besetzung

201 Vgl. Hilberg, Vernichtung, S. 209.

202 Vgl. Krakowski, Avedot, S. 232.

203 Vgl. Fridman, Umkum, S. 2; Datner, Eksterminacja, S. 7.

204 Vgl. Gilbert, Endlosung, S. 36.

205 Ebende, S. 65.

206 Ähnlich wie Krystyna Kersten, Repatriacja ludności polskiej po II wojnie światowej, Wroctaw 1974, S. 31.

207 Vgl. Levin, Holocaust, S. 270.

208 Vgl. ebenda. - Nora Levin nennt diese Zahl realistisch, andererseits schwanken die Schätzungen bezüglich der von den Sowjets Deportierten zwischen 50000 und 500000. 1939/40 erhielten auf freiwilliger Besis 50-80000 Arbeit im Inneren der Sowjetunion (Vgl. Homowa, Powrót, S. 107). Im Sommer 1940 sollen 240000 zwangsweise deportiert worden sein. General Anders nennt in seinen Memoiren aufgrund einer NKVD-Information 475000 Polen UND Juden, Ginesy allein 350000 Juden. Bis 1941 wurden darüber hinaus Juden und Polen in die Rote Armee und in „Baubrigaden" ( $d$ h. zur Zwangsabeit) eingezogen. Verläßliche Zahlen liegen nicht vor.

209 Vgl. Gilbert, Endlösung, S. 36.

$210 \mathrm{Vgl}$. Krakowski, Avedot, S. 232. 
auch seitens der einheimischen ukrainischen Bevölkerung der Westukraine zu Massakern an Juden, die man für die Leiden verantwortlich machte, denen die nichtkommunistischen Ukrainer in den Jahren der Sowjetherrschaft ausgesetzt gewesen waren. Da bei den mit der Sowjetisierung dieser neuen Gebiete befaßten Partei- und Sicherheitsbehörden zahlreiche sowjetische Juden aktiv gewesen sein sollen, identifizierte man in den antisemitisch eingestellten Kreisen die Juden mit den Kommunisten. Das basierte auf einem alten Topos und kam den ukrainischen Nationalisten nicht ganz ungelegen, die sich mit den deutschen Eroberem gut stellen wollten, um damit den Plan der Errichtung eines ukrainischen Nationalstaats unter deutschem Schutz zu fōrdern.

Diese Problematik kann hier nicht verfolgt werden; wir wollen nur feststellen, daß es in den ersten Wochen nach dem deutschen Einmarsch zu Ausschreitungen der Ukrainer ebenso kam wie zu einer offenen Zusammenarbeit zwischen den Einsatzgruppen und der einheimischen Bevōlkerung, die den SD-Leuten Verstecke von Juden zeigte und jüdische Mitbewohner als angebliche GPU-Kollaborateure denunzierte. Um den 30. Juni 1941 herum kamen in Lemberg etwa 1000 Juden durch die ukrainische Hilfspolizei ums Leben. ${ }^{211}$ Friedman berichtet von ukrainischen Judenrazzien in der Zeit vom 25.-27. Juni 1941, die als "Petljura-Aktion" bezeichnet wurden, weil das Gerücht kreiste, die Deutschen hātten den Ukrainern anläßlich des Jahrestages der Ermordung von Symon Petljura durch einen Juden in Paris (1926) für drei Tage die "Judenjagd" freigegeben.212 Dieser "Aktion" sollen wieder mehrere Tausend Juden zum Opfer gefallen sein. Während die Lemberger Ereignisse von Friedman recht gut dokumentiert wurden, ist für die übrigen, kleineren Orte der Westukraine das Material rar. Da anders als in Polen in diesem Gebiet nach 1945 - es wurde bekanntlich wieder der Ukrainischen SSR einverleibt - keine solide historische Forschung betrieben werden konnte, sind die Historiker auf verstreute Einzelangaben angewiesen, da sich die ukrainische Exilliteratur ebenfalls kaum mit dieser Problematik befaßt hat.

Nicht immer sind deutsche und ukrainische Aktionen klar voneinander zu trennen; manchmal wiesen Ukrainer die deutschen Kommandos auf „Sowjetfreunde ${ }^{*}$ hin; insbesondere in der "Interregnum"-Zeit zwischen dem Abzug der Sowjettruppen und dem Einmarsch der Achsen-Verbānde hat sich manch eine Mordtat in diesen Territorien abgespielt - belegt ist das für die Gegend um Kolomea. ${ }^{213}$ Aber man muß mit einer Generalisierung sehr vorsichtig sein. Aus Obertyń im Gebiet Kolomea wird auch berichtet, daß Ukrainer Juden vor ihren eigenen Landsleuten schützten, bis die Ungarn dieses Gebiet am 9. Juli 1941 besetzten. ${ }^{214}$ Quantitativ dürften die deutschen Taten die ukrainischen bei weitem übertroffen haben, Angaben aus Stanislau, wo am 3./4. August etwa 1000 Angehörige der städtischen Intelligenz ermordet und weitere 9-12000 Menschen am 12. Oktober 1941 auf dem Friedhof umgebracht wurden ${ }^{215}$,

211 Vgl. Filip Friedman, Zaglada Zyd6w Iwowskich w okresic okupacji niemieckiej, München 1947², S. 9.

212 Dieses Gerücht fügt sich ohne Schwierigkeiten in die Struktur osteuropäischer Judenpogrome früherer Jahre ein und gewinnt dadurch an Wahrscheinlichkeit.

213 Vgl. Markus Willbech, Skupisko zydowskie w Obertynie podczas II wojny światowej, in: BZIH 35 (1960), S. 110.

214 Vgl. ebenda

215 Vgl. Juliusz Feuerman, Pamiętnik ze Stanistawown (1941-1943), in: BZIH 59 (1966), S. 64-68; Elisabeth Freundlich, Die Ermordung einer Stadt namens Stanislau, Wien 1986, S. 154-164. 
belegen deutlich, daß sich das anti-jüdische Verhalten seit dem Polenfeldzug mit seinen eher vereinzelten Mordtaten deutlich verstärkt hatte und durch die gezielt vorgehenden Einsatzgruppen nun auch systematisiert wurde. „Aktionen“ wie in Tarnopol oder Zborów, wo jeweils etwa 600 Juden sofort ermordet wurden, sprechen eine deutliche Sprache. ${ }^{216}$

Dabei hörten die Morde nach dem Weiterwandem des Kriegsschauplatzes nicht auf. Im August 1941 wurden 900 jüdische Geiseln umgebracht, die eine Kontribution der Lemberger Juden sichem sollten.217 Bei der Einrichtung des Lemberger Ghettos fielen auf dem Zugangsweg einige Tausend Personen der Mordlust der deutschen und ukrainischen Posten zum Opfer, die insbesondere nicht arbeitsfähig Aussehende, vor allem Frauen und Kinder, gar nicht erst in die durch eine Bahnlinie abgetrennten Stadtteile hineinließen. ${ }^{218}$ Friedman schātzt, daß auch in den "ruhigen“ Zeiten ca. 50-100 Personen täglich durch Razzien und Einzeltaten sowie durch Deportationen zu kaum zu überlebenden Arbeitseinsātzen ums Leben kamen. Im Oktober 1941 waren nach Angaben des Lemberger Judenrates 119000 Juden in der Stadt, im Januar 1942 nur mehr 103 000. In Stanislau wurde im Dezember 1941 das Ghetto eingerichtet, in dem dann 18000 Juden lebten. 219

Man kann davon ausgehen, daß die einfallenden Truppen im spāteren Distrikt Galizien auf etwa 500000 Juden getroffen sind. Ebenso wie Ostgalizien war auch das Gebiet von Białystok ein Zentrum jüdischer Siedlung. Białystok hatte, was für eine gröBere Stadt ungewōhnlich war, vor der Eingemeindung von umliegenden Dörfern eine jüdische Bevölkerungsmehrheit gehabt. Am 27. Juni 1941 marschierten die Deutschen in Bialystok ein. Hatten sie im Süden ukrainische Helfer gehabt, so vollzogen sie hier die Mordtaten anfangs alle selber. Sofort beim Einmarsch wurden 700 Personen in einer Synagoge verbrannt.220 Der Augenzeuge Szymon Datner schreibt in einem kurz nach dem Krieg erschienenen Buch, aus den umliegenden Orten seien laufend Gerüchte über Morde eingetroffen, die niemand mehr zāhlen konnte. Noch im Herbst 1941 wurden 6000 Białystoker Juden nach Pruzana in Hāuser gebracht, die Weißrussen weggenommen worden waren, die man zur $Z$ wangsarbeit ins $R$ Reich verfrachtet hatte. Im November 1941 wurden in Slonim etwa 10000 Juden erschossen, darunter viele Flüchtlinge aus Białystok, denen es nicht gelungen war, weiter nach Osten auszuweichen.221 Bereits am 1. August 1941 war das Białystoker Ghetto geschlossen worden. Nach Mark lebten zu Beginn etwa 50000 registrierte Einwohner darin und weitere 5000 mit illegalem Status. ${ }^{222}$ Krakowski gibt die Zahl mit 46600

216 Vgl. Henri Monneray, La persécution des Juifs dans les pays de l’Est, présentée à Nuremberg, Paris 1949, S. 288.

217 Vgl. Friedman, Zagtada, S. 10.

218 Vgl. ebenda, S. $16 \mathrm{f}$.

219 Vgl. ebenda, S. 27; Feuerman, Pamiçtnil, S. 68.

220 Vgl. Kazimierz Leszczyński, Eksterminacja ludności na ziemiach polskich w latach 1939-1945 (woj. bialostockie, gdańskie i kieleckie), in: Biuletyn GKBZHwP 8 (1956), S. 124. - Andere Literaturpositionen nennen 800-1000 Opfer (Vgd. Kowalczyk, Zbrodnie, S. 101). Mit weiteren Exekutionen forderte allein der erste Tag der deutschen Herrschaft 2000 Tote. Am 3. Juli "verschwanden“ 300 Angehörige der jüdischen Intelligenz ohne Spur (Vgl. Szymon Datner, Walka i zagtada Bialostockiego ghetta, Lódź 1946, S. 14), am 11. Juli wurden in Pietrasze bei Biatystok gar $\mathbf{4 0 0 0}$ Juden erschossen (ebenda) - Datner berichtet aus Bialystok als Augenzeuge und als Historiker.

221 Vgl. Bernard Mark, Ruch oporu $\mathbf{w}$ getcie białostockim. Samoobrona - zagtada - powstanie, Warszewa 1952, S. 51.

222 Vgl. ebenda, S. 46. 
an.223 In der gesamten Wojewodschaft Białystok dürften im Juni und Juli 1941 von den insgesamt 13400 Todesopfern circa 11000 Juden gewesen sein ${ }^{224}$, davon etwa 6000 in der Stadt selber.225

Nach den ersten Tagen fanden die Deutschen auch hier Helfer: Aus Korycin wird über eine polnische Petition für einen Pogrom berichtet ${ }^{226}$, in Jedwabne tat sich die polnische „blaue Polizei“ (policja granatowa) hervor. 227 Die nach Tausenden zāhlenden Exekutionen setzten sich bis in den Herbst 1941 fort. Szymon Datner beziffert die Zahl der jüdischen Opfer im Bezirk Białystok in den ersten drei Monaten der deutschen Besetzung mit 40-50000.228

Anders als im Distrikt Galizien, wo erst Ende 1941 damit begonnen wurde, erfolgte die Ghettobildung im Bezirk Białystok überaus schnell, was Datner mit dem besonders ausgebildeten Judenhaß des auch hier herrschenden ostpreußischen Gauleiters Erich Koch begründet. Bereits am 21. Juli 1941 wurde das Ghetto in Szczuczyń errichtet. Im August folgen nach dem Hauptort Bialystok Augustów, Bielsk Podlaski, Czyżewo, Grajewo, Lomża, Wasilków, Wysokie Mazowieckie und Zambrów. Am 1. September entstand das Ghetto in Grodno, etwas spāter dasjenige von Prużana und weitere Wohnbezirke in einigen kleineren Orten. Dort, vor allem im Osten des Bezirkes, waren die Ghettos meist „offen ${ }^{4}$, d.h. die Juden besaßen im ganzen Ort Bewegungsfreiheit, aber in den mittleren Gemeinden wurden diese „offenen“ Ghettos bald geschlossen, in den Städten waren sie (mit Ausnahme von Bielsk) von Anfang an geschlossen.229 Das Vorgehen in den besetzten neu-sowjetischen Gebieten war überall āhnlich. Nach ersten Mordaktionen großen Umfangs wurden die Úberlebenden in Ghettos zusammengesperrt und damit dem Status angepaßt, der in den früher besetzten polnischen Gebieten bereits herrschte. Vom Herbst 1941 an ist $\mathrm{zwischen}$ den 1939 und 1941 okkupierten Gebieten, was die Behandlung der Juden betrifft, kaum mehr ein Unterschied festzustellen. Der Winter 1941/42 stellt, obwohl im Westen Polens die Massenvernichtung bereits einsetzte, eine Konsolidierungsphase dar, die es gestattet, anhand der in langen Jahren in Polen gesammelten und veröffentlichten Daten eine „Bestandsaufnahme“ der unter deutscher Herrschaft in Polen lebenden Juden zu machen.

\section{Die Situation im Januar 1942}

Zu einer der vorrangigen Aufgaben des Beitrags gehört die Diskussion der Zahl der in Polen ermordeten Juden. Der Weg von einer der größten jüdischen Bevölkerungsgruppen in der Welt zu einer jüdischen Minoritāt, die quantitativ kaum noch in Erscheinung trith, verlief in Etappen. Ende 1941 hatte der Prozeß der Umgestaltung,

223 Vgl. Krakowski, Avedot, S. 233.

224 Vgl. Kowalczyk, Zbrodnie, S. 102.

225 Vgl. Datner, Eksterminacja, S. 191

226 Vgl. ebenda, S. 20.

227 Vgl. ebenda, S. 22.

228 Vgl. ebenda, S. 23.

229 Vgl. ebenda, S. $13 f$. - Datners Aussagen zu den anderen Ghettos stützen sich auf Eriasse und Zeugenaussagen. 
dem die deutschen Eroberer Ostmitteleuropa unterzogen, eine erste Zwischenform erreicht: Bis zum neuerlichen Durchzug der Fronten im Zusammenhang mit der deutschen Niederlage blieben die Verwaltungsgrenzen in den ehemals polnischen Gebieten nun stabil, und in ihrem Rahmen vollzog sich die organisierte Massenvernichtung, die neben den Juden Europas auch Zigeuner, sowjetische Kriegsgefangene, politisch oder sozial Mißliebige erfaßte. Im Osten hatten die Einsatzgruppen das früher polnische Territorium inzwischen verlassen und trieben auf erobertem sowjetischem Gebiet ihr Unwesen, im bereits 1939 besetzten Gebiet war Ende 1941 die Zusammenfassung der Juden in Ghettos weitgehend beendet.

Der Eindruck einer Ruhepause vor dem „eigentlichen “ Beginn der Massenvernichtung trügt jedoch aus mehreren Gründen. Die Lage in den Ghettos war so grauenhaft, $\mathrm{da}$ die rapide anwachsenden Todesziffern - auch wenn die Krankheiten selber „na-

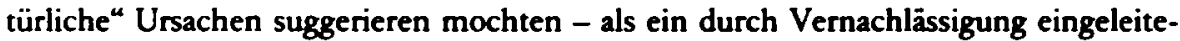
tes Morden gewertet werden müssen. Und auch die aktive Tötung hatte abgesehen von Exekutionen und willkürlichen Morden den Bereich der Zufälligkeit längst verlassen: Im Juli 1941 trug der SS-Hauptsturmführer Heinz Hōppner - auf die „Euthanasie -Erfahrung verweisend - dem Posener Gauleiter Greiser seinen Plan der Massentōtung von Juden durch Abgas-Lkws vor. Am 16. Juli 1941 wurde dieser Vorschlag Eichmann zugeschickt.230 Am 31. Juli 1941 betraute Hermann Göring als Beauftragter für die Regelung der Judenfrage Reinhard Heydrich mit den „organisationellen, sachlichen und materiellen Vorausmaßnahmen zur Durchführung der angestrebten Endlōsung der Judenfrage “.231 Damit hatte Heydrich freie Hand; die SS hatte den sie „absichernden “ Befehl. Im Oktober 1941 wurden in Kazimierz Biskupi, Kreis Konin noch etwa 3000 jüdische Bewohner diese Kreises erschossen. ${ }^{232}$ Im Oktober/ November 1941 entstand in Chelmno am Ner das erste mit Abgasen operierende Vernichtungslager Kulmhof.

Vom 8. Dezember 1941 an erfolgte hier die Massentōtung der Juden aus dem Umkreis dieses Ortes im Kreis Kolo; von Januar 1942 an wurde das Einzugsgebiet erweitert und umfaßte nun den ganzen Warthegau einschließlich der Großstadt Lódź/Litzmannstadt. Der qualitative Sprung von mobilen Mordkommandos, die mehr oder weniger unsystematische Mordtaten begangen, zum stationären, durchorganisierten Mordbetrieb mag sophistisch erscheinen, er ist jedoch deswegen so wesentlich, weil nunmehr jeder Zusammenhang mit aktuellen Kampfereignissen und sog. Kriegserfordernissen verlorenging und die einzige und vorrangige Absicht von Einrichtungen wie

230 Auf die Zusammenhānge zwischen "Euthanasie" und „Endlösung" stößt man wiederholt. Neben Hōppner ist auf Dieter Allers hinzuweisen, der zunächst "Geschäftsführer" der Euthanasie-Aktion "T $4^{\prime \prime}$ und dann „Geschäftsführer" der Aktion Reinhard" war (Vgl. Diskussionsbeitrige R. Hilberg, Hans Mommsen, G. Serenyi, in: Jāckel/Rohwer, Mord, S. 142 f.). Vgl. auch Eisenbach, Polityka, S.257.

231 Der Text des Schreibens lautet: „In Ergänzung der Ihnen bereits mit Erlaß vom 24.1.39 übertragenen Aufgabe, die Judentrage in Form der Auswanderung oder Evakuierung einer den Zeitverhälenissen entsprechend mōglichst günstigen lōsung zuzuführen, beauftrage ich Sie hiermit, alle erfordertichen Vorbereitungen in organisatorischer, sachlicher und materieller Hinsicht zu treffen für eine Gesamtlösung der Judenfrage im deutschen Einflußgebiet in Europa ... Ich beauftrage Sie weiter, mir in Bäde einen Gesamtentwurf über die organisatorischen, sachlichen und materiellen Vorausmaßnahmen zur Durchführung der angestrebten Endlösung der Judenfrage vorzulegen. Göring." Göring an Heydrich, (ohne Tagesangabe) 7.1941, Nümberger Dokument 710-PS; Jäckel (in: Jäckel/Rohwer, Mord, S. 15) vermerkt quellenkritisch, daß Heydrich sich offenbar Görings Unterschrift unter ein vorbereitetes Dokument ngeholt" hat.

232 Vgl. Dạbrowska, Zaglada, S. 135, 171; S. auch S. 431 zu den ersten Gas-Versuchen in Kalisz. 
Kulmhof und vielen anderen Mordanlagen, der systematisch durchgeführte und organisierte Mord an allen faßbaren Personen der jüdischen Bevölkerungsgruppe, in aller Schärfe und unwiderlegbar zutage tritt. Der manchmal mit den Judenmorden verglichene Völkermord der Osmanischen Regierung an den Ameniem basierte zumindest formal auf einer Befürchtung der Parteinahme dieses Volkes für das feindliche Rußland. Die Vernichtungspraxis der Deutschen war selbst von solchen Scheinrationalisierungen frei.

Obwohl der Vernichtungsapparat von Chelmno bereits lief und täglich viele Menschen an den Mißhhandlungen und der Unterversorgung der Ghettos starben, soll auf der Basis der zur Verfügung stehenden Daten zu ermitteln versucht werden, wieviele Juden sich in den polnischen Gebieten Anfang 1942 noch am Leben befunden haben. Zusammengestellt wurden die Daten nach Zeugenaussagen, amtlichen Dokumenten und anderen Quellen von Mitarbeitern des Jüdischen Historischen Instituts in $\mathbf{W}_{\text {ar- }}$ schau, die sie im Laufe der Jahre in ihrem Biuletyn veröffentlichten. Daß sich dabei sowohl in die Erinnerung der Befragten als auch in die amtlich festgestellten Größen Fehler eingeschlichen haben, dürte feststehen. Manche Zahlenangaben widersprechen einander, in anderen Fällen fehlen Daten zu größeren Territorien, die nur mühsam erschlossen werden kōnnen. Dennoch bieten die Ergebnisse einen Anhalt für die Ausgangslage in Polen vor dem Beginn der systematischen Judenvernichtung, die gemeinhin mit der Formalisierung des Mordbeschlusses auf der "Wannsee-Konferenz" vom 20. Januar 1942 markiert wird - auch wenn die eigentlichen Entschlüsse vorher gefallen waren und die Vernichtung längst angelaufen war.

Uber die Zahlen hinaus vermittelt diese Ubersicht auch einen gewissen Eindruck davon, wie verstreut die jüdische Bevölkerung Polens trotz den ersten Konzentrationsversuchen immer noch lebte - und damit auch einen Hinweis auf die Motive der Deutschen, den Vemichtungsprozeß, der die deutsche Beaufsichtigung und Verwaltung der zahllosen jüdisch bewohnten Orte erforderte, zum Zwecke der Reduzierung des eigenen Aufwandes zu beschleunigen. ${ }^{233}$

\section{a) Eingegliederte Gebiete}

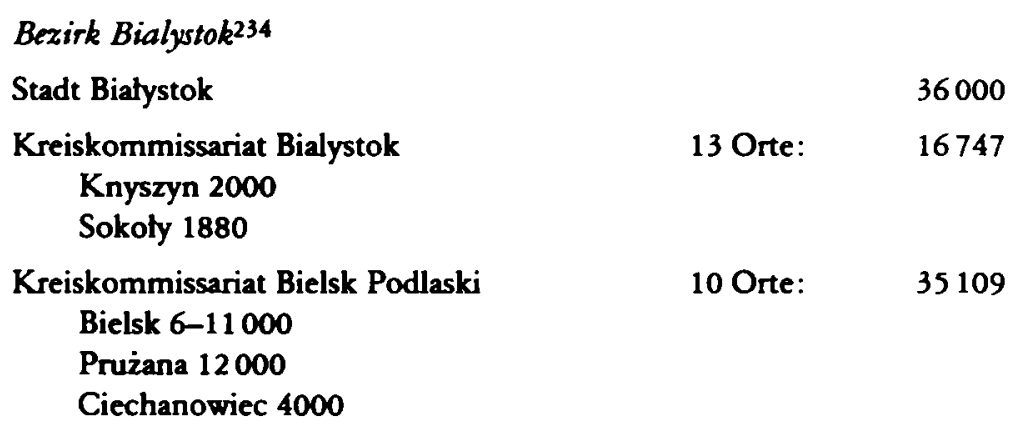

233 Wir verzichten hier auf den durchaus möglichen Nachweis der einzelnen Zahlen in den diversen Publikationen und beschränen uns auf den Hinweis auf die Sammelpublikationen, in denen großenteils die Angaben zurückverfolgt werden.

234 Nach Datner, Eksterminacja, passim. 
Kreiskommissariat Grajewo

5 Orte:

5615

Grajewo 2500

Augustów ca. 2500

Kreiskommissariat Grodno

9 Orte:

Grodno 24000

Skidel 3000

Kreiskommissariat Lomża

22 Orte:

17319

Lomża 4500-12500

Wysokie Maz. 3700

Zambrów 2330

Kreiskommissariat Sokólka

Sokótka ca. 9500

Krynki 5000

Suchowola 5100-7000

Kreiskommissariat Wolkowysk

Wolkowysk 7-10000

Swisłocz 3500

Różana 3000

10 Orte: $\quad 28000$

Zusammen im Bezirk Bialystok ca.

193460

in 80 Ortschaften

\section{Reichsgau Wartheland235}

Stadt Lódź (Litzmannstadt) 1.1.1942:

162681

Anm.: Diese Angabe findet sich in der Ghettochronik (L. Dobroszycki, The Chronicle of the Lódź Ghetto 1941-1944, New Haven 1984, S. 107 - im Chroniktext wird weiter nach Männern und Frauen aufgeschlüsselt, die hierfür angegebenen Zahlen ergeben jedoch nur 159681 - lt. Dobroszycki handelt es sich um einen Rechenfehler.)

Kreis Litzmannstadt

in 4 Orten: 9294

Brzeziny 6000

Zgierz ca. 2600

Kreis Kalisz

Kalisz ca. 150

Koźminek ca. 1400

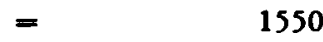

Kreis Lask

in 7 Orten: 25000

Lask 3700

Bełchatów 5300

Pabianice 9000

235 Nach Dạbrowske, Zaghada passim. 


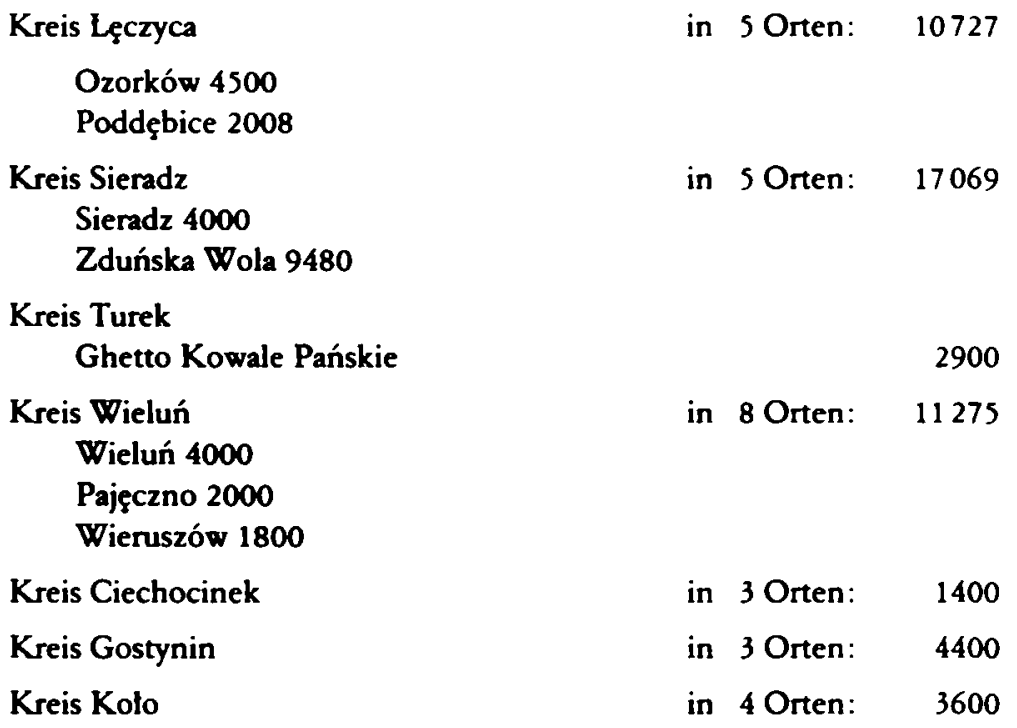

(Die Juden des Kreises Kolo wurden bis Januar/Februar 1942

in das Lager Chelmno transportiert und getōtet.)

Kreis Konin

keine Juden

Kreis Kutno

Kutno, Krośniewice,

Zychlin

in 3 Orten: 10000

(Die Juden des Kreises wurden im März/April 1942 in

Cheimno ermordet.)

Kreis Wloclawek

in 5 Orten: 4300

Zusammen im Gau Wartheland 264196 Juden in 501 Ortschaften

Mit Ausnahme der Bewohner des Ghettos Lódź wurden die Juden des Warthelandes 1941/42 als erste der Massenermordung in Chelmno ausgesetzt.

In Ostoberschlesien wurden die Juden aus den umliegenden Gebieten in mehreren großen und vielen kleineren Orten, die noch nicht als Ghettos registriert wurden, zusammengefaßt. Einige waren 1941 angelegt worden (die Zahlen dürften sich bis Januar 1942 nur geringfügig verāndert haben), andere entstanden als geschlossene Bezirke erst kurz vor der endgültigen Deportation 1943.

Eisenbach zāhlt für Ende 1942 folgende Ghettos in Ostoberschlesien auf:

Sosnowitz/Sosnowiec

Bendsburg/Będzin

Krenau/Chrzanów

Wadowitz/Wadowice

Dombrowa/Dạbrowa Górnicza

Warthenau/Zawiercie

Sucha 
Czeladź

Strzemieszyce

Modrzejów236

Auf der "Karinhall-Konferenz" vom 12. Februar 1940 hatte der oberschlesische Gauleiter Wagner die Zahl der Juden in Ostoberschlesien noch mit 100-120000 angegeben. 237

Martin Gilbert nennt als Gesamtzahl (mit kleineren Ghettos) für dieses Gebiet 93628 Juden. Der Korherr-Bericht und der Auschwitzer Lagerkommandant Rudolf Höß bestātigen Zahlen um 50000 (für Ende 1942). ${ }^{238}$ Angesichts dieser Diskrepanzen ist ein Ansatz von ca. 70000 Juden für Anfang 1942 zwar letztlich nicht ganz gesichert, aber im Rahmen der Wahrscheinlichkeit durchaus zu rechtfertigen. Wir operieren im folgenden mit dem bestātigten Minimalwert 50000 .

Regierungsbezirk Zicbenau 239

Ciechanów/Zichenau: 7000

Drobin:

etwa 650 wurden am 7.3.1941 in das Durchgangslager Soldau (Dzialdowo) deportiert; da es sich um Alte und Kranke handelte, dürtten sie alle umgekommen sein. (Liquidiert Februar 1942, umgesiedelt nach Strzegowo)

Maków Mazowiecki/Mackeim:

Mlawa/Mielau:

6000

Ein Teil der ca. 7000 jüdischen Bewohner der Vorkriegszeit wurde in das Generalgouvernement deportiert, andere aus der Umgebung nahmen ihre Stelle ein.

Nowy Dwór:

mit den Einsiedlungen aus Czerwińsk, Wyszogród und Zakroczym 1941; ein Teil der Juden aus Nowy Dwór war 1940 nach Warschau vertrieben worden.

Nowe Miasto:

Plońsk/Plöhnen :

Sierpc/Sichelberg:

im Januar 1942 nach Strzegowo umgesiedelt

Strzegowo:

ca. 500

Zusammen im Reg.Bez. Zichenau in 9 Ortschaften 


\section{b) Generalgouvernement}

Distrikt Warschau 240

Stadt Warschau 241 : 400000

Kreis Warschau in 14 Orten: 40744

Piaseczno 2500

Falenica 6500

Ludwisin 2800

Otwock 14000

Wolomin 2800

Kreis Garwolin

Zelechów 10000

in 6 Orten:

22583

Kreis Mińsk Mazowiecki

in 8 Orten: $\quad 13676$

Mińsk 5000

Kaluszyn $\mathbf{4 0 0 0}$

Kreis Siedlce

in 5 Orten:

21937

Losice 5000

Siedlce 11700

Kreis Sokolów-Węgrów

Kosów 3800

in 7 Orten: 21355

Sokotów Podl. 5400

Węgrów $\mathbf{8 0 0 0}$

Die Juden der Kreise Grójec, Lowicz, Skiemiewice und Sochaczew-Blonie waren vor 1942 in das Ghetto von $W$ arschau deportiert worden.

Damit ergeben sich für insgesamt 41 Orte

520295 Juden. 242

\section{Distrikt Lublin 243}

Stadt Lublin:

36000

Kreis Biala Podlaska

in 11 Orten: 17346

Biala 8200

Janów 1850

\section{Kreis Bilgoraj}

Szczebrzeszyn 2800

in 10 Orten: 13681

Tamogród 2700

240 Nach Brustin-Berenstein, Deportacje, passim.

241 Nach Berenstein/Rutkowski (Liczbe, S. 79) wurden durch die Einwohnerabteilung des Judenrates nach Meldekarten für den 31.1.1942 insgesamt 368902 Juden namentlich festgestellt. Die Verfasser kommen aufgrund von Fortschreibungen der Sterblichkeitsziffem und unter Berücksichtigung der Einsiedlungen aus dem Reg.Bez. Zichenau auf $\mathbf{4 1 0 0 0 0}$ jüdische Einwohner. Deutsche Schätzungen gehen bei den Zahlen für Warschau jeweils von etwas höheren Werten aus.

242 Vergleichsdaten: Mitte 1940: ca 600 000; Ende 1942: ca. 50000; nach Eisenbach, Polityka, S. 429.

243 Nach Berenstein, Martyrologia, passim. 
Kreis Chelm

in 19 Orten: 28000

Cheim 11000

Wlodawa 5590

Kreis Hrubieszów

in 12 Orten: 12913

Dubieńka 2100

Hrubieszów 5816

Kreis Janów Lubelski

in 16 Orten: 19208

Kraśnik 6000

Modliborzyce 2300

Zaklików 2500

Kreis Krasnystaw

Izbica 6500

Turobin 3300

Zólkiewka 2200

Kreis Lublin

in 14 Orten: 24543

Bełżyce $\mathbf{4 4 0 0}$

Lubartów 2393

Ostrów 3000

Piaski 4919

Kreis Pulawy

in 12 Orten: 17165

Dęblin-Irena 3943

in 13 Orten: 26561

Opole 6000

Ryki 2935

Kreis Radzyń

in 13 Orten: 40434

Kock 3180

Luków 7800

Międzyrzec Podlaski 15300

Parczew 6359

Kreis Zamość

in 11 Orten: 15718

Komarów 2700

Tyszowce 2000

Zamość 7500

Somit ergeben sich für den Distrikt Lublin, der am Beginn des Krieges als Judenreservat" vorgesehen war und in den eine Zeitlang Juden aus den „eingegliederten Gebieten“ eingesiedelt wurden, für 132 Orte 251569 Juden. 244

244 Vergleichsdaten: April 1941: 250000; Mitte 1942: 190000; Ende 1942: 20000; nach Eisenbech, Polityke, S. 426. 
Distrikt Krakau245

Stadt Krakau 246

17000

Kreis Dębica247

in 7 Orten:

15000

Kreis Jaroslaw 248

Zahl der Orte unbekannt:

6000

Kreis Jasto 249

in mehr als 7 Orten:

20000

Kreis Krakau 250

in 17 Orten:

10500

Kreis Krosno

in 4 Orten:

Krosno 600

Korczyna 2000

Kreis Miechów

in 5 Orten:

14000

(nach Obozy 1979)

Kreis Nowy Sạcz

in 6 Orten: ca. 21500

Kreis Nowy Targ in Nowy Targ und Rabka

Kreis Przemyśl in Przemyśl und Dubienka

Kreis Rzeszów

in 11 Orten:

25000

Rzeszów 12200

Kolbuszowa 2500

Sokolów Malopolski 3000

Kreis Sanok

in 5-7 Orten:

Kreis Tarnów

in 8 Orten:

48000

Damit lebten Anfang 1942 im Distrikt Krakau in etwa 81 Orten ca. 218800 Juden. Diese Zahl liegt etwas höher als die von der Jüdischen Unterstützungsstelle für den Mai 1941 angegebene Gesamtzahl von 200000 Juden, was unter anderem daran liegen mag, daß nach dem Angriff auf die Sowjetunion eine nicht genauer zu ermittelnde Zahl aus dem neu dem Generalgouvernement angeschlossenen Distrikt Galizien in

245 Nach Podhorizer-Sandel, O zagładzie, passim.

246 Zugrundegelegt wird hier die Angabe bei Podhorizer-Sandel (ebenda, S. 109) nach dem Bulletin des Krakauer Stadthauptmanns vom 13.10.1941 unter Abzug der Mitte November 1941 in Orte des Kreises Hrubieszów, Distrikt Lublin, deportierten 2000 Personen (ebenda, S. 92). Bieberstein (Zaglada, S. 53) nennt für den Oktober 1941 ca. 2200 Deportierte. Ein Verzeichnis der Jüdischen Gemeinde nennt für den 1. April 194217163 Ghetto-Bewohner; Bieberstein setzt für diesen Zeitpunkt die Zahl der Juden ohne Kennkarte mit etwa 2000 an (Zaglada, S. 57).

247 Diese Zahl erscheint bei du Prel, Generalgouvernement, S. 257. - Es ist nur ungenau zu ermitteln, auf welche Zeit sich du Prel bezieht, es kann sich jedoch nicht um die bei Podhorizer-Sandel gleichen Zahlen für 1939 handeln, da bei den anderen Positionen eine Anpassung an die spätere Kriegslage erkennbar ist. Aus Rozwadów und Tamobrzeg wurden die Juden bereits 1939 vertrieben (Vgl. Podhorizer-Sandel, O zagladzie, S. 89); 1940 gestattete jedoch der zuständige Kreishauptmann die Ansiedlung von Krakauer Juden.

248 Laut Podhorizer-Sandel (O zagladzie, S. 89) wurden die vor dem Krieg 20000 Juden des Kreises 1939 vertrieben. Du Prel (Generalgouvemement, S. 255) gibt 19426000 an, wobei es sich um bei den Umsiedlungen und den Vertreibungen "Ubersehene“ handeln kann.

249 In den Kreis wurden $1939 / 40 \mathrm{ca} 3000$ Juden aus dem Wartheland eingesiedelt. Die für die Vorkriegszeit angegebene Zahl von 10480 erhōhte sich laut du Prel (Generalgouvernement, S. 251) aul das Doppelte.

250 Nach der Eingemeindung umliegender Orte wurden deren jüdische Bewohner zum Umzug in das Krakauer Ghetto gezwungen. Im Restkreis erhöhte sich die Zahl dann wieder durch Umsiedlungen aus den „eingegliederten Gebieten“ und emeute Vertreibungen aus der Hauptstadt Krakau. 
den Distrikt Krakau gekommen ist und daß infolge einer Verschiebung der Distriktsgrenzen (etwa bei Przemyśl) gegenüber Mai 1941 weitere Territorien dem Distrikt einverleibt wurden. ${ }^{251}$

\begin{tabular}{|c|c|c|}
\hline Stadt Lemberg: & & 103000 \\
\hline $\begin{array}{l}\text { Kreis Brzeziany } \\
\text { Podhajce } 3500 \\
\text { Rohatyń } 2600\end{array}$ & in 8 Orten: & 16000 \\
\hline $\begin{array}{l}\text { Kreis Czortków } \\
\text { Czortków } 7000 \\
\text { Buczacz } 4000\end{array}$ & in 14 Orten: & 30200 \\
\hline $\begin{array}{l}\text { Kreis Drohobycz } \\
\text { Drohobycz } 12781 \\
\text { Borysław } 10734 \\
\text { Sambor } 6686\end{array}$ & in 11 Orten: & 37000 \\
\hline $\begin{array}{l}\text { Kreis Kamionka Strumitowa } \\
\text { Kamionka } 2800 \\
\text { Sokal } 6000\end{array}$ & in 8 Orten: & 16100 \\
\hline $\begin{array}{l}\text { Kreis Kolomea } \\
\text { Kolomea } 11000 \\
\text { Sniatyń } 3400 \\
\text { Horodeńka } 2500\end{array}$ & in 12 Orten: & 29325 \\
\hline $\begin{array}{c}\text { Kreis Lemberg } \\
\text { Bóbrka } 3200 \\
\text { Gródek } 4500 \\
\text { Źólkiew } 6000\end{array}$ & in 18 Orten: & 32100 \\
\hline $\begin{array}{l}\text { Kreis Rawa Ruska } \\
\text { Rawa Ruska } 7400 \\
\text { Lubaczów } 2250\end{array}$ & in 9 Orten: & 16630 \\
\hline $\begin{array}{l}\text { Kreis Stanislau } \\
\text { Stanislau } 20000 \\
\text { Kalusz } 6000 \\
\text { Nadworna ca. } 3600\end{array}$ & in 11 Orten: & 39450 \\
\hline $\begin{array}{l}\text { Kreis Stryi } \\
\text { Stryj } 10000 \\
\text { Bolechów } 4000\end{array}$ & in 16 Orten: & 28050 \\
\hline
\end{tabular}

251 Im Korherr-Bericht werden für Ende 1942 etwa 37000 Juden für den Distrikt genannt.

252 Nach Tatiana Berenstein, Eksterminacja ludności żydowskiej w dystrykcie Galicja (1941-1943), in: BZIH $61(1967)$ S. 3-58. 
Kreis Tarnopol

in 16 Orten: $\quad 33200$

Tamopol 13000

Skalat $\mathbf{4 0 0 0}$

Kreis Zloczów

in 15 Orten:

23107

(Angaben der Jüdischen Unterstützungsstelle für Januar 1942)

Zloczów $\mathbf{5 8 0 0}$

Brody 7500

Przemyślany 3000

Im Distrikt Galizien lebten

in 139 Orten: 404162

demnach im Januar 1942

Juden.253

Distrikt Radom 254

Stadt Radom:

32000

Stadt Kielce:

27000

Stadt Częstochowa/Tschenstochau: $\quad \mathbf{4 8 0 0 0}$

Kreis Piotrków/Petrikau

in 10 Orten: 22900

Piotrków 15000

Kreis Radomsko

in 11 Orten: 16000

Radomsko 7100

Zarki 3200

Kreis Jẹdrzejów

in 14 Orten: 17000

Kreis Busko

in 10 Orten: 21667

Chmielnik 8300

Nowy Korczyn 3700

Stopnica 4700

Kreis Kielce

in 10 Orten: $\quad 15800$

Bodzentyn 3625

Chęciny 3600

Skarżysko-Kamienna 2600

Kreis Końskie

in 10 Orten: $\quad 15756$

Końskie 7400

Przedbórz 3300

Radoszyce 3000

Kreis Tomaszów Maz.

in 18 Orten: 44683

Tomaszów 14000

Biala Rawska 4500

Opoczno 4000

Przysucha 4000 (Anfang 1941 : 3000)

253 Vergleichsdaten November 1942: 200000 (Katzmann-Bericht); Ende Dezember 1942: 161514 (Korherr-

Bericht).

254 Nach Rutkowski, Martyrologia, passim. 
Kreis Radom

in 28 Orten:

39646

Kozienice $\mathbf{4 5 0 0}$

Szydlowiec 11500

Zwoleń $\mathbf{4 0 7 0}$

Kreis Starachowice

in 13 Orten:

20732

Kreis Opatów

in 21 Orten:

54625

Opatów 7000

Ostrowiec 15000

Staszów 5550

In 148 Orten lebten demnach

375809

Juden. 255

Anhand der hier gesammelten Angaben ergibt sich die folgende Richtzahl für die in diesem Beitrag betrachteten Gebiete für den Januar 1942:

a) eingegliederte Gebiete

Bezirk Bialystok

193460

Wartheland

264196

Ostoberschlesien 50000

Südostpreußen (Reg.-Bez. Zichenau)

\section{b) Generalgouvernement}

Distrikt Warschau

Distrikt Lublin

251569

Distrikt Krakau

Distrikt Galizien

Distrikt Radom

375809

2316541 Juden. 256

Es erscheint aufgrund der lokalen Ermittlung und der bei der Auswertung allgemein beachteten Vorsicht, überhöht erscheinende Angaben zu vermeiden, vertretbar, in dieser Zahl (unter Beachtung der in diesem Artikel nicht behandelten Einwohner Wolhyniens, der zum Ostland geschlagenen Gebiete und unter Abzug der Uberlebenden - ohne die hier nicht figurierenden Juden, die bereits Anfang 1942 versteckt waren oder auf ,arische Papiere“ lebten) eine Ausgangsgröße für die durch die Massenvernichtung (im Unterschied zu den bei Kriegsereignissen und den Tötungen der „Einsatzgruppen ()) umgekommenen polnischen Juden zu sehen.

255 Vergleichsdaten: März 1940 nach deutschen Quellen: 282380 Juden; 1941 (nach Rutkowski, Martyrologia) 327 583. - Mitte 1942: 300000; Ende 1942: 30000 (Korherr-Bericht).

256 Vergleichsdaten: Generalgouvernement ohne Galizien - Zweite Hālfte 1940, nach Angaben der Jüdischen Selbsthilfe: 1945000 . - Amtliche Angaben Generalgouvernement, Sommer 1941 : 2000000 Juden; Korhert-Bericht (31.12.1942): 297914 (nach Eisenbach, Polityka, S. 442 f.). 


\section{Die erste Vernichtungswelle (1942)}

Nach dem Einsetzen der gezielten Mordmaßnahmen in Chelmno/Kulmhof seit Dezember 1941 wurde, von der "Wannsee-Konferenz ${ }^{\mu}$ weitergehend abgesichert und von "höchster Stelle" gestützt und angeordnet, der Judenmord perfektioniert. Hatte es sich bis dahin um Provisorien gehandelt, wurde nun das angegangen, was nur noch schwach verschleiemd mit "Endlösung" umschrieben wurde. Die Ansiedlungsplāne der frühen Kriegszeit hatten sich alle als kurzfristige Projekte erwiesen, die nur vorübergehend politische oder gar praktische Bedeutung hatten. Nach den Exzessen des Krieges und den Massenmorden der Einsatzgruppen war eine Ghettowelt entstanden. Inzwischen sind viele Berichte zumindest über die größeren Ghettos erschienen. Immerhin lebten in fast 700 Orten in Polen Anfang 1942 Juden noch unter einer von den deutschen organisierten Selbstverwaltung und bewacht von SS, Polen und einer fragwürdigen Jüdischen Polizei - gehetzt von als "Aktionen“ bezeichneten Razzien, unter schrecklichen hygienischen Verhältnissen, unterversorgt und zum Teil als Sklaven ausgebeutet. Für die deutsche Verwaltung war das Typhus-Problem und die Angst vor anderen Seuchen offenbar nicht nur ein Vorwand: Bei den zumeist aus spießigem Milieu stammenden NS-Machthabern waren propagandistische Diffamienungen der Juden Osteuropas auf fruchtbaren Boden gefallen - unbeschadet der Tatsache, daß die Zusammenschließung unter fatalen Bedingungen und die Verhinderung einer ausreichenden Lebensmittel- und medikamentösen Versorgung erst unhaltbare Zustānde heraufbeschworen hatten. ${ }^{257}$

Zu dauernden Beschwerden über die sanitären Verhältnisse, deren Gefahr für das Umland man nicht zu unterstreichen müde wurde, traten Versorgungsüberlegungen, die sicherlich nicht ohne Zusammenhang mit der sich im Winter 1941/1942 als immer prekärer erweisenden Lage der deutschen Truppen waren. Beim Versuch, alle Wirtschaftskräfte in den Dienst der Front zu stellen, mag der Entschluß gereift sein, sich derjenigen Juden zu entledigen, die für diesen Produktionsprozeß unbrauchbar waren. Daß man dieses Vorhaben mit der "Vernichtung durch Arbeit" kombinierte, entsprach nur der grausamen, immanenten Logik der Uberlegung, daß letztlich diese Anstrengung doch nur von kurzfristiger Dauer sein würde. Noch am 16. Juli 1941 trat der Posener SS-Offizier Höppner mit dem Plan auf, alle Jüdinnen zu sterilisieren, um so die Judenfrage „noch in dieser Generation endgültig zu lösen“.258 Etwas spāter muß die Entscheidung über die Beschleunigung des Prozesses gefallen sein. Höppner meinte nun, es sei ${ }_{n}$ die menschlichste ${ }^{\text {}}$ Lōsung, die Juden mit einem schnell wirkenden Mittel zu „erledigen“.259

Die Frage der Entscheidung über den Vernichtungsprozeß ist nicht Gegenstand dieses Beitrags - hierzu sei auf die Arbeit von Christopher Browning und die den Diskussionsstand widerspiegelnde Publikation von Eberhard Jäckel und Jürgen Rohwer und die Auseinandersetzung um den Hitler-Befehl verwiesen. ${ }^{260}$ Eine kurze Anmer-

257 Interessanterweise hat Joseph Marcus (Social and Political history of the Jews in Poland 1919-1939, Berlin 1983, S. 183-193) für die Zwischenkriegszeit herausgefunden, daß die Wohnverhältnisse der polnischen Juden eher besser als die ihrer christlichen Mitbürger waren. Vgl. Diensttagebuch, S. 379, 389, 433.

258 S. Anm. 230.

239 Nach Eisenbach, Polityka, S. 285.

260 Christopher R. Browning, Fateful Months, New York 1986; Jäckel/Rohwer, Mord. - Hingewiesen sei auch auf die polnische Diskussion, ob es für Kulmhof/Cheimno Vorbilder gebe. Im Ergebnis läßt sich festhal- 
kung muß aber zu diesem Komplex erfolgen, soweit er sich im geographischen Rahmen dieses Beitrags abgespielt hat. Der Krakauer Generalgouverneur Frank sprach im Dezember 1941 von „Eingriffen ..., die irgendwie zu einem Vernichtungserfolg führen" 261 , schloß hierbei einen Abtransport in den Osten aus („Glauben Sie, man wird sie im Ostland in Siedlungsdörfern unterbringen?') und verwies gleichzeitig auf eine eindeutige Mordanweisung ("Man hat uns in Berlin gesagt, ... liquidiert sie selber!) . Wer konnte Frank, der stets auf seinen Rang pochte, nin Berlin “ dies gesagt haben, wenn nicht Hitler oder jemand aus seiner nāchsten Umgebung?

Der Beginn der Vernichtung, deren Tarnname „Aktion Reinhard“ (nach dem nach einem Attentat vom 27. Mai 1942 am 6. Juni 1942 verstorbenen Beauftragten für die Endlōsung und Reichsprotektor in Bōhmen und Māhren Reinhard Heydrich) war und die der Lubliner SS-Chef Odilo Globocnik leitete, überschnitt sich manchmal mit anderen, aus früheren Jahren stammenden Vorhaben. So berichtete der stellvertretende Amtschef des Distrikts Radom Alfons Oswald auf der "Polizeisitzung“ in Krakau am 18. Juni 1942: „In der Judenumsiedlung sei der Distrikt Radom etwas ins Hintertreffen geraten. Im Distrikt habe man im Laufe des letzten Jahres jüdische Wohnbezirke gebildet, in die man um die 15000 Juden aus Radom umsiedeln wollte. Der Verteilungsplan sei bereits aufgestellt gewesen, als die Umsiedlung nach dem Distrikt Lublin [dort lagen Bełżec und Sobibór] akut geworden sei. Diese Aussiedlung der Juden hānge jetzt nur noch von dem Transportproblem ab, und hier sei erklārt worden, daß der Distrikt noch sechs bis acht Wochen warten müsse. $" 262$

Der endgültige Vernichtungsprozeß war eine Kombination von auf Tötung hinauslaufender arbeitsmäßiger Ausbeutung einerseits und einer vorangestellten und begleitenden Beseitigung aller derjenigen Personen, die für diesen Ausbeutungsproze $\beta$ nicht benōtigt wurden, ihn nicht mitmachen konnten oder ihm sonstwie hinderlich waren. ${ }^{263}$ Diese Kombination sollte sich bald zu einer Aktion ausweiten, in der alle jüdischen Aussiedlungen liquidiert wurden. ${ }^{264}$ Hierbei wurden vor den Deportationen

ten, daß „Emähnungsprobleme“ die Vemichtungsentscheidung gefōrdert haben und daß Bezüge zum deutschen Euthanasie-Programm in der Verwendung von „Spezialisten“ bei der Durchführung erkennbar sind. Vgl. Artur Eisenbach, O należyte zrozumienie genezy zaglady Zydów, in: BZIH 4/104 (1977), S 55-69; J. Leszczyński, Jeszcze w sprawie genezy zaglady Zydów, in: BZIH 1/109 (1979), S. 99-102. Eine Zusammenfassung des neuesten Diskussionsstandes bietet Wolfgang Scheffler, Probleme der Holocaustforschung, in: Deutsche - Polen - Juden, S. 259-281.

261 Diensttagebuch, S. 457. - Diese Passage ist auch abgedruckt in Yitzhak Arad/Yisracl Gutman/Abraham Margaliot (Hrsg.) Documents on the Holocaust, Jerusalem 1981, S. 248, Dok. 116; vgl. Browning, Fateful Months, S. 33.

262 Diensttagebuch, S. 511.

263 Einem Befehl Himmlers an den Polizeichef Krüger (Nbg. Dok. NO-5574; abgedruckt in: Arad/Gutman/ Margaliot, Documents, S. 275f, Dok. 124) vom 19.7.1942 zufolge sollte die gesamte Aktion“ bis zum 31. Dezember 1942 abgeschlossen sein, Juden sollte es dann nur in Arbeits-_Sammellagem“ in Warschau, Krakau, Tschenstochau, Radom und Lublin geben. Aus „technischen Gründen“ konnte die SS den Befehl nicht ausführen; hinzu traten im September 1942 Uberlegungen, die Arbeitskraft qualifizierter Juden länger auszubeuten.

264 Gutman vermerkt zum $W_{\text {arschauer Ghetto, }{ }_{n} \text { daß }}$ gerade in den letzten Monaten des Gettos im Jahre 1942 eine gewisse Beruhigung eintrat. Das Leben verlief in einigermaßen geregelten Bahnen, die Sterblichkeit nahm ab, immer mehr Leute fanden Atbeit. Eine gewisse Stabilisierung war zu spüren, die Hoffnung keimte auf, daß ein Uberleben vielleicht doch noch möglich war. Der Beschluß über die Aussiedlung und Liquidierung der Juden im Warschauer Getto wurde also nicht zum Zeitpunkt der schlimmsten Notlage bekannt. Der Befehl zur physischen Vernichtung der Gettobevölkenung kam ausgerechnet zu einer Zeit, da man schon hoffte, das Schlimmste überwunden zu haben und vielleicht doch noch überieben zu können "(I. Gutman, Vorwort, in: Czerniaków, Im Warschauer Getto, S. XXIII). 
alle direkt getötet, die für einen Arbeitseinsatz ungeeignet schienen. Dort, wo nach den Kalkulationen der Deutschen das Vorhandensein von Juden die Nachfrage nach ihrer Arbeit weit überstieg, wurden die notorischen Vernichtungslager (Chetmno, Sobibór, Bełzec, Treblinka) eingerichtet, in denen ohne Unterschied fast alle ermordet wurden, die mit den Transporten anlangten. An anderen Orten wurde ein System von Arbeitslagern aufgebaut, das aber keineswegs eine Úberlebensgarantie für die Eingelieferten bot. So wie in Auschwitz, dem bekanntesten der kombinierten Arbeits- und Vernichtungslager, bei der Einlieferung der "Zugänge ${ }^{*}$ in einer ${ }_{n}$ Selektion ${ }^{*}$ die Trennung der āußerlich Arbeitsfähigen von denjenigen erfolgte, die sofort in die Gaskammem geschickt wurden, so waren auch in den Arbeitslagern die Insassen periodisch ähnlichen Augenscheinuntersuchungen ausgesetzt, deren negatives Ergebnis die Deportation zu einer der industriell betriebenen Vernichtungsstātten bedeutete.

Gleichzeitig perfektionierte die SS das Arbeitsausbeutungssystem. Arbeitslager hatte es davor auch schon gegeben: Immer wieder hatten die Ghettos Arbeitskräfte für Rüstungs-, Militär- und Privatvorhaben bereitstellen müssen, in den Ghettos selber siedelten sich Firmen an (shops), bei denen eine Stelle zu haben zu Arbeitsbescheinigungen berechtigte, die manchmal vorübergehend vor den Deportationen in die Vernichtungslager schützten. Nun vermehrten sich bis 1942 diese Lager - sie boten den überlebenden Juden perfiderweise nur dann eine geringe Uberlebenshoffnung, wenn sie sich an den auch gegen sie gerichteten wirtschaftlichen und militärischen Aktivitāten der Deutschen beteiligten.

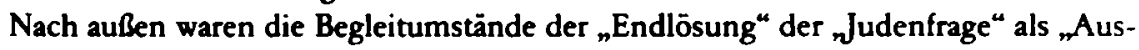
siedlung" oder „Evakuierung" getarnt. Bis zuletzt wurde der Schein aufrechterhalten, der nach Aussagen von Uberlebenden jedoch nach den ersten Monaten nur mehr wenige über das im Unklaren ließ, was ihnen wirklich blühte. Manche klammerten sich noch an das Wort, das die letzte verbliebene Möglichkeit des Hoffens begründete und grausam enttāuschte. Die Hoffnung auf eine Ansiedlung irgendwo im Osten mußte angesichts der Kriegslage bald utopisch erscheinen. Noch weniger glaubhaft dürten diese Behauptungen für die Bewohner derjenigen Orte gewesen sein, die nicht allzu weit von den jeweiligen Vernichtungsstātten entfernt lagen. Wenn Züge mit „Ausgesiedelten" am nāchsten Tag leer zurückkamen, was man z.B. in Warschau wußte, da durfte kaum noch jemand glauben, die "Passagiere" seien in der kurzen Zeit bis in unbewohnte Landstriche Osteuropas gebracht worden. In den Ghettos halfen Postsperren, das Wissen um die Ermordung zu unterdrücken. Vom 1. Dezember 1941 an nahm die Post keine Paketsendungen von Juden mehr an, was die Versorgungslage weiter verschlimmerte. ${ }^{265} \mathrm{Nach}$ dem 24 . November 1941 erfolgte die Postzustellung an Juden nur noch über die Judenräte. Immer häufiger wurden Rücksendungen mit dem Vermerk „Empfänger unbekannt verzogen“.

Den "Aussiedlungen" ging die ErschieBung derjenigen voraus, die für etwaige Arbeitsvorhaben nicht in Frage kamen oder die man auch für mehr oder weniger lange Vernichtungstransporte an die Vernichtungsorte für ungeeignet hielt, sei es, daß sie zu alt und krank gewesen wären, sei es, daß man Aufsässigkeit vermutete. Die ErschieBungen vor den Deportationen trugen - so unglaublich dies klingen mag - dazu bei, die Chimāre einer Ansiedlung unter harten, aber letztlich Úberleben ermöglichenden 
Umstānden aufrechtzuerhalten. Dabei handelte es sich bei der Zahl der so Umgekommenen um eine weitgehend unbekannte Größe, da (anders als in der Zeit der „Einsatzgruppen ) keine Unterlagen geführt wurden, die Zeugenaussagen rudimentär sind und die geographische Erfassung schwierig ist. Alle bekannten Zahlen kōnnen nur Annāherungswerte sein, sie dienen allgemein dem Hinweis auf die Vorgehensweise. Meistens wurden Alte und Kranke sofort erschossen: so im Kreis Miechów im August/September 1942; der Rest der lokalen Bevölkerung wurde nach Belzec zur Tötung deportiert. 266 In Czesstochowa/Tschenstochau wurden mit den 2000 Juden, die am Beginn der Ghetto-Evakuierung unmittelbar ermordet wurden ${ }^{267}$, auch 188 Insassen eines Altersheims umgebracht. ${ }^{268}$ Im Warschauer Ghetto traf es im Juni 1942110 Häftlinge ${ }^{269}$, in Wolkowysk im August 1942 zehn Ärte und Apotheker ${ }^{270}$ und in Grybów und Bilgoraj die Mitglieder des örtlichen Judenrates. 271 Am 12 . Mai 1942 wurden 250 Insassen des Rzeszówer Gefāngnisses in einem Waldstūck bei Nowa Wieś erschossen. ${ }^{272}$

Um einen Hinweis auf die Ungenauigkeit von Zahlenangaben zu erhalten - wenn nicht, wie etwa bei einem Lubliner Waisenhaus, dessen 320 Zöglinge im März 1942 erschossen wurden ${ }^{273}$, die genauen Zahlen rekonstruierbar sind - reicht es hin, auf den Kreis Nowy Sacz hinzuweisen, wo mindestens 1150 Personen erschossen wurden - die Addition von Größen aus Zeugenaussagen ergibt allerdings auch Werte zwischen 8000 und 13000, und ein Verfasser ist sogar unter Vorbehalt bereit, eine Endzahl um 16000 zu akzeptieren. ${ }^{274}$ Besonders zahlreich waren die erfaßbaren ErschieBungen vor dem Beginn der Deportation im Distrikt Lublin, wohin zahlreiche Juden aus den anderen Gegenden des Generalgouvernements geflohen und aus den eingegliederten Gebieten deportiert worden waren. Im Gebiet von Szczebrzeszyn sollen allein "mindestens $5000^{4}$ Juden erschossen worden sein ${ }^{275}$, in Majdanek bei Lublin wurden im April 19423800 polnische Juden aus dem Ghetto Majdan Tatarski erschossen. 276 Angesichts der erwähnten Ungenauigkeiten soll hier keine Quantifizierung versucht werden. Die Zahl der im Zusammenhang mit der Deportation in die Vernichtungslager und der Liquidierung der Ghettos Erschossenen wird eine der unsichersten Größen der Mordbilanz bleiben - sicher ist nur, daß sie sehr hoch ist.

Die Erschießungen vor den Deportationen waren jedoch nur der Anfang. Was die nationalsozialistische Judenverfolgung am deutlichsten von historischen Vorbildern

$266 \mathrm{~V}$ I. Podhorizer-Sandel, O zaghedzie, S. 97.

$267 \mathrm{Vgl}$. Pietrzykowski, Hitlerowcy w Częstochowie, S. 183.

268 Vgl. Jan Pietrzykowski, W obliczu śmierci. Przyczynki do historii Częstochowy w okresie hitlerowskiej okupacji, Katowice 1966, S. 71.

269 Vgl. Dawidowicz, War, S. 300.

270 Vgl. Datner, Walka, S. 21.

271 Vgl. Malgorzata Zymialkowska, Kronika ziemi sqdeckiej 1939-1945 r, in: Okupacja w Sqdecczý́nie. Praca zbiorowa, Warszawa 1979, S. 306. - Die Mitglieder des Judenrates von Bilgoraj wurden erschossen, weil sie sich weigerten, Judentransporte zum Abtransport nach Betżec zusammenzustellen (Vgl. Jerzy Markiewicz/ Ryszard Szczygiel/Wieslaw Sladkowski, Dzieje Bitgoraja, Lublin 1985, S. 242).

272 Vgl. Poradowski, Zaglada, S. 88. - Die Leichen wurden 1951 exhumiert und auf dem jüdischen Friedhof Kolbuszowa beigesetzt.

273 Vgl. Berenstein, Martyrologia, S. 35.

274 Vgl. Andrzej Wiśniewski, Martyrologia sqdeckich Zydów w okresie 1939-1943, in: Okupacja w Ş̨decczýnie, S. 305.

275 Vgl. Zygmut Klukowski, Niedola i zagłada Zydów w Sxczebrzeszynie, in: BZIH 19-20 (1956, S. 223-237.

$276 \mathrm{~V}$ gl. Berenstein/Rutkowski, Zydzi, S. 11. 
unterschied, war die Errichtung und Betreibung einer industriellen Mordmaschinerie, der nach dem Sommer 1941 die Endlösung ${ }^{4}$ übertragen wurde. Trotz geringfügigen zeitlichen Diskrepanzen verliefen Ausbau und Betrieb der Einrichtungen im wesentlichen zeitgleich, so daß Unterschiede mit den jeweiligen örtlichen Umstānden und pragmatischen Lōsungsversuchen, nicht aber mit unterschiedlichen politischen Ansichten zusammenhingen. Trotz der organisatorischen Trennung zwischen den Vernichtungsanstalten von Chełmno/Kulmhof einerseits und den Mordanlagen in Treblinka, Bełzec und Sobibór andererseits, besteht zwischen ihnen ein deutlicher Zusammenhang - wohingegen etwa Majdanek und Auschwitz gesondert gesehen werden müssen.

An den erstgenannten Orten installierte man Anlagen, deren ausschließlicher Zweck der Massenmord war - sie waren nicht einmal Vernichtungslager, da ihnen größere permanente Möglichkeiten zur Unterbringung von Menschen fehlten. Ihre Erfassungsgebiete waren regional gegliedert, und ihren Zweck, die Ermordung von Juden, erfüllten sie mit jeweils nur leicht voneinander abweichenden Maßnahmen. Das Ziel war allein die radikale Vernichtung der jüdischen Bevölkerung. Chetmno/Kulmbof war bei dieser regionalen Gliederung für die nördlichen "eingegliederten Gebiete“ "zustāndig“. Von Dezember 1941 an wurde das "Einzugsgebiet" durchkāmmt, bis Litzmannstadt als einziges Ghetto, in das noch aus anderen Orten „Einsiedlungen“ hinzukamen, übrigblieb. Die Tötung erfolgte in Chełmno/Kulmhof durch Gaswagen während des Transports der an der Bahnstation eintreffenden Juden (z.T. nach einem Zwischenaufenthalt in einem Adelspalast) zu einem in der Nähe gelegenen Wald. Die in das Wageninnere geleiteten Abgase der Dieselmotoren töteten die Insassen langsam, etwaige Uberlebende dieses Transports wurden im Wald erschossen, wo die Leichen zeitweise in Massengräbern begraben wurden. 277 Im April 1943 wurde die „erste Phase ${ }^{\star}$ in Chelmno/Kulmhof durch die Sprengung des als " $\mathrm{Z}$ wischenlager“ verwendeten Palastes und der Krematorienöfen, in denen die Leichen vom Sommer 1942 an verbrannt worden waren, abgeschlossen. ${ }^{278}$

Betżec diente als Vemichtungsort für die Juden des polnischen Südostens - für die Distrikte Krakau, Radom, Lublin und Galizien. Mit dem Bau wurde im November 1941 begonnen. Die Einrichtung war als Vernichtungsort nur während eines Sommerhalbjahres in Betrieb: zwischen dem 17. März 1942 und Anfang Dezember 1942. Die Tötung erfolgte nach anfänglichen Versuchen mit Zyklon-B-Gas aus Flaschen durch Abgase stationārer Dieselmotoren, die in Gaskammern eingeleitet wurden. Der makabre NS- ${ }_{n}$ Humor ${ }$ erreichte in der Aufschrift ${ }_{n}$ Hackenholt-Institut ${ }^{\star}$ einen seiner grausigen Höhepunkte: Hackenholt war der Name des Mechanikers, der die Dieselmotoren bediente.

277 Der Posener Gauleiter Artur Greiser hatte am 1. Mai 1941 Himmler gemeldet, die ,Sonderbehandlung“ (Tarnbezeichnung für Ermordung) von 100000 Personen sei in 2-3 Monaten möglich (vgl. Serwański, Obóz, S. 34). Nach einer Aussage aus dem „Kulmhof-ProzeB" in Bonn (1963) wurden die nach Kulmhof Transportierten zeitweise angehalten, an ihre Verwandten vor ihrer Vergasung beruhigende Postkarten über "Arbeit im Reich“ zu schicken. Das Tagebuch des Ghettos Litzmannstadt bestātigt den Eingang entsprechender Nachrichten (The Chronicle of the Lodź Ghetto, S. XIX, 141). Die Chronik berichtet darüber hinaus, daß am 12.4.1942 ein hoher Gestapo-Offizier berichtet habe, 100000 seien in $W$ arthbrücken/Kolo angesiedelt worden (ebenda, S. 145). Bei Warthbrücken lag Kulmhof in der Tat; die $\mathbf{4 4 0 0 0}$ bis dahin aus Lodí deportierten Juden waren jedoch längst tot.

278 Vgl. Serwański, Obóz, S. 34, 36, 49. 
Einen àhnlichen Einzugsbereich hatte Sobibór, das im Mai 1942 den Betrieb aufnahm (Baubeginn Februar 1942) und ihn mit Unterbrechungen bis Oktober 1943 fortsetzte. Da über Sobibór die wenigsten Unterlagen erhalten geblieben sind, ist die genaue Bestimmung des Einzugsgebiets nicht möglich. Es scheint sich vor allem um den Distrikt Lublin und Teile des Distrikts Warschau gehandelt zu haben ${ }^{279}$, wozu noch Transporte aus Westeuropa (Frankreich, Niederlande), dem Reich, der Slowakei, Böhmen und Māhren sowie aus dem deutsch besetzten Teil der Sowjetunion kamen. ${ }^{280} W$. Scheffler nennt Sobibór eine Ausweichstelle für Belzec, dessen Anlagen nicht für die erforderlichen Tötungen ausreichten. ${ }^{281}$ Die Zahl der Ermordeten war trotz der längeren „Betriebsdauer ${ }^{“}$ niedriger als in Belzec. Aus allen Berichten geht hervor, daß es bei der Organisation der Vernichtungsmaschinerie zahlreiche Probleme gab: die Tötungsanlagen konnten nicht mit den in Transporten eintreffenden Juden Schritt halten ${ }^{282}$, oder die Tötungsapparaturen selber erwiesen sich als wenig $n^{2}$ weckmäßig".

Treblinka ist stärker in das allgemeine Bewußtsein der Öffentlichkeit gedrungen, weil es nicht so abgelegen war wie Bełżec oder Sobibór und weil es zur Vernichtung der größten Konzentration von Juden im deutsch besetzten Europa, des Warschauer Ghettos, diente. Von Juli 1942 an verließen Transporte Warschau, die über Malkinia das Lager erreichten, in dem ebenfalls durch Motorabgase in luftdicht abgeschlossenen Gaskammern gemordet wurde. Neben den Warschauer Juden und den Menschen aus dem Distrikt Warschau wurde ein großer Teil der Juden des Distriks Radom und des Bezirks Bialystok in Treblinka umgebracht. 283 In der Nāhe des Vernichtungsortes bestand seit 1941 ein Arbeitslager für nicht-jüdische Polen, das etwa 10000 Personen durchliefen, die nach Feig ${ }^{284}$ zu 75\% umkamen. Im August 1943 kam es wie am 14. Oktober 1943 auch in Sobibór zu einem Aufstand, der dazu führte, daß das Lager im Herbst desselben Jahres geschlossen wurde. ${ }^{285}$

In Anbetracht der Tatsache, daß es über die Vernichtungslager kaum auswertbare Quellenbestānde gibt, ist die Zahl der in diesen Mordorten getöteten Juden besonders

279 Vgl. Berenstein, Martyrologia, S. 40; Marian Kowalski un (Hrsg.) Zbrodnie hitlerowskie w regionie bielskopodlaskim 1939-1944, Lublin 1977, S. 132.

280 Vgl. Konnilyn G. Feig, Hitler's Death Camps, New York 1981, S. 286

281 In: Jäckel/Rohwer, Mord, S. $149 \mathrm{f}$.

282 Einen Brief über die Verzögerungen der Vernichtung und die dadurch entstandenen zusítzlichen Qualen der in den geschlossenen Zügen auf ihre Emordung wartenden Menschen zitiert Bieberstein (Zaglada, S. $79 \mathrm{f.l}$

283 Vgl. Krystyna Marczewska/Wtadystaw Ważniewski, Treblinka w świetle akt Delegatury Rządu RP na Kraj, in: Biuletyn GKBZHwP 19 (1968), S. 137.

284 Death Camps, S. 296.

285 Raul Hilberg hat (in: Jäckel/Rohwer, Mord, S. 1291.) die These aufgestellt, daß der schlecht durchorganisierte Aufbau des Vernichtungsapparats (Ausbau der Gaskammem erst nach den ersten „Stockungen“ im Mordprozeß, Primitivität der Anlagen) haushaltsrechtlich begründet gewesen sei. Es habe keinen "Etat" für die Endlösung gegeben. Für Kenner deutscher bürokratischer Prozesse ist diese These durchnus nicht abwegig. Ohne hier argumentativ weiterzugehen, sei der Hinweis angebracht, dal die zahlreichen Tambezeichnungen der Mordaktionen ebenso wie die von Hilberg erwähnte Verwendung der Benennung "Kriegsgefangenenlager der SS“ für Birkenau und Majdanek die Inanspruchnahme von bestimmten Haushaltstiteln ermöglichte. In diesem Sinne dienten die den Juden vor ihrer Vernichtung auferlegten Kontributionen (bis hin zur Erstattung der Kosten für bei den Deportationserschießungen verbrauchte Munition in Bochnia [Vgl. J. Chrobaczyński/J. Golębiowski, Getto w Bochni i zagłada ludności żydowskiej 1939-1945, in: BZIH 1-2/121-2 (1982), S. 53D möglicherweise tatsichlich dem Ausgleich einer makabren „Buchhaltung des Mordes“. - Zur Kontrolle der Gestapo durch den Rechnungshof vgl. den Diskussionsbeitrag Wolfgang Schefflers (in: Jäckel/Rohwer, Mord, S. 138 f.). 
schwer zu ermitteln. Sie stützt sich vorwiegend auf Schätzungen von Zeugen, die Analyse der regelmäßigen Transporte und deren Stärkeangaben und auf die Einwohnerzahlen in denjenigen Gebieten, aus denen die jeweiligen Tōtungsorte „beliefert" wurden.

In den ersten Monaten des Jahres 1942 wurden etwa 44000 Personen aus dem Ghetto Litzmannstadt in Cbetmno/Kulmbof umgebracht. ${ }^{286}$ Zuvor waren bereits die Juden aus der näheren Umgebung der Vernichtungsstātte ermordet worden, im Laufe des Jahres 1942 folgten dann Transporte aus dem Ghetto Brzeziny (Mai 1942, ca. 3000 Personen) ${ }^{287}$, aus Żychlin (ca. 3200), aus den Kreisen Sieradz, Wieluń (10000), Zduńska Wola $(10700)^{288}$ und emeut aus Litzmannstadt, von wo aus im September 1942 etwa 15000 nicht arbeitsfāhige Alte und Kinder nach Chelmno gebracht wurden.289 Im Mai 1942 wurden darüber hinaus etwa 10000 Juden aus dem übrigen Europa, die zunächst nach Litzmannstadt gebracht worden waren, in Chelmno ver-

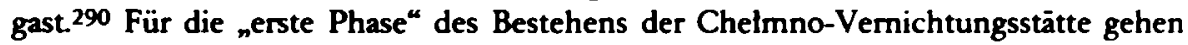
die Schātzungen der Opfer-Zahlen weit auseinander. Ein Augenzeuge hielt die Zahl von 250000 bis 1943 für möglich, der Staatsanwalt im Bonner Prozeß 1962/63 sah die Zahl 180000, der Richter die Mindestzahl 145000 als gesichert an. ${ }^{291}$ Aufgrund von unterschiedlichen Ausgangsdaten für Differenzbestimmungen kommt Whodzimierz Bednarz ${ }^{292}$, der sich auf die Angaben der deutschen Stellen stützt, auf etwa 330000 Getōtete, von denen etwa 25000 aus dem nichtpolnischen Ausland gekommen seien, wāhrend D. Dạbrowska293 durch eine sehr hohe Zahl angenommener Aussiedlungen ins Generalgouvernement vor der Ghettoisierung insgesamt "nur" auf etwa 215000 kommt. Angesichts der großen Zahlenunterschiede verliert die Unterscheidung $\mathbf{z w i -}$ schen polnischen und nicht-polnischen Juden an Bedeutung, ebenso auch die Berücksichtigung der ebenfalls in Chelmno getöteten ca. 5000 Zigeuner, 5000 sowjetischen Kriegsgefangenen und einigen hundert Polen aus der unmittelbaren Umgebung des Ortes. Serwański nimmt als niedrigstmögliche Zahl 300000 an. ${ }^{294}$ Wir halten für die Berechnung 215000 für realistisch.

In Sobibór wurden im Mai 1942 etwa 16800 Juden aus dem Kreis Pulawy ermor$\operatorname{det}^{295}$, daneben 5-6000 Bewohner des Kreises Krasnystaw und eine unbekannte Zahl aus der Umgebung von Chelm. Für den Juni 1942 sind 10000 Juden aus dem Kreis Hrubieszów und 3000 aus Biała Podlaska ${ }^{296}$ nachgewiesen. Die polnische Hauptkommission für die Untersuchung von NS-Verbrechen nimmt eine Gesamtzahl (zwischen

286 Vgl. Dẹprowska, Zagłada, S. 136; Kronika getta tódzkiego, Lódź 1965/6, S. 402, 425, 434, 448.

287 Vgl. Pakentreger, Polityka, S. 40; Miroslaw Cygański, Powiat lódzkj w latach okupacji hitlerowskiej (1939-1945), in: Rocznik Lódzki 16 (1972), S. 107; Kronika, S. 574-596

288 Vgl. Serwański, Obóz, S. 28.

289 Vgl. ebenda, S. 30; Kronika, S. 244; Julian Leszczyński, Od formuly obozu zaglady - Höppner Chelmno nad Nerem - do ,Endlösung', in: BZ1H 1/101 (1977), S. 49.

$290 \mathrm{Vgl}$. Serwański, Obóz, S. 27; Kronika, S. 501.

291 Vgl. Serwański, Obóz, S. 66; Adalbert Rückerl, Nationalsozialistische Vernichtungslager im Spiegel deutscher Strafprozesse, München 1978², S. 292.

292 Wodzimierz Bednarz, Obóz straceń w Cheimnie nad Nerem, Warszawa 1946.

293 Dąbrowska, Zaglada, passim. Diese Zahl erschließt sich aus der Addition der registrierten Einzeldeportationszahlen nach Kulmhof. Da sicherlich diverse Transporte der Aufmerksamkeit der Forscherin entgangen sein dürtten und auch die Zahlenangaben nicht durchweg verlälich sind (die meisten entstammen Schätzungen), kann der hier genannte Wert nicht in jeder Hinsicht als gesichert gelten.

294 Vgl. Serwański, Obóz, S. 69.

$295 \mathrm{Vgl}$. Berenstein, Martyrologia, S. 40.

296 Vgl. ebenda; Kowalski, Zbrodnie, S. 32. 
Mai 1942 und Oktober 1943) von 250000 Getöteten an, von denen etwa 34000 Niederländer waren, deren Transporte einzeln nachweisbar sind, so daß die Zahl der polnischen Juden etwa bei 210000 liegen dürfte. Das Urteil des Schwurgerichts Hagen vom 20. Dezember 1966, zu dem die gutachterlichen Aussagen von Wolfgang Scheffler herangezogen wurden, kommt zu ähnlichen Gesamtzahlen, die jedoch aufgrund der Spezifik juristischer Argumentation anders gewichtet werden, da über die Deportationen aus den polnischen Ghettos keine ausführlichen Unterlagen geführt wurden. Hier wurde von 150000 Juden ausgegangen. Im Urteil heißt es: „Die Ergebnisse der polnischen Untersuchungen aus dem Jahre 1947 werden dadurch grundsätzlich nicht in Frage gestellt, eher bestātigt, da durch die hier vorgenommene strafrechtliche Bestandsaufnahme nur in dubio pro reo das Dunkelfeld größer bleibt." Setzt man von den 150000 etwa 70000 für Personen ab, die aus anderen als polnischen Gebieten kamen, verbleiben 80000 polnisch-jüdische Opfer, wobei jedoch die Dunkelziffer gar nicht genügend hervorgehoben werden kann. 297

Noch letaler als Sobibór war im Frühjahr 1942 Betżec. Hier kamen nahezu täglich Züge aus Lublin und Lemberg an, die in ihren jeweils ca. 20 Waggons um die 2000 Personen an ihre Todesstātte transportierten. ${ }^{298} \mathrm{Da}$ eine deutliche Trennung zwischen den Ursprungsorten der dokumentierten Züge und ihrer Passagiere nicht immer mōglich ist, mögen einige Daten einen Hinweis auf die Quantifizierung und die geographische Einordnung geben. Aus Lublin kamen zwischen März und Mai 1942 etwa 30000 Personen 299 , aus Lemberg zwischen März und April etwa 15000300, aus Stanislau im Mārz 5000301, bis zum Juli 19424500 aus Rawa Ruska. ${ }^{302}$ Im weiteren AprilVerlauf wurden die Juden des Lubliner Distrikts in Belżec ermordet: 2000 aus Izbica, 2500-3000 aus Zamość. ${ }^{303}$ Im Mārz begann auch die Aussiedlung aus dem Distrikt Krakau. Bereits zuvor hatten Aussiedlungen aus der Hauptstadt des Generalgouvernements stattgefunden: Im November 1941 hatte man etwa 1000 Arbeitsunfähige in die Gegend von Kielce geschickt und dort freigelassen - die meisten sollen jedoch nach Krakau zurückgekehrt sein. ${ }^{304}$ Die im Mär 1942 angeblich nach Plasz6w deportierten 1500 Juden endeten aber fast alle bereits im Vernichtungslager Beliec. ${ }^{305}$ Seit Juni 1942 wußte man in Krakau durch Berichte polnischer Eisenbahner über die Mordfabrik Bełzec Bescheid. 306 Die grōßeren Deportationen im Mai/Juni aus der Stadt Krakau umfaßten zwischen $4000^{307}$ und $7000^{308}$ Personen, ca. 1000 wurden noch in der Stadt oder auf dem Weg zum Verladebahnhof Plasz6́w umgebracht ${ }^{309}$, nur ganz wenigen gelang die Flucht aus dem Transportwagen. Im Oktober 1942 nannte das Bulletin

297 Vgl. Miriam Novitch, Sobibór. Martyrdom and Revolt, New York 1980, S. 33; Alexander Donat, The Death Camp Treblinka, New York 1979, S. 13; Urteil des Schwurgerichts Hagen vom 20.12.1966, in: Rükker, Vemichtungslager, S. 145-157.

298 Vgl. Klukowski, Niedola, S. 223.

299 Vgl. Dowidowicz, War, S. 298.

300 Vgl. ebenda, S. 299; Friedmen, Zegtada, S. 19.

301 Vgl. Feuerman, Pamiętrik, S. 74.

302 Vgl. Jakub Iszchułów, Zagtada Zydów w miescie i powiecie Rawa Ruske, in: BZIH 2/102 (1977), S. $97 \mathrm{f}$.

303 Vgl. KJukowski, Niedola, S. 224; Berenstein, Martyrologia, S. 37 ff.

$304 \mathrm{Vgl}$. Bieberstein, Zagtada, S. $53 \mathrm{f}$.

$305 \mathrm{Vgl}$. ebenda, S. 56 - nach einem Augenzeugenbericht.

306 Vgl. ebendes, S. $57 f$.

307 Jan Dạbrowski, Kraków pod rząami wroga 1939-1945, Kraków 1946, S. 35.

308 Michai Borwicz ua, W trzecią rocznicę zagłady ghettl w Krakowie (13.3.1943 - 13.3.1946), Kraków 1946, S. 38; Bieberstein, Zaglada, S. 65.

309 Vgl. ebendg, S. 63. 
des Stadthauptmanns 12000 in Krakau lebende Juden (zu denen noch die "Illegalen" zu addieren wären). Die zweite „Aktion" am 28. Oktober 1942, nach der noch etwa 10000 Juden in Krakau übrigblieben, erfaßte $z$ wischen $5000^{310}$ und $7000^{311}$ Personen. Nach Bieberstein wurden etwa 4500 Juden nach Bełżec transportiert und ca. 600 noch in Krakau umgebracht. Mit der Ausfertigung individueller Sterbekarten hielt man sich nicht auf. ${ }^{312}$ Bei der im Juni begonnenen „Durchkāmmung des Distrikts Krakau kamen 11000 Juden aus Tarnów, 21000 aus dem Kreis Rzeszów, 12000 aus dem Kreis Dębica und im August 10000 aus Przemyśl nach Belżec. ${ }^{313}$

Im August schlossen sich nicht nāher quantifizierbare Deportationen aus dem Lubliner Distrikt an ${ }^{314}$, und man holte die Durchkämmung der noch nicht systematisch erfaßten Kreise nach. Das Gesamtbild gestaltet sich unübersichtlich - so wurden etwa ${ }_{n}$ Zwischen-Konzentrationslager ${ }^{\text {" }}$ eingerichtet. ${ }^{315}$ In Wieliczka wurden die noch in kleineren Orten lebenden Juden gesammelt und am 18. August gemeinsam mit den Bewohnern des Ghettos von Wieliczka nach Szebnie und Bełżec deportiert. 316 Die Juden aus Tyczyn, Kolbuszowa, Czudec, Strzyzów und anderen Orten brachte man im Juni 1942 zunāchst in das Ghetto der Kreishauptstadt Rzeszów. ${ }^{317}$ Der Abtransport von 16000 Juden aus dem Kreis Jasto, weiteren 16000 aus Neu Sandez/Nowy Sacz und 2500 aus Neumarkt/Nowy Targ im August 1942 weist bereits auf die erweiterten Mordkapazitāten in Bełżec hin. Im September 1942 wurden 11000 Juden aus dem Kreis Sanok und weitere 7-8000 aus dem Kreis Tarnów fortgebracht. ${ }^{318}$ Die „Saison" der Mordmaschine Belżec lief im Oktober mit Transporten aus Krakau und kleineren Kontingenten aus Szczebrzeszyn 319 sowie im November mit 500 Juden aus Bochnia aus. ${ }^{320}$ Uber die Zahl der in Bełżec ermordeten jüdischen Menschen ist kein Quellenmaterial bekannt geworden. Die Schātzungen stützen sich deshalb auf die Anzahl der Ausgesiedelten, die im allgemeinen in der polnischen Literatur mit 600000 angegeben wird ${ }^{321}$; als Mindestzahl wird 390000 genannt. ${ }^{322}$ Ungesichert wie diese Zahl ist,

310 Borwicz, $\mathbf{W}$ trzecią roczniç, $S .38$.

311 Dębrowski, Kraków, S. 35.

312 Vgl. Bieberstein, Zaglada, S. 76.

313 Vgt. Podhorizer-Sandel, O zagładzie, S. 93 ff.- Unabhägig von den Deportationen in die Vernichtungslager wurden Kontingente von Juden in Arbeitslager verschleppt, so etwa am 9.3.1942 nach Pustków 536 Juden aus Mielec und später 75 aus Ropczyce, 50 aus Sędziszów, 228 aus Dębica, 1500 aus Dạbrowa Tarnowska, 200 aus Nowy Sạcz/Neusandez usw. (Ngl. Stanislaw Zabierowski, Pustków, Rzeszów 1981, S. 52). 1942 waren im Arbeitslager Pustków etwa 2000 Juden. Die Juden Rzeszóws wurden am 7., 10., 14. und 19.7.1942 über die Bahnstation Staroniwa nach Beliec transportier. Etwa 2000 Alte und Kranke wurden in einem Waldstück bei Glogów, Kr. Rzeszów erschossen, Dutzende anderer auf dem Fußmarsch zur Bahnstation. Die Schātzungen der aus Rzeszów nach Belizec Deportierten schwanken zwischen 18000 und 22000 - Poradowski nennt die Zahl 21000 als die realistischste (Poradowski, Zagiada, S. 97 ff.). 1000 Frauen und Kinder gelangten am 7.8.1942 über Pelkinie nach Beliec (vgl. ebenda, S. 101) - Am 25. August um 14 Uhr fuhr der erste "Aussiedlerzug" aus Bochnia mit 2000 Menschen ab; 500 nicht transportierfähige Frauen, Kinder und alte Menschen wurden im Wald bei Baczków (Puszcza Niepolomicka nördlich von Bochnia) erschossen (Vgl. Chrobaczyński/Golębiowski, Getto, S. 52).

314 Vgl. Berenstein, Martyrologia, S. 41.

315 vgl. Podhorizer-Sandel, O zagładzie, S. 96.

316 Vgl. Bieberstein, Zagłada, S. 68; Chrabaczyński/Golębiowski, Getto, S. 55. - Etwa 6-700 Juden wurden zuvor bei Niepotomice erschossen.

$317 \mathrm{Vgl}$. Poradowski, Zaglada, S. 89.

318 Vgl. Podhorizer-Sandel, O zagladzie, S. $97 \mathrm{f}$.

319 Vgl. Klukowski, Niedola, S. 233.

320 Vil. Chrobaczyński/Golębiowski, Getto, S. 53.

321 Vgl. Novitch, Sobibór, S. 33.

322 Vgl. Donat, Treblinka, S. 12; diese Mindestzahl ergab der Münchner Strafprozeß gegen Oberhauser 1964, 
bietet sie doch einen Anhalt, um die Morde von Bełzec in einen Bezug zu denjenigen anderer Tötungsstätten zu bringen.

Bei diesem makabren Vergleich ergibt sich, daß von den reinen Vernichtungslagem Treblinka die größte Zahl von Opfern zu verzeichnen hatte. Von 23. Juli 1942 an trafen mit einer kurzen Unterbrechung zwischen dem 28. August und dem 4. September bis in den Dezember 1942 täglich bis zu drei Transportzüge in Treblinka ein ${ }^{323}$, wobei die Transporte aus Warschau in der Regel bis zu 5000 Personen stark waren. Zwischen dem 22. Juli und dem 7. August 1942 wurden 113000 bis 116000 Juden aus Warschau in Treblinka sofort umgebracht. ${ }^{324}$ Bis Oktober 1942 waren allein aus Warschau 300000 Juden nach Treblinka gebracht worden. ${ }^{325}$ Hinzu kamen jedoch noch Juden aus anderen Gegenden Polens. Zwischen dem 19. und dem 24 . August 1942 wurden die noch verbliebenen Ghettos in der Nāhe Warschaus geräumt. Etwa 7000 Juden zählten die Transporte aus Otwock (dort waren zuvor 3000 weitere erschossen worden), zu den übrigen Orten wie Mińsk Mazowiecki, Rembertów, Siedlce etc. liegen genaue Zahlen nicht vor. ${ }^{326}$

Von August 1942 an gab es neben den Warschauer Zügen auch Transporte aus dem Distrikt Radom. Wie Wolfgang Scheffler betont hat, wurde der Distrikt innerhalb von fünf Wochen geräumt “ ${ }^{327}$ Eines der Zentren jüdischer Bevölkerung war hier die Stadt Tschenstochau/Częstochowa, die 1942 noch zwischen 37000 (gemeldete) und 48000 (incl. nicht gemeldeter) Juden beherbergte. ${ }^{328}$ Die Zahl der Stadtbewohner war bis 1942 dadurch angestiegen, daß sich zahlreiche Migrationen aus der nāheren und weiteren Umgebung (Litzmannstadt, Wieluń, Krakau, Płock) nachweisen lassen.

Vom 22. September 1942 an wurden die Ghettobewohner systematisch in die Gaskammern von Treblinka transportiert. Am ersten Tag verließen 6000 bis $8000^{329} \mathrm{Ju}$ den die Stadt, bis zum 7. Oktober hatte sich diese Zahl auf $\mathbf{4 0 0 0 0}$ summiert ${ }^{330}$ Vor der Deportation waren hier etwa 2000 Menschen an Ort und Stelle umgebracht worden. ${ }^{331}$ Nach der Deportation blieben in Tschenstochau in einem drastisch reduzierten Ghetto und Arbeitslager $5000^{332}$, vielleicht auch 6000 Juden übrig. ${ }^{333}$ Gerade die Transporte aus Tschenstochau nach Treblinka sind recht gut dokumentarisch nachzuweisen. Für sie sind die Sonderfahrplāne der Reichsbahn erhalten, die die Zeiten für die Fahrten der Züge nach Treblinka und die Rückkehrfahrplāne der "Leerzüge ${ }^{\text {« aus- }}$ weisen. ${ }^{334}$

nach Scheffler liegt die Zahl weitaus hōher und soll sogar die polnischen Schätzungen übersteigen (vgl. Rückerl, Vernichtungslager, S. 136).

323 Vgl. Zdzisław Lukaszkiewicz, Obóz straceń w Treblince, Warszawa 1946, S. 14.

324 Vgl. Marczewska/Wainiewski, Treblinka, S. 137; Brustin-Berenstein, Deportacje, S. $90 \mathrm{ff}$.

325 Vgl. Dawidowicz, War, S. 212; die deutsche unvollständige Statistik kommt bis zum 21. September auf 253741 (Yisrael Gutman, The Jews of Warsaw 1939-1943, Brighton 1982, S. 212).

326 Vgl. Brustin-Berenstein, Deportacje, S. 92.

327 In: Jäckel/Rohwer, Mord, S. 150.

328 Vgl. Pietrzykowski, W obliczu, S. 66. - Das Einwohnermeldeamt registrierte für den $17.9 .194236520 \mathrm{Ju}-$ den, der Judenrat hatte 1942 als letzte Zahl 48000 angegeben (Pietryykowski, Hitlerowcy w Częstochowie, S. 178).

329 Vgl. ebenda, S. 183.

330 Vgl. Pietrzykowski, W obliczu, S. 71.

${ }^{331}$ Vgl. Pietrzykowski, Hitlerowcy w Częstochowic, S. 186.

332 Vgl. ebenda, S. 187

333 Vgl. Brener, O pracy, S. 49; Pietrzykowski (Wobliczu, S. 73) spricht von real ce 6000 Personen, von denen jedoch nur 5200 offiziell erfaBt waren.

334 Vgl. daru die Studie von Heiner Lichtenstein, Mit der Reichsbahn in den Tod. Massentransporte in den Holocaust, Kōln 1985, passim. 
Aus der „ersten Phase“ der Mordtätigkeit Treblinkas sind 135 Transporte zwischen Juli und Dezember 1942 ermittelbar. ${ }^{335}$ Jeweils etwa 500 bis 1000 jüngere Jüdinnen

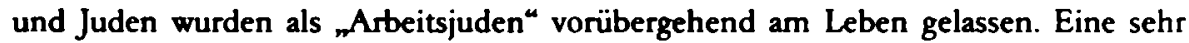
frühe, wenngleich nicht überhōht erscheinende Schätzung spricht für diese Zeit von 675000 Opfern, von denen etwa 300000 aus Warschau gekommen sein dürten. ${ }^{336}$ Von Mitte November 1942 bis Anfang 1943 kamen keine neuen Transporte. Zwischen Januar und Mai 1943 verloren dann weitere 19000 Warschauer Juden in Treblinka ihr Leben, hinzu kamen nicht näher quantifizierbare Transporte aus den gerade erst neu verordneten, im Laufe dieser Monate schon wieder liquidierten ,Judenwohnbezirken “, was die Feststellung der Zahlen der Opfer Treblinkas besonders schwierig macht. Die deutschen Unterlagen verbrannten beim Lageraufstand im August 1943.

Erste polnische Schātzungen von 3000000 Toten erwiesen sich bald als überhōht. Helmut Krausnicks auf den Transportraum gestützte Berechnungen für den ersten Treblinka-Prozeß in Düsseldor ${ }^{337}$ ergaben mindestens 700000 , Wolfgang Schefflers ${ }^{338}$ bis zu 900000 ; Zdzislaw Lukaszkiewicz sprach 1946 von 785300 Opfern. $^{3 j y}$ Rachel Auerbach, die mit Ringelblum im Warschauer Ghetto-Archiv arbeitete und den Holocaust überlebte, kam in ihrer 1946 erschienenen Arbeit, in der sie für die „2weite Periode“ 1943 insgesamt 35 Transporte mit etwa 210000 Menschen annahm, auf 1074000 Juderı. 340 Laut dem Bericht des Ubberlebenden Samuel Rajzman feierte die SS „lange vor dem Ende des Lagers“ den 1000000 sten Häftling. Dies läßt zusam. men mit der Nachricht über eine Zahl von 1200000 , die die polnische Heimatarmee (AK) ermittelt hatte ${ }^{341}$, eine Zahl von Opfern gerechtfertigt erscheinen, die sich in der Nähe der Auerbach-Schätzung bewegt. ${ }^{342}$ Gegen 100000 von ihnen kamen aus den Gebieten außerhalb des geographischen Rahmens dieses Beitrags (Österreich, Tschechoslowakei, Bulgarien, Griechenland). 343

Zwei weitere Namen von Vernichtungsstātten verbreiten heute allein durch ihre bloße Nennung Grauen: Auschwitz und Majdanek. Das Konzentrationslager Auschwitz (Auschwitz I) war bereits im Mai 1940 in einer polnischen Kaserne eingerichtet und in „Betrieb" genommen worden, zunāchst allerdings mit deutschen Häftlingen (aus Dachau) und polnischen Gefangenen nicht-jüdischer Herkunft aus Tamów. ${ }^{344}$

Nach Himmlers Besuch des Lagers am 1. März 1941 entstand das Projekt, hier ein großes Arbeits- und Gefangenenlager anzulegen. Nach dem Beginn des Rußlandfeldzugs wurde vorübergehend ein $Z$ wangsarbeitslager für sowjetische Kriegsgefangene

335 Vgl. Lukaszkiewicz, Obóz, S. 38.

336 Ebenda; Nach Yitzhak Arad (Belzec, Sobibor, Treblinka. The Operation Reinhard Death Camps, Bloomington 1986, S. 87, 127) nimmt auch Wladystaw T. Bartoszewskj (in: Samuel Willenberg, Surviving Treblinke, Oxford 1989, S. 12 ff.) die Zahl 750600 für diesen Abschnitt an.

337 Uneil vom 3.9.1965, Az: LG Düsseldorf II-931638.

338 Im Gutachten für den zweiten Treblinka-Prozeß (Urteil vom 22.12.1970, Az: LG Düsseldorf XI-148/69); vgl. Rücker, Vemichtungslager, S. 199.

339 Vgl. Lukaszkiewicz, Obóz, S. 39.

340 Nach Neuabdruck in Donat, Treblinka, S. 531.

341 Ihr Beauftragter, der Stationsvorsteher von Treblinka Franciszek Zabecki, addierte die Zahlen, die mit Kreide auf den Außenwänden der Waggons standen; vgl. Gitta Serenyi, in: Jäckel/Rohwer, Mord, S. 158.

$342 \mathrm{Vgl}$. Donat, Treblinka, S. 14. Wir halten an dieser Zahl abweichend von dem bisherigen Ansatz fest, da sie uns realistischer erscheint, als der nachweisliche Minimalwert

343 Auerbach, in: Donat, Treblinka, S. 56.

344 "Ein paar Dutzend Juden" unter ihnen sollen schon bald von der SS erschlagen worden sein (Yehuda Bauer, in: Jäckel/Rohwer, Mord, S. 164). 
errichtet, während gleichzeitig Industrie angesiedelt wurde und man daranging, im nahegelegenen Birkenau (Brzezinka, Auschwitz II) das Arbeits- und Vernichtungslager aufzubauen, in dem im Januar 1942 mit der systematischen Ermordung (Vergasung) von Juden aus allen Teilen Europas begonnen wurde. Anders als in den zuvor besprochenen Orten erfolgte die Vergasung in Auschwitz nicht mit Abgasen, sondern mit dem eigens zu diesem Zweck gekauften, auf Blausāurebasis produzierten Ungeziefer-

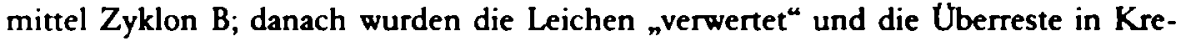
matorien verbrannt.

Die Stadt Auschwitz war 1940 zu einem Sammelpunkt der Juden aus den ohne Polizeigrenze dem Reich angeschlossenen ostoberschlesischen Gebieten geworden; im April 1941 wurden alle jüdischen Bewohner nach Bendsburg/Będzin und Sosnowitz/Sosnowiec umgesiedelt. Von dort aus erfolgte ab Januar 1942 ein schrittweiser Rücktransport, nun in das Arbeits- und Vernichtungslager Birkenau. ${ }^{345}$ Außerdem kamen nach Auschwitz zunāchst Juden aus Westeuropa - vermehrt wurden polnische Juden erst nach Auschwitz gebracht, als die anderen Vernichtungslager ihre Tãtigkeit eingestellt hatten.

Für die Zeit 2wischen September 1941 und Frübjabr 1942 nimmt Yehuda Bauer als Mindestzahl 107000 Opfer an - so viele Leichen wurden nach der Aussage des Lagerkommandanten Rudolf $\mathrm{Höß}$ bis November exhumiert, um verbrannt zu werden. ${ }^{346}$ Nach Ansicht von Czesław Madajczyk ${ }^{347}$ bezieht sich die Zahl 107000 jedoch auf die Zeit bis November 1942, da zunächst das Krematorium mit der Leichenverbrennung nicht nachkam und parallel verbrannt und verscharrt worden sei. Die Gesamtvemichtungsangaben für Auschwitz schwanken zwischen 1000000 und 2500000 . Am realistischsten erscheint vor dem Abschluß in Oświęcim laufender Studien die Schätzung Raul Hilbergs, der von 1000000 jüdischer Opfer (also ohne die 6400 Zigeuner, Kriegsgefangenen, nicht-jüdischen Polen etc.) ausgeht, davon 400000 aus Ungarn (1944), 300000 aus den verschiedensten Teilen Europas und ca. 300000 aus polnischen Gebieten. ${ }^{348}$

345 Vgl. Tadeusz Iwaszko, Die Häftlinge, in: Auschwitz, Reinbek 1980, S. 119; Dokumenty o eksterminacji Żydów Zagłębia Dąbrowskiego podczas okupacji hitlerowskiej, in: BZIH 43/44 (1962), S. 113.

346 Der Anteil polnischer Juden an dieser Zahl ist unbekannt; etwa 6000 der Genannten dürften sowjetische Kriegsgefangene gewesen sein.

347 In: Jäckel/Rohwer, Mord, S. 174 f.

348 Aus Oberschlesien, Białystok, Zichenau, Litzmannstadt und den „Uberresten der Ghettos im Generalgouvernement" (Hilberg, in: Jackel/Rohwer, Mord, S. 1761.). - Die Juden aus dem Regierungsbezirk Zichenau/Ciechanów wurden Ende 1942 in Auschwitz umgebracht, obwohl dies einen Transport quer durch Polen erforderlich machte. Es ist unbekannt, warum das näherliegende Treblinka nicht öfter ${ }_{n}$ benutzt ${ }^{*}$ wurde. Nach Treblinka ging nur am 10.11.1942 ein Transport aus Mlawa ab. Nach Auschwitz gingen u.a. folgende Transporte ab - z.T. in Anwesenheit des ostpreußischen Gauleiters Erich Koch:

6./7.11.1942

18.11.1942

18.11.1942

2./24.11.1942

bis zum 12.12 .1942

20.11./9.12./12.12.1942

im Dezember 1942

(nach Grynberg, Zydzi, passim) aus Zichenau/Ciechanów

aus Nowe Miasto

aus Mackeim/Maków Mazowiecki

aus Strzegowo

aus Mielau/Mlawa

aus Nowy Dwór Mazowiecki

aus Plōnen/Płońsk
5000

(Zahl unbekannt)

5500

1000

4000

5000

12000

ca. 32500

Grynberg beziffert die Ende 1942 nach Auschwitz und Treblinka aus dem Regierungsbezirk zur Emordung Verschleppten auf 36000 (Ebenda, S. 108). 
Parallel zu Auschwitz wurde in Lublin im Ortsteil Majdan Tatarski ein Lager errichtet, das zunāchst (vielleicht auch nur scheinbar) ebenfalls gleichzeitig als Kriegsgefangenen- und Konzentrationslager dienen sollte. Als erste jüdische Gruppe wurden hier etwa 1200 jüdische Soldaten der ehemaligen polnischen Armee untergebracht, die bei den Aufbauarbeiten helfen mußten. ${ }^{349}$ Anders als die vorgenannten Lager war das Konzentrationslager Lublin, für das sich nach dem Krieg der Name Majdanek einbürgerte, kein Vemichtungslager und auch kein spezielles Judenlager; der Hauptzweck lag in der Ausbeutung der Arbeitskraft, und so gelangten in der ersten Zeit auch vorwiegend arbeitsfähige Mānner ins Lager. Zwischen Dezember 1941 und März 1942 wurden 2000 Juden aus Lublin als Opfer von Razzien nach Majdanek gebracht. ${ }^{350}$ Die späteren Majdanek-Transporte des Jahres 1942 kamen aus der Slowakei sowie aus Böhmen und Māhren. Im Zuge der Auflōsung der Ghettos im Distrikt Lublin kamen in der zweiten Jahreshälfte 1942 die Juden aus Lublin, Piaski, Izbica, Belżyce, Bychawa und Lęczna, soweit es sich um arbeitsfāhige Mānner handelte, nach Majdanek. ${ }^{351}$ Ihre Gesamtzahl wird mit etwa 40000 angegeben ${ }^{352}$; nicht sofort umgebracht wurden davon ca. $14900^{353}$, etwa 17000 Menschen starben 1942 aus verschiedenen Gründen im Lager. Die nicht Arbeitsfāhigen waren zuvor zur Vernichtung nach Betżec gebracht worden. ${ }^{354} \mathrm{Im}$ August/September 1942 schickte man ca. 12000 im Ghetto Warschau selektierte arbeitsfähige Juden nach Majdanek. ${ }^{355}$ Im September wurden hier ca. 500 Frauen und Kinder aus Lublin nach einem kurzen Lageraufenthalt erschossen. ${ }^{356}$

In Lemberg waren im Oktober 1942 noch 10000 Juden $^{357}$, in Warschau etwa 70000 vor dem Winter übriggeblieben. ${ }^{358}$ Bei der Sitzung der Regierung des Generalgouvernements vom 24. August 1942 hörte sich das im Referat des Hauptabteilungspräsidenten Karl Naumann so an: „Die Versorgung der bisher mit 1,5 Millionen Juden angenommenen Bevölkerungsmenge fällt weg, und zwar bis zu einer angenommenen Menge von 300000 Juden, die noch im deutschen Interesse als Handwerker oder sonstwie arbeiten. ... Die anderen Juden, insgesamt 1,2 Millionen, werden nicht mehr mit Lebensmitteln versorgt." 359

\section{Die „Zweitghettoisierung“}

Der Winter 1942/43 brachte mit der Schlacht von Stalingrad den Beginn der deutschen Niederlagen an der Ostfront. In Polen bot sich nach den „Evakuierungen“ des Jahres 1942 ein grauenvolles Bild. Die großen Ghettos waren entvölkert und zusammengeschrumpft, die kleinen aufgelöst worden - zum Teil waren Ałbeitslager an ihre

349 Vgl. Józef Marszalek, Majdanek, Reinbek 1982, S. 67.

350 Vgl. ebenda, S. 74; nach ebenda, S. 136: 3000 bis April.

351 Vgl. Berenstein/Rutkowski, Zydzi, S. 12 f.

352 Vgl. Marszalek, Majdanek, S. 75; Berenstein/Rutkowski, Żydzi, S. 14: 36500.

353 Vgl. ebenda.

354 Vgl. ebenda, S. 11.

355 Vgl. ebenda, S. 12.

356 Vgl. Marszalek, Majdanek, S. 137.

357 V l. Hanns von Krannhals, Die Judenvemichtung in Polen und die Wehrmacht, in: Wehrwissenschaftliche Rundschau 15 (1965), S. 577.

358 Vgl. Stroop-Bericht, Nbg. Dok. 1061-PS (s. Anm. 382).

359 Diensttagebuch, S. 549. 
Stelle getreten. Von den freigewordenen Immobilien ergriffen nicht-jüdische Polen Besitz.

Auf einer Konferenz (20.-22. September 1942), auf der es zu einem Streit zwischen dem Rüstungsminister Speer und Himmier um die Organisation der Rüstungsindustrie gekommen war, hatte sich Hitler mit Fritz Sauckels Antrag einverstanden erklär, vorübergehend qualifizierte jüdische Arbeiter im Generalgouvernement weiterzubeschäftigen. Himmler, dessen SS- und Polizeiorganen inzwischen die Gesamtkompetenz in Judenangelegenheiten übertragen worden war, befahl daraufhin am 9. Oktober 1942, alle für Armeebedürfnisse arbeitenden Juden in besonderen Arbeitslagern zusammenzusperren. 360 Den Zwecken dieser „Reorganisation“ diente auch die sog. Zweitghettoisierung. Der Staatssekretār der Regierung des Generalgouvemements, SS-Obergruppenführer Friedrich-Wilhelm Krüger, verfügte die Einrichtung von in der polnischen Literatur so genannten „Sekundärghettos “ (getta wtórne). Am 28. Oktober 1942 unterzeichnete Krüger die „Polizeiverordnung über die Bildung von Judenwohnbezirken in den Distrikten Warschau und Lublin ${ }^{\text {“361; }}$; eine weitere Verordnung vom 10. November 1942 nannte zusätzliche Orte in den übrigen Distrikten Krakau, Radom und Galizien. ${ }^{362}$ Von den über 650 Orten, in denen Anfang 1942 noch Juden in Polen gelebt hatten, waren 54 übriggeblieben. ${ }^{363}$ Dabei handelte es sich nicht um "neue Ghettos". Es waren Teile der früheren Judenghettos, die - geographisch reduziert - quasi bestätigt wurden. Sie waren meist geteilt: in A-Ghettos lebten arbeitsfāhige, in B-Ghettos nicht arbeitsfāhige Juden. Damit waren die folgenden Mordmaßnahmen bereits erleichtert und absehbar.

Die wenigen verbliebenen Einwohner klammerten sich jedoch an die Hoffnung, die Deportationen seien eingestellt worden und die letzten Ghettos hätten nunmehr eine Art Bestandsgarantie erhalten. Illegal Lebende, Versteckte meldeten sich manchmal in diesen neuen Wohnbezirken, um der dauernden Anspannung der Illegalitāt (und den z.T. von den ${ }_{n}$ Wirten ${ }^{4}$ erpreßten enormen Kosten) zu entgehen. Die Deportationen wurden wegen des Winters vorübergehend unterbrochen; wegen Stalingrad wurde eine Transportsperre für Nichtrüstungsgüter erklärt. ${ }^{364}$ Der Terminus „Ghetto“ wurde nur noch selten verwendet; die Judenviertel hießen in der NS-Terminologie „Judenwohnbezirke“, was ihnen eine Art „Menschlichkeit“ verleihen und die Einwohner tāuschen sollte. In Wirklichkeit war die Konsolidierung nur eine kurze Etappe vor der endgültigen Restdeportation in die Vernichtungsanlagen.

Im Distrikt Warschau erhielten sechs Standorte den neuen Status: Warschau, Kaluszyn, Siedlce, Sobolew, Rembertów. 365 Im November 1942 wurden einige Arbeitslager im Warschauer Umkreis aufgelöst und ihre Arbeiter in die Wohnbezirke umgesiedelt. Nach Warschau kamen Juden aus Lagern in Karczew, Kuflów und Klimon-

360 Eisenbach, Polityka, S. 362 f. - Am 18.9.1942 hatte der Wehrkreisbefehlshaber im Generalgouvemement, General von Gienanth, gemeldet, daß die sofortige Entfernung der Juden die Reduzierung des deutschen militärischen Potentials zur Folge haben würde; es werde so unmöglich, die laufenden Anforderungen fristgemä zu erfüllen (abgedr. in: Arad/Gutman/Margaliot, Documents, S. 288 , Dok. 131). Himmlers Rundbrief an die SS-Führer in den Distrikten vgl. ebenda, S. 289 , Dok. 132; Nbg. Dok. NO-1611.

361 VOBIGG 94/1.11.1942, S. 665 f.

362 VOBIGG $98 / 14.11 .1942$, S. $683 \mathrm{ff}$.

363 An manchen Orten blieben Ghettos bestehen, ohne in der Verordnung genannt worden zu sein; dadurch erhōht sich die Gesamtzahl der Orte geringfügig.

364 Vgl. Madajczyk, Polityka, Bd. 2, S. 318.

$365 \mathrm{Vgl}$. Brustin-Berenstein, Deportacje, S. 96. 
tów366, nach Kałuszyn aus Chyżyny, nach Sobolew aus Wilga im Kreis Garwolin. ${ }^{367}$ Im Distrikt Krakau gab es Wohnbezirke in Krakau (10000), Bochnia ${ }^{368}$ (3500). Tarnów (12000), Rzeszów - inzwischen in Reichshof umbenannt - (3000), Przemyśl (5500) und (in der Verordnung nicht genannt) Dębica (2000). ${ }^{369} \mathrm{Im}$ Distrikt Lublin bestanden jüdische Wohnbezirke in Międzyrzec, Końskowola, Parczew, Zaklików, Luków, Wodawa, Piaski und Izbica ${ }^{370}$, im Distrikt Radom in Tschenstochau, (in der Verordnung nicht genannt) Petrikau/Piotrków, Radomsko, Ujezd, Sandomierz und Szydłowiec. ${ }^{371}$ Im Distrikt Galizien wurden 32 Wohnbezirke genehmigt. Im Bezirk Białystok lebten Juden noch in Bialystok, Jasinówka, Grodno, Sokólka, Krynki und Prużana. 372

Der Aufschub war nur kurz. Bereits im Januar 1943 begannen die Deportationen in die Vernichtungsstätten wieder mit großer Hārte. Das Bestreben, Juden in der Rüstungsindustrie zu halten, hielt nicht lange an. Ubergeordnete Überlegungen der SS und der politischen Führung kollidierten mit Erwägungen der "Leute vor Ort". Es setzte sich eine Art "Kompromiß" durch: „Freie ${ }^{4}$ Juden in Ghettos sollte es nicht mehr geben, dafür sollten erneut Arbeitslager jüdische $Z$ wangsarbeit, solange sie nōtig sein sollte, organisieren helfen. ${ }^{373}$ Auch der stāndige Transfer von Menschen hatte nicht aufgehört, da ja laufend Einsiedlungen in die neuen "Wohnbezirke" stattfanden. In diesem Zusammenhang wollte die SS zum 31. Dezember 1942 einen Uberblick über den Stand der jüdischen Bewohner der polnischen Gebiete gewinnen. Der Inspektor für Statistik beim Reichsführer SS Richard Korherr legte am 19. April 1943 eine Dokumentation zur "Endlösung der Judenfrage in Europa“ vor, aus der sich ergab, daß nach SS-Auffassung Ende 1942 im Generalgouvernement noch 297914 Juden lebten ${ }^{374}$, in den eingegliederten Gebieten weitere 233210.375

366 Vgl. ebends, S. 97.

367 Vil. ebenda.

368 Die Wirksamkeit der deutschen $Z$ Weitghettoisierung und der damit verbundenen Hoffnungszeugung erschließt sich daraus, daß die Einwohnerzahl des Ghettos Bochnia zwischen Januar und April 1943 (trotz einer hohen Sterberate und minimaler natürlicher Vermehrung) von 3500 auf 4200 anwuchs (vgl. Podhorizer-Sandel, O zagladzie, S. 99; Chrobaczyński/Golębiowski, Getto, S. 54). Der zunehmende Druck auf Nicht-Juden, die Juden versteckten, und die scheinbare Konsolidierung bewogen manch einen, sich im Ghetto zu melden.

369 Vgl. Podhorizer-Sandel, O zagladzie, S. 98.

370 Vil. VOBIGG 94/1.11.1942, S. 665.

371 Vgl. Ruthowski, Martyrologin, S. 117.

372 VOBIGG 98/14.11.1942, S. 684: Lemberg, Bóbrles, Jaryczów Nowy, Gródek, Rudki, Jaworów, Zlocz6w, Przemyslany, Brody, Rawa Ruske, Lubeczbw, Busko, Sokal, Brzeżany, Bukaczowce, Podhajce, Rohatyń, Tamopol, Skalat, Trembowia, Zborów, Zbaraz, Czortków, Buczacz, Borszczów, Kopyczyńce, Thuste, Stanislau, Stryj, Drohobycz, Borystaw, Sambor. - Vgl. Datner, Eksterminacja, S. 11.

373 Am 21.9.1942 wurde auf der Hauptabteilungsleitersitzung in Krakau die allmähliche Ersetzung von Juden in Rüstungsbetrieben durch Polen besprochen (Diensttagebuch, S. 564). Der Warschauer Gouverneur Fischer konstatierte im Monatsbericht vom 15.10.1942, der Abgang von 100000 jüdischen Arbeitskräften bedeute große wirtschaftliche Verluste (AZIH, nach Eisenbach, Przesiedlenia, S. 308).

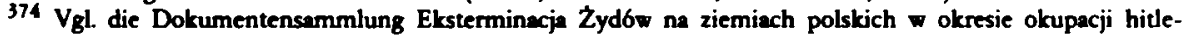
rowskiej, Warszawa 1957, S. 321 f.; Eisenbach, Polityka, S. 443. - Der Korherr-Bericht ist als Dokument Nr. NO-5194 bei den Nümberger Prozelakten. Abgedruckt wurde er u^ in: Serge Klarsfeld (Hrsg.), The Holocaust and the Neo-Nazi Mythomania, New York 1978, S. 163-203; hierin auch der Beitrag von George Wellers, The Number of Victims of the "Final Solution' and the Korherr Report, S. 139-162; deutsch: Die Zahl der Opfer der "Endlösung" und der Korherr-Bericht, in: Aus Politik und Zeitgeschichte, B 30/1978, 5-22-39. Vgl. auch den Abdruck in: BZIH 49 (1964), S. 74-84.

375 Hilberg (Vernichtung, S. 371) ist der Ansicht, die Korherr-Angaben für Warschau seien wegen der großen Zahl "Illegaler" zu niedrig, diejenigen für den Distrikt Galizien zu hoch - die dortigen Erschießungen 
Anfang 1943 nahmen die Vernichtungslager wieder ihren „Betrieb“ auf. Aus Warschau wurden zwischen dem 18. und dem 22. Januar 1943 ca. 6000 Juden nach Treblinka zur Ermordung deportiert, im gleichen Monat starben in dieser Stadt etwa 1300 Juden eines „natürlichen ${ }^{4}$ Todes, weitere 1171 wurden erschossen: Erstmals hatte die jüdische Kampforganisation den Deportationen bewaffneten Widerstand entgegengesetzt. 376 Die Wiederaufnahme der Warschauer Deportationen ging auf eine Anweisung Himmlers zurück, der im Januar 1943 die Stadt besucht hatte und die ihm mitgeteilte Zahl von $\mathbf{4 0 0 0 0}$ noch lebenden Juden (unter Einberechnung von nicht offiziell Gemeldeten dürfte der Wert eher bei 70000 gelegen haben) für zu hoch erklārt hatte. ${ }^{377}$

Die Liquidierung der anderen, gerade erst bestātigten Wohnbezirke setzte gleichfalls wieder ein. Bevor dies geschah, widmete man sich aber dem Bezirk Bialystok, der als Teil Ostpreußens nicht unter die Verordnungen Krügers fiel. In der zweiten Januarhālfte wurden die kleinen Ghettos im Bezirk Bialystok liquidiert. Als erste aufgelöst wurden die Ghettos Sokótka, Krynki, Jasionówka, und Prużana. Zwischen dem 5. und dem 12. Februar 1943 fand die erste "Aktion" in Bialystok statt, bei der etwa 10000 Personen nach Auschwitz und Treblinka deportiert, weitere 1000 an Ort und Stelle erschossen wurden. ${ }^{378}$ Gleich anschließend, vom 13. bis zum 16. Februar 1943, wurden weitere 4000 Juden aus Grodno deportiert ${ }^{379}$ Ebensolche „Aktionen " gab es Anfang des Jahres auch in Galizien. Aus Stanislau besitzen wir einen Bericht über die endgültige Liquidierung des Ghettos am 23. Februar 1943.380 Wie an manchen anderen Orten verblieben im Stadtgebiet kleinere Arbeitslager, deren Insassen nun jedoch auch die scheinbare, beschränkte "Freiheit“ der Ghettos nicht mehr genossen.

Die Reduzierung der gesamten jüdischen Bevölkerung Polens auf „Restbestände“ in Arbeitslagem kann auf die Himmler-Anweisung im Januar zurückgeführt werden. Mit ihr, mit dem Befehl, auch die letzten Relikte einer beschränkten Eigenverwaltung zu beseitigen, erlosch auch der schwache Hoffnungsschimmer, der von der ${ }_{n}$ Zweitghettoisierung ${ }^{\star}$ ausgegangen war, begann das letzte Kapitel des polnischen Judentums: Systematisch wurden nun die ,Wohnbezirke“ liquidiert und ihre Bewohner in die großen Vernichtungsanlagen abtransportiert.

\section{Die Liquidierung der Ghettos}

Im Laufe des Jahres 1943 wurden mit Ausnahme von Lódź/Litzmannstadt alle verbliebenen jüdischen "Wohnbezirke" ,ausgesiedelt" - d.h. die Einwohner wurden in ihrer Mehrheit in Vernichtungslager verbracht, zu einem geringeren Prozentsatz in Arbeitslager eingeliefert. Die Deportationen aus der Hauptstadt Warschau gingen in unregelmäßigen Abstānden weiter, wobei schrittweise das Ghettogebiet verkleinert

Ende 1942 seien nicht berücksichtigt worden. Es sei angemerkt, daß nach dem Korherr-Bericht am 31.12.1942 in Majdanek 7342 und in Auschwitz 1412 Juden gemeldet" waren.

376 Vgl. Berenstein/Rutkowski, Liczba, S. 82.

377 Vgl. Hilberg, Vernichtung, S. 356 - dort Hinweis auf Himmler an Krüger, Januar 1943, Nbg. Dok. NO1882.

378 Vgl. Datner, Eksteminacja, S. 27.

379 Vgl. ebenda.

380 Vgl. Feuerman, Pamiętnik, S. 87; Freundlich, Ermordung, S. 184. 
wurde. Im Mārz 1943 kamen etwa 30000 Juden nach Majdanek ${ }^{381}$, sonst war weiterhin Treblinka das Ziel der Todeszüge. Nachdem auch die letzten Hoffnungen zerstoben waren, daß arbeitsfāhigen Juden eine weitere Frist gewāhrt würde, entschloß sich die Führung der jüdischen Kampforganisation, obwohl Widerstand keinen wirklichen Erfolg haben konnte, zum bewaffneten Kampf. Erste Gefechte in der Zeit vom 18. bis zum 20. Januar 1943 führten zur vorübergehenden Unterbrechung der Transporte. Der am 19. April 1943 ausgebrochene sog. Ghetto-Aufstand, der seitens der nicht-jüdischen Polen nur halbherzig unterstützt wurde, konnte nichts am Schicksal der Juden Warschaus àndern. Er revidierte allein die äußere Einschātzung, da nunmehr das Bild der Juden, die sich wie Schafe widerstandslos zur Schlachtbank führen ließen, nicht mehr stimmte. Das kämpfende Ghetto wehrte sich bis zum 16. Mai 1943. Seine Gegner waren neben der SS Kräfte der Ordnungs- und Sicherheitspolizei, regulāre Wehrmacht (Pioniere), lettische und ukrainische Angehōrige der Kollaborations„Schutzmannschaften " aus dem Lager Trawniki und die polnische (blaue) Polizei. Nach den Berichten fielen auf deutscher Seite 14 Deutsche, ein Ukrainer aus dem Ausbildungsbataillon des Freiwilligen Wachdienstes und ein polnischer Polizist. ${ }^{382}$

Laut dem abschließenden Bericht des Warschauer SS-Brigadeführers Jürgen Stroop wurden 56065 Juden während der Kampfhandlungen bis zum Mai gefaßt bzw. getötet. Die "Gefaßten" wurden entweder sofort erschossen, in das Vernichtungslager Treblinka (6929 Menschen) oder in den Distrikt Lublin (Majdanek, Poniatowa, Trawniki) deportiert. Die Zahlen sind eher Schätzungen als solide Größen. ${ }^{383}$ Da ein Teil des „Kampfes“ der SS gegen die Warschauer Juden darin bestand, Häuser und die Kanalisation zu sprengen, wo sich die noch im Ghetto lebenden Juden verborgen hatten, ist letztlich nicht zu ermitteln gewesen, wie viele Juden unter den zusammenstürzenden Bauten den Tod gefunden haben. Die Zahl vom Januar 1943, die offiziell 40000 betragen hatte, ist ohne die Berücksichtigung der unbekannten Dunkelziffer ebenfalls nicht von großer Bedeutung. ${ }^{384}$ Man kann aber wohl von ca. 30000 Illegalen ausgehen. 385

$381 \mathrm{Vgl}$. Berenstein/Rutkowski, Zydzi, S. 16 - Am 16.2.1943 hatte Himmler befohlen, das Warschauer Ghetto niederzureißen und das Konzentrationslager zu verlegen, da es sonst keine Ruhe in Warschau geben werde (Himmler an Krüger, 16.2.1943, Nbg. Dok. NO-2494, abgedr. bei Arad/Gutman/Margaliot, Documents, S. 292, Dok. 134).

$382 \mathrm{Vgl}$. "Es gibt keinen jüdischen Wohnbezirk in Warschau mehr". Bericht des SS- und Polizeiführers im Distrikt Warschau, SS-Brigadeführer und Generalmajor der Polizei Jürgen Stroop, 16.5.1943, Nbg. Dok 1061-PS (Bd. 26, S. 626-693); GenLt Herbert Becker als Befehlshaber der Ordnungspolizei und SS-Brigadeführer Dr. Eberhard Schöngarth beziffern die Stärke der Polizeikräfte im Generalgouvernement am 21.11.1942 auf 12000 deutsche Polizisten, 12000 polnische Polizisten, 1500-1800 ukrainische Polizisten, 2000 deutsche und 3000 polnische Angehōrige der Sicherheitspolizei (nach Madajczyk ist damit die Kriminalpolizei gemeint) und 3000 Mann aus den Völkern Osteuropas rekrutierte Angehörige des „Sonderdienstes" (Diensttagebuch, S. 574). Ulber die Hilfe der Polen gehen die Meinungen auseinander. Während Czestaw Madajczyk die These vertritt, die Heimatamee habe gute strategische Gründe gehabt, dem Ghetto nicht zu helfen, vertritt Yisrael Gutman die gegenteilige Ansicht. Seiner Meinung nach habe der Heimatarmee-General Tadeusz Bór-Komorowski sogar in seinen Memoiren eine diesbezügliche Aktion frei erfunden, um das Bild im nachhinein zu schōnen. $V_{g}$. Yisrael Gutman, Polish and Jewish historiography on the question of Polish-Jewish relations during Wordd War II, in: Ch. Abramsky (Hrsg.), The Jews of Poland, Oxford 1986, S. 177-189; einen Aspekt der Diskussion bildet ab Polish-Jewish Relations during the Second World War: A Discussion, Polin 2 (1987), S. 337-358.

383 Vgl. Stroop-Bericht, Nbg. Dok. 1061-PS; Gutman (Jews, S. 395) nimmt an, daß sich nicht mehr als 40000 Juden während des Aufstands im Ghetto befanden.

$384 \mathrm{Vgl}$. Stroop-Bericht, S. 11.

385 Vgl. Berenstein/Rutkowski, Liczba, S. 81 
Stroop nahm an, daß sich nach dem Ende des Ghettokampfes noch bis zu $3000 \mathrm{Ju}$ den in verschiedenen Teilen $W$ arschaus versteckt hielten bzw. aus dem engeren Stadtgebiet geflohen waren. ${ }^{386}$ Rechnet man hinzu, was sich nach anderen Schätzungen an Juden ermitteln läßt, die mit falschen „arischen“ Papieren lebten oder die schon zuvor ein Dauerversteck gefunden hatten, es mögen $25000^{387}$ oder auch nur 15000 gewesen $\operatorname{sein}^{388}$, dann erkennt man, wie gering der Anteil derjenigen war, die sich aus der größten jüdischen Stadt Polens vor der unmittelbaren Verfolgung retten konnten. ${ }^{389}$

Mōglicherweise mit tatsāchlicher Austauschabsicht, vielleicht auch nur, um die Versteckten aufzuspüren, veranstalteten die Deutschen im Juni/Juli 1943 einen Lockruf an Illegale, sich zu melden: Im „Hotel Polski“ wurden fragwürdige, verfälschte Berechtigungsscheine zu einer Ausreise aus dem deutschen Machtbereich ausgegeben. Weil die Austauschaktion mit lateinamerikanischen Staaten, der Schweiz und Palāstina nur in wenigen Fällen gelang, wurden 400-600 Juden sofort im Warschauer Pawiak-Gefängnis erschossen, die restlichen (4-5000) ereilte der Tod nach einer langen Irrfahrt über Frankreich und Bergen-Belsen in Auschwitz. ${ }^{390}$ Etwa 170 Personen dürften gerettet worden sein. Für die übrigen gelang es anscheinend nicht, die Anerkennung der verfälschten Promessen durch die Zielstaaten zu erreichen. 391

Auf dem Gelānde des ehemaligen Warschauer Ghettos wurde am 19. Juli 1943 ein Arbeitslager eingerichtet, dessen Insassen die Aufgabe hatten, die noch vorhandene Bausubstanz abzutragen und zur erneuten Verwendung bei anderen deutschen Bauvorhaben nötigen Schutt bereitzustellen. Hier arbeiteten neben deutschen Kriminellen vorwiegend ausländische Juden - nur 70 polnische Juden werden in den Berichten genannt. ${ }^{392}$ In den folgenden Monaten wurden immer wieder einzelne Gruppen von Juden oder Einzelpersonen entdeckt und umgebracht, Einzelexekutionen wurden bis zum Ausbruch des Warschauer Aufstandes im August 1944 fortgesetzt.

Auch die anderen Ghettos wurden im Laufe des Jahres 1943 endgültig beseitigt. Białystoks etwa 45000 Juden deportierte man zwischen August und September nach Majdanek, Treblinka und Auschwitz.393 Am 18. November 1943 erfolgte ein letzter Transport aus dem Bialystoker Gefängnis. 394 Die jüdischen Wohnbezirke in Ost-

386 Vgl. ebenda, S. 82.

$387 \mathrm{Vgl}$. Krakowski, Avedot, S. 234.

$388 \mathrm{Vgl}$. Brustin-Berenstein, Deportacje, S. 100.

389 Zum Ghetto-Aufstand in Warschau gibt es zahlreiche Publikationen, vgl. u. Dan Kurman. The Bravest Battle. The Twenty-Eight Days of the Warsaw Ghetto Uprising, New York 1976 (dt: Der Aufstand, München 1979); Yismel Gutman, The Jews of Warsaw 1939-1942, Brighton 1982. - Uber die jüdische Kampforganisation, die Kämpfe im Januar und April/Mai 1943 und das weitere Schicksal eines Ghettokämplers im Versteck und im Warschauer Aufstand von 1944 vgl. Tuvia Borzykowski, Between Tumbling Walls, Lohame HaGetaot 1972.

$390 \mathrm{Vgl}$. Brustin-Berenstein, Deportacje, S. $99 \mathrm{f}$.

391 Vgl. dazu Abraham Shulman, The Case of Hotel Polski, New York 1982, S. 214 f; dazu auch den eine Rezension überschreitenden Beitrag von Teresa Prekerowa in: Dzieje Najnowsze 18 (1986), H. 3-4, S. 332-342.

392 Vgl. Berenstein/Rutkowski, Obóz koncentracyjny dla Żydów w Warszawie (1943-1944), in: BZIH 63 (1967), S. 4 ff.; Piotr Matusak, Obóz koncentracyjny dla Zydów w Warszawie, in: BZlH 2-3/86-87 (1973), S. 254.

393 Vgl. Krakowski, Avedot, S. 235; Datner, Eksterminacja, S. 12; Bogdan Chrzanowski, Eksterminacja ludności polskiej i żydowskiej na terenach pótnocnego Mazowsza i Bialostocczyzny w świetle alkt delegatury rądu RP na kraj, Stutthof. Zeszyty Muzeum 4 (1981), S. 134; Anna Kubiak, Dzieciobójstwo w getcie lódzkim, in: BZIH 2 (1952), S. 269; Auerbach, in: Donat, Treblinka, S. 53.

$394 \mathrm{Vgl}$. Datner, Eksterminacja, S. 12. 
Oberschlesien wurden im Juli/August 1943 aufgelöst. Arbeitsfāhige kamen in Arbeitslager im Generalgouvernement und im Reich, die meisten jedoch nach Auschwitz, über 1000 wurden schon wāhrend der Liquidierung erschossen. 395

Bis auf einige wenige Handwerker wurden die restlichen 3-400 Juden Stanislaus, die in einer ${ }_{n}$ Rohstofferfassungsstelle ${ }^{\mu}$ arbeiteten, im Juni 1943 zur Ermordung fortgebracht ${ }^{396}$ In Lemberg begann die Räumung der Ghettos mit einer „Aktion“ im Mai 1943, um im Juni 1943 mit der vollstāndigen Liquidierung abgeschlossen zu werden. Einige Lemberger Juden wehrten sich gegen den Abtransport. SS- und Polizeiführer Friedrich Katzmann, der die „Aktion“ leitete, erwähnte in seinem Bericht Waffen, die die Juden italienischen Soldaten abgekauft hatten. Anstelle der erwarteten ngemeldeten $^{\star} 12000$ Juden wurden in Lemberg allein etwa 20000 von der Deportation erfaßt. Etwa 3000 Leichen fand man - Opfer von Selbstmorden in letzter Stunde. Ca. 7000 Personen wurden in ein Arbeitslager an der Janowska-Straße gebracht, wo aber ein Teil dieser Menschen sofort erschossen wurde. 397

Das Restghetto der Hauptstadt Krakau hatte man bereits am 13. und 14. Mārz 1943 gerāumt. Aus dem Ghetto A für die Arbeitsfähigen wurden die Einwohner in das Lager Plaszów gebracht, das damit zu einem der größten Arbeitslager wurde. ${ }^{398}$ Das Ghetto B wurde mit Lastwagen nach Auschwitz „evakuiert“. Etwa 2000 Personen wurden an Ort und Stelle erschossen. ${ }^{399}$ Auch die Mitglieder des Krakauer Judenrates, die meisten Angehōrigen des jüdischen Ordnungsdienstes und jüdische Spitzel mit ihren Familien (insgesamt ca. 50 Familien), die zunāchst im Ghetto hatten bleiben dürfen, wurden - wie Bieberstein schreibt - aufgrund der Rivalitāt zwischen Gestapo und SS Ende Mārz nach Płaszów verbracht. Die letzten Ordnungsdienst-Angehörigen wurden am 15. Dezember 1943 erschossen. 400

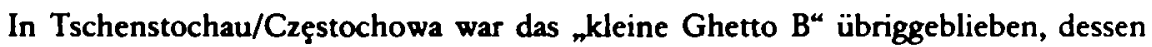
nicht arbeitsfähige Insassen Ende Juni 1943 erschossen bzw. nach Auschwitz gebracht wurden. Bestehen blieb ein großes Arbeitslager der Firma Hasag, in dem ebenfalls stāndig , selektiert" wurde; um den 20. Juli 1943 etwa wurden allein 400 Personen in diesem Lager der Apparatebau-Firma umgebracht. 401 Nach Plaszów ins Arbeitslager kamen auch die Juden aus Tarnów (2. September 1943) - und nach Zwischenaufenthalten in Szebnie bzw. Stalowa Wola die Arbeitsfähigen aus Przemyśl und Rzeszów. ${ }^{402}$ Aus Bochnia brachte man am 2. und 3. September 19431560 Arbeitsfähige (vor allem Schneider) in das Arbeitslager Szebnie, die übrigen (etwa 2300) nach Auschwitz. ${ }^{403}$ Die als nicht-arbeitsfähig ${ }_{n}$ Selektierten ${ }^{4}$ endeten in den Gaskammem von Birkenau. Diese Aufzählung ließe sich weiter fortsetzen - hier mag als Resümee

\footnotetext{
395 Vgl. Andrzej Szefer (Hrsg.). Miejsca straceń ludności cywilnej województwa katowickiego (1939-1945), Katowice 1969. S. 239 f.

396 Vgl. Feuerman, Pamiçtnik, S. 89; Freundlich, Emordung, S. 186.

397 Vgl. Friedman, Zaglada, S. 29.

398 Vgl. Borwicz, W trzecią rocznice, S. 38

399 Vgl. Podhorizer-Sandel, O zagladzie, S. 99 f. - Am Rande sei daraul hingewiesen, daß die beiden Ghettoteile am 13.3.1943 voneinander getrennt wurden. Die Polizei gestattete nur den Ubergang von A nach B nicht in umgekehrter Richtung. Die Zahl der am Leben Gelassenen sollte möglichst klein gehalten werden (vgl. Bieberstein, Zagtada, S. 82 f.)

$400 \mathrm{~V}$ l. ebenda, S. 91-94.

401 V l. Pietrzykowski, W obliczu, S. 76; Pietrzykowski, Hitlerowcy w Częstochowie, S. $191 \mathrm{ff}$.

402 Vgl. Podhorizer-Sandel, O zagladzie, S. 100.

403 Vgl. Chrobaczyński/Golębiowski, Getto, S. 54.
} 
genügen, daß Ende 1943 bis auf Lódź keine polnische Stadt mehr über jüdische Whnbezirke verfügte.

Entgegen verbreiteten Vorstellungen verlief diese letzte Phase nicht überall nglatt". Schon vor dem Warschauer Ghetto-Aufstand schien eine Art Bann gebrochen zu sein: die Juden, die keine Aussicht mehr auf irgendeine Art Rettung haben durften, organisierten Revolten, bewaffnete Fluchtversuche und andere Widerstandsakte, um nicht ganz wehrlos unterzugehen. Es gelang ihnen zumindest, einige ihrer Peiniger mitzunehmen - wirklich retten konnten sich nur sehr wenige.

In Nowogródek war es angeblich bereits im September 1941 zur ersten organisierten Gegenwehr gekommen, auch wenn die faktische Lage mehr als fraglich ist $404 \mathrm{Im}$ sog. Ostland, außerhalb des eigentlichen geographischen Berichtraums dieses Beitrags, gab es die ersten Widerstandshandlungen bei der Liquidierung der Ghettos in Kleck am 21. Juli 1942 (25 von 400 Geflohenen überlebten) und in Nieśwież am 22. Juli 1942. ${ }^{405}$ Gegen die Liquidierungen wehrten sich die Judenrat-Vorsitzenden in Marcinkańce im Bezirk Bialystok und in Lachwa (Polesien) Ende 1942.406 In den Ghettos bestanden zahlreiche kleine und größere Widerstandsgruppen. Zum Teil gliederten sie sich nach den jüdischen Vorkriegsparteien, zum Teil vereinigten sie auch ihre Kräfte, z.B. zur linken überparteilichen Kampforganisation des Antifaschistischen Blocks (Bojowa Organizacja Bloku Antyfaszystowskiego) im April 1942 in Warschau 407 oder zur ŻOB (Żydowska Organizacja Bojowa - Jüdische Kampforganisation) unter zionistischer Führung, aber auch unter Beteiligung von Bundisten, die Ende 1942 endgültig Gestalt angenommen hatte. ${ }^{408}$ In Warschau gab es daneben auch den eher rechtsgerichteten jüdischen Militärverband (Żydowski Związek Wojskowy). Erst im Ghettoaufstand selber gelang eine Koordination der Widerstandsbemühungen. ${ }^{409}$ Die Ghettoaufstānde, aber auch Einzelaktionen, Exekutionen von Zuträgern, deutschen Beamten und Mitgliedern polnischer und anderer Kollaborationsorgane, gingen auf das Konto des Widerstands. Man hielt Verbindungen zum polnischen Untergrund, wobei der kommunistische wegen des andauemden Antisemitismus nicht-linker polnischer Einheiten eher den Kontakt mit den Ghettos aufrechterhielt $\mathbf{4 1 0}$

Am 23. Dezember 1942 griffen in Krakau jüdische Kämpfer und Kommunisten ein deutsches Café an. In Mińsk Mazowiecki leisteten die letzten 400 Juden am 10. Januar 1943 gegen ihre Liquidierung Widerstand. Sie wurden von den Deutschen im

404 Vgl. Ruta Sakowska, Dwa etapy, Wroctaw 1986, S. 37 f. Zum jüdischen Widerstand vgl. u.a. Yitzhak Arad, Jewish Armed Resistance in Eastem Europe. Its Characteristics and Problems, in: Gutman/Rothkirchen, Catastrophe, S. 490-517. Die bisher umfassendste Darstellung bieten Reuben Ainsztein, Jewish Resistance in Nazi-Occupied Eastern Europe, London 1974, und Shmuel Krakowski, The War of the Doomed. Jewish Resistance in Poland 1942-1944, New York 1984, der neben den großen Ghettos bewaffnete Einheiten in Ghettos wie Wlodawa, Tomaszów Lubelski, Sandomierz, Tarnów und Pilica und in Lagern wie Mińsk Mazowiecki, Pionki, Kraszyna und Trawniki nennt. Zahlreiche Revolten gab es in Wolhynien und Polesien.

405 Vgl. Datner, Zbrojne, S. $17 \mathrm{f}$.

406 Vgl ebenda, S. 15

407 Vgl. Sakowska, Etapy, S. 40

408 Zur Organisation der Bundisten im besetzten Warschau vgl. Goldstein, Sterne, passim.

$409 \mathrm{Vgl}$. Sakowska, Etapy, S. 60.

410 Vgl. Bieberstein, Zagłada, S. 232-250 (zu Krakau und Płaszów); Sakowska, Etapy, S. 52 ff.; Stanislaw Poradowski, Zydowscy gwardziści w pierwszych oddzialach partyzanckich GL (Gwardii Ludowej) na Rzeszowszczyźnie, in: BZIH 1-2/121-122 (1982), S. 15-26; Szymon Datner, Szkice do studiów nad dziejami żydowskiego ruchu partyzanckiego w okręgu bialostockim (1941-1944), in: BZIH 73 (1970), S. 3-46. 
Schulgebäude, aus dem heraus sie mit Ziegeln etc. warfen, lebendig verbrannt. ${ }^{111} \mathrm{Am}$ 2. August 1943 kam es zu einer Revolte im Lager Treblinka. ${ }^{412}$ Von den etwa 1000 Funktionshäftlingen brachen 200 aus, etwa 60 überlebten. ${ }^{413}$ Am 16. Juli 1943 erhoben sich die letzten Einwohner des Ghettos von Bialystok: Etwa 200 Juden leisteten 3000 deutschen, ukrainischen und weißrussischen SS-Leuten erbitterten Widerstand. 414

Am 14. Oktober 1943 gelang es Juden in Sobibór, die SS-Wachmannschaft zu überwältigen, die Drähte zu durchschneiden und etwa 300 Lagerinsassen die Flucht zu ermöglichen. ${ }^{415}$ Inzwischen hatte sich die polnische Untergrundbewegung konsolidiert, und wenn auch die Aufnahme von Juden in die polnischen bürgerlichen Untergrundeinheiten nur selten möglich war, so dürfte doch eine Anzahl dieser Flüchtlinge mit Hilfe der Partisanen ihr Leben gerettet haben. Das nur dünn besiedelte Lubliner Gebiet schien der deutschen Führung so gefährlich, daß die Regierung des Generalgouvernements mit SS und SD am 19. Oktober 1943 eine „Sicherheitssitzung" abhielt, auf der Frank äußerte, die Judenlager seien eine, akute Gefahr für die Sicherheit der Deutschen “416 Die Folge dieser Feststellung war eine Aktion, die die Deutschen mit der Bezeichnung „Erntefest" versahen. Zwischen dem 3. und dem 7. November 1943 wurden in großer Eile die meisten Juden in den Lubliner Lagern ermordet: 10000 in Trawniki, etwa $20000^{417}$ oder 18000 in Majdanek.418 Hinzu kamen die Lager in Poniatowa und Budzyń. Die Angaben für die Endziffer des „Erntefestes ${ }^{4}$ schwankten zwischen $42000^{419}$ und 45000.420 In Majdanek lebten am 4. November 1943 nur noch 612 Juden ${ }^{421}$, etwa 300 Juden waren auf dem Lubliner Schloß eingesperrt ${ }^{422}$, einige andere waren in kleinen Lagern am Flugplatz etc. Diese große Mordaktion markierte das grausige Ende dessen, was als Judenreservat" begonnen hatte. Wolfgang Scheffler beziffert die Gesamtzahl jüdischer Opfer des Lagers Majdanek auf 50-60000423, von denen für die Zwecke dieses Beitrags die Angehörigen der Transporte aus den tschechoslowakischen Gebieten abzuziehen sind.

Vereinzelt kam es auch später noch zu Widerstandshandlungen: In der Nacht vom 19. auf den 20 . November 1943 gelang durch die Uberwätigung von Wachposten ei-

411 Vgl. Datner, Zbrojne, S. 20.

412 Vgl. Marczewska/Ważniewski, Treblinka, S. 134.

$413 \mathrm{Vgl}$. Ausbruchsbericht Stanislaw Kon, in: Donat, Treblinka, S. 224-230. Die Schätzungen der SS-Leute im Düsseldorfer Treblinka-ProzeB beliefen sich auf 500 Geflüchtete (nach Ainsztein, Resistance, S. 737 ).

414 Vgl. Datner, Walka, S. 40; Datner, Zbrojne, S. 21.

415 Vgl. Berenstein/Rutkowski, Žydzi, S. 40; Edward Dziadosz/ Józef Marszałek, Wiçzienia i obozy w dystrykcie lubelskim w latach 1939-1944, in : Zeszyty Majdanka 3 (1969), S. 105; Novitch, Sobibór, S. 33; Richard Rashke (Escape from Sobibor, Boston 1982) hat das Geschehen roman- und reportagenhaft dargestellt. Nach Datner (Zbrojne, S. 21) überlebten etwa 30 Personen. Nach Ainsztein (Resistance, S. 764) starben 150 polnische Juden durch Kugeln und Minen beim Ausbruch, von den 300 Entkommenen seien etwa 100 zwischen dem 14. und dem 21. Oktober gefaßt bzw. getötet worden. Richtig schreibt er: “... enough survived to defeat Himmler's efforts to conceal the extent and nature of the crimes committed in the death camps". (Ebenda, S. 766).

416 Diensttagebuch, S. 742.

417 Vgl. Chrzanowski, Eksterminacja, S. 135

$418 \mathrm{Vgl}$. Berenstein/Rutkowski, Żydzi, S. 40.

419 Vgl. ebenda, S. 45.

$420 V_{g}$ l. Berenstein, Martyrologia, S. 45

421 Vgl. Berenstein/Rutkowski, Zydzi, S. 45

422 Vgl. Moszyński/Policha, Lublin, S. 78.

423 In: Jäckel/Rohwer, Mord, S. 148. 
ner Häftlingsgruppe die Flucht aus dem Lemberger Lager an der Janowska-Straße. Am gleichen Tag revoltierten die Juden des Lemberger Kremierungskommandos. ${ }^{424}$ Am 7. Oktober 1944 erhoben sich die Häftlinge des "Sonderkommandos“ in Auschwitz-Birkenau. Auch ihre Aufgabe war die Bedienung des Krematoriums gewesen. Alle fanden den Tod. Die mit dem Abriß der Vernichtungsstātte Kulmhof/Chelmno beschäftigten 47 jüdischen Häftlinge, denen die Erschießung sicher war, nahmen in der Nacht vom 17. auf den 18. Januar 1945 einen aussichtslos scheinenden Kampf auf. Immerhin erlebten dadurch zwei von ihnen das Ende des Krieges. ${ }^{425}$ Die Mordstätten selber konnten nunmehr, nachdem der größte Teil der grauenhaften „Arbeit" geleistet worden war, vorerst geschlossen werden. Die Deutschen ließen es sich angelegen sein, die Spuren der Vernichtungslager möglichst gut zu verwischen - was allerdings nur unvollkommen gelang. Die Vertuschungsaktionen des Jahres 1943 dokumentieren die Scheu, die offenbar die Verantwortlichen vor einer Offenlegung ihrer Aktionen empfanden - für diejenigen, die Wert darauf legen, ein Unrechtsbewußtsein zu dokumentieren, hier wird es deutlich. In Belzec wurde bereits zu Beginn des Jahres ein Wäldchen an der zerstörten Vernichtungsstätte gepflanzt, in Lemberg machte man sich daran, die eingegrabenen, nicht verbrannten Leichen zu exhumieren und nachträglich zu verbrennen. ${ }^{426}$ Aus Treblinka brachte man die letzten Häftlinge Anfang November 1943 nach Sobibór - das Lager wurde abgerissen, das Gelände umgepflügt, und man siedelte Ukrainer an. ${ }^{427}$ Bereits seit Frühjahr 1943 wurden die früher angelegten Massengräber in der Umgebung aufgerissen und die Leichen kremiert. ${ }^{428}$ Auch in Sobibór wollte man die Reste des Lagers unter einem frisch angelegten Wäldchen verstekken. ${ }^{429}$ Es half nichts. Ende 1943 waren die weitaus meisten polnischen Juden umgebracht worden, und die Spuren und Mitwisser der Verbrechen sind und waren so zahlreich, daß kein Zweifel an dem Verlauf und am annähernden Umfang der Mordaktionen bestehen kann.

Der Zensus des Generalgouvernements hatte für den 1. März 1943 noch 203679 Juden ausgewiesen ${ }^{40}$, dazu kamen die Juden des Ghettos Litzmannstadt (86000) und die noch nicht ,ausgesiedelten“ Juden in Białystok und Oberschlesien. Ende 1943 waren noch 83000 Juden im Litzmannstädter Ghetto - die Stadt war zum Ort mit der größten jüdischen Wohnbevölkerung geworden. ${ }^{431}$ Daneben gab es in Polen Juden

424 Vgl. Eisenbach, Polityka, S. 553.

$425 \mathrm{~V}_{\mathrm{B}}$ l. Datner, Zbrojne, S. $21 \mathrm{f}$. - Datner schreibt, es habe auch an anderen Orten Widerstandshandlungen gegeben, die bisher nicht erforscht seien.

426 Vgl. Leon Weliczker, Brygada śmienci (Sonderkommando 1005). Pamiętnik, Lódź 1946.

427 Vgl. Lukaszkiewicz, Obóz, S. 16.

$428 \mathrm{Vgl}$. Auerbach, in: Donat, Treblinke, S. 53.

429 Vgl. Dziadosz/Marszalek, Wiezienia, S. 105. - Es dürte der Eindruck der Entdeckung der Massengräber polnischer Offiziere in Katyń im Frühjahr 1943 gewesen sein, der zur Exhumierung und Einäscherung der Mordopfer geführt hatte. Angesichts der vorrückenden Roten Armee mag man vor einer Propagandakampagne mit umgekehrten Vorzeichen, die derjenigen geähnelt hätte, die Deutschland 1943 angestrengt hatte, Angst gehabt haben. In diesem Zusammenhang sei auch auf das Rundschreiben Martin Bormanns vom 11.7.1943 an die Reichsleiter, Gauleiter und Verbändeführer hingewiesen. Darin hieß es: „In der öffentlichen Behandlung der Judenfrage muß jede Erörterung einer zukünftigen Gesamtlösung unterbleiben. Es kann jedoch davon gesprochen werden, $d a \beta$ die Juden geschlossen zu zweckentsprechendem Arbeitseinsatz herangezogen werden“ (Nbg. Dok. NO-2710, abgedr. in Arad/Gutman/Margaliot, Documents, S. 343, Dok. Nr. 160).

$430 \mathrm{Vgl}$. Kopeć, Straty, S. 152.

431 Vgl. Dạbrowska, Zagłada, S. 144 
nur noch in Arbeitslagern und in Verstecken - alle anderen waren von den Deutschen und ihren Helfern ermordet worden. Vereinzelt waren noch Räumkommandos in den ehemaligen jüdischen Wohnbezirken an der Arbeit, die die Viertel entrümpeln und für eine Neubesiedlung vorbereiten sollten. Daneben gehōrte die Entdeckung versteckter Juden zu ihren Aufgaben. In Bochnia waren es zunāchst 250 Juden; bald wurde ihre Zahl auf 100 reduziert, im Januar 1944 lieferte man auch sie in das Arbeitslager Plaszów ein. 432

An dieser Stelle bōte es sich an, eine Ubbersicht über die Arbeitslager zu schaffen, in denen Juden für Wehmachts- und SS-Standorte (etwa in Pustków im Distrikt Krakau), für die Belange der deutschen Rüstung und der Privatwirtschaft Sklavenarbeit leisteten. Aber eine auch nur annāhernd vollstāndige Ubersicht über die Arbeitslager ist bisher kaum möglich. Nur für einige wenige gibt es eine halbwegs zuverlässige Quellenbasis und verwertbare Forschungsergebnisse. Die ins Auge springende Unstetigkeit der Lagerwelt (manche Arbeitsstellen bestanden nur wenige Monate lang) und die Fluktuation ihrer Belegschaften erschweren konkrete Angaben ungemein. Selbst wo es angenāherte Zahlenangaben gibt, wird kaum zwischen den Nationalitāten der Insassen differenziert - und wo in der zugänglichen Literatur die Angabe „Juden “ erscheint, ist nicht immer erkennbar, um Juden aus welchen Ursprungslāndern es sich handelte. Die 1979 erschienene, bisher umfassendste Zusammenstellung der Lager auf dem Gebiet des heutigen Polen (ohne die polnischen Ostgebiete, dafür mit den ehemaligen deutschen Ostgebieten), die auf der Basis von Archivalien eine optimale Erfassung versuchte, verdeutlicht vor allem die Schwierigkeiten, konkrete Angaben vorzustellen. ${ }^{433}$ Dennoch soll hier eine vorsichtige Schātzung auf der Basis dieses groBen Werkes versucht werden.

Wir wählen als Erhebungszeitraum den Sommer 1944. Zu dieser Zeit waren die polnischen Ostgebiete bereits befreit - wobei davon auszugehen ist, daß die dortigen früheren Arbeitslager entweder in das noch deutsch besetzte Gebiet evakuiert worden sind oder aber daß deren Insassen vor dem Einmarsch der Sowjets umgebracht wurden. Da bereits ein Teil der Arbeitslager in die Ostgebiete des Reiches verlegt worden war (genannt sei hier nur der Komplex Groß-Rosen), sind die in der polnischen Publikation genannten Zahlenangaben für diese Gebiete von Interesse und werden hier ausnahmsweise über die geographische Eingrenzung des Beitrags hinaus nachgewiesen. Im übrigen hatten im Sommer 1944 die Umsiedlungen in das hier nicht erfaßte Innere des Deutschen Reiches (Sachsenhausen, Ravensbrück, Bergen-Belsen etc.) noch nicht voll eingesetzt.

Eine überschlāgige Schātzung (bei der versucht worden ist, die unklaren Nationalitāten- und Belegungszahlen zu bereinigen) ergibt folgendes Bild:

432 Vgl. Chrobaczyński/Golębiowski, Gerto, S. 54

433 Obozy hitlerowskie na ziemiach polskich 1939-1945. Informator encykiopedyczny, Warszawa 1979. Vgl. auch Ishaia Trunk, Idishe arbet-lagem in ,Varteland', in: Bleter far geshichte 1 (1948), H. 2, S. 33-45. - In einem Bericht an den Verband Polnischer Patrioten in der UdSSR schātzten die Leiter des Referats für jüdische Angelegenheiten beim konspirativen kommunistenfreundlichen Landesnationalrat (Krajowa Rada Narodowa) Dr. Adolf Berman und Pola Elster am 15. Juni 1944 die Zahl der Juden in Arbeitslagem auf dem Gebiet des Generalgouvernements auf etwa 100000 , die vor allem in den Räumen Radom/Kielce und Krakau gelegen seien (nach B. Mark, Do dziejów odrodzenia osiedla zydowskiego w Polsce po Il wojnie swiatowej, in: BZIH 51 (1964), S. 7). 
Distrikt Lublin

(Zahl wegen bereits fortgeschrittener

Befreiung fraglich)

Bezirk Bialystok

Reg.Bez. Zichenau

Distrikt Warschau

Distrikt Krakau

Distrikt Radom

Eingegliederte Gebiete (o. Auschwitz)

Ostgebiete des Reiches

20000

Ghetto Litzmannstadt (30.7.1944)

68000

Auschwitz (Stammlager, Birkenau und Arbeitslager)

Von diesen Personen wurden die meisten Litzmannstādter Juden im August 1944 vergast, bis Oktober 1944 erfolgten in den Arbeitslagern „Selektionen “ der arbeitenden Juden, wobei die als arbeitsunfähig Ausgesonderten ebenfalls umgebracht wurden. Die sich danach ergebende Restzahl beschreibt die Quantitāt der Juden, über die die letzten Todeswellen hinweggingen: Viele kamen auf den Evakuierungs-Todesmärschen um oder wurden bei der Annāherung der Roten Armee exekutiert.

Die Vernichtungslager hatten Ende 1943 mit einer Ausnahme ihre Tätigkeit eingestellt. Die Ermordung der einheimischen Juden in Polen war nahezu abgeschlossen. Zentralisiert war die Judenermordung nunmehr im Komplex Auschwitz-Birkenau, dem vor allem Lódźer, oberschlesische und nicht-polnische Juden zur Vernichtung zugeführt wurden. Um Auschwitz herum hatten sich große deutsche Konzerne mit ihren Betrieben etabliert, es entstand eine Art neuen Industriegebiets, dessen Sklavenarbeiter aus allen Teilen Europas in diese „Metropole“ herbeigekarrt wurden. In die Gaskammern von Auschwitz-Birkenau gelangten neben den Opfern der neuerlichen Deportationen (z.B. aus der Slowakei und aus Ungarn) vor allem die Opfer der „Selektionen " in den Arbeitslagern, d.h. diejenigen, die sich dort als nicht mehr arbeitsfähig erwiesen hatten. Nur für eine kurze Zeit wurde Chelmno 1944 noch einmal reaktiviert. Einzeln entdeckte Versteckte wurden 1944 meist an Ort und Stelle erschossen. Das letzte Kapitel der deutschen Judenvernichtung in Polen begann.

\section{Die Rāumung Polens}

Die Jahre 1942/43 markieren den Höhepunkt der Vernichtung der polnischen Juden. Dies bedeutet nicht, daß danach die Mordaktionen in Polen eingestellt worden wären, sie betrafen jedoch nun überwiegend aus dem übrigen Europa stammende Juden.

Auf polnischem Gebiet existierte 1944 nur noch ein Ghetto in Lódź/Litzmannstadt (andere Ghettos bestanden unter anderem weiterhin in Theresienstadt und im rumänisch besetzten Transnistrien), seine Liquidierung steht mit der sich wandelnden Kriegslage im Zusammenhang. Wāhrend es zuvor Plāne gegeben hatte, die Lódźer Ju- 
den ins Generalgouvernement zu bringen oder aber - angesichts der sich nāhernden Ostfront - die Rüstungsproduktion des Generalgouvernements nach Lódź zu verlagern, schritt man nach Beginn der Invasion in der Normandie zur Liquidierung auch dieses letzten jüdischen Wohnbezirks.

Erneut versuchte man, die eigentlichen Ziele der Aussiedlung der Juden zu verschleiem. Handelte es sich 1942/43 um eine angebliche Ansiedlung im Osten, so wurde nun eine Deportation „zur Arbeit" vorgetäuscht. Am 15. Juni 1944 forderte man den „Ätesten “ Rumkowski auf, von nun an jede Woche 3000 Personen bereitzustellen. ${ }^{44}$ Rumkowskis Proklamation Nr. 416 vom 16. Juni rief zur freiwilligen Registrierung zu Arbeiten außerhalb des Ghettos auf.435 Als Anreiz sollte dienen, daß man Familien nicht zu trennen und eine vollstāndige Arbeitskleidungsausstattung zur Verfügung zu stellen versprach. Neben einer vorfristigen Aushāndigung von Rationen sollte die Befreiung von der Postsperre zur freiwilligen Meldung veranlassen. Es ist nicht bekannt, ob man damals in Lódź wußte, daß es keine anderen jüdischen Wohnbezirke mehr gab, mit denen Korrespondenz mōglich geworden wäre. Allgemein wird in der Literatur die Isolation und Uninformiertheit Lódźs betont. Lucjan Dobroszycki, der Herausgeber des Ghetto-Tagebuches von Lódź, ist sich nicht im klaren darüber, ob dem Älesten Rumkowski bei der Herausgabe dieser Proklamation klar war, daß ihr Ziel ebensowenig die Arbeitsaufnahme sein würde, wie es die Ansiedlung im Osten ein Jahr zuvor gewesen war. Von 23. Juni 1944 an verließen jedenfalls alle paar Tage Transporte den Bahnhof der Stadt - ihr Ziel war jedoch nicht eines des durchaus noch existierenden Juden-Arbeitslager, sondern zunāchst die reaktivierte Vernichtungsstātte Chełmno/Kulmhof am Ner. Bis zum 15. Juli 1944 wurden von den 76000 Juden, die noch in Lódź am Leben geblieben waren, etwa 7000 deportiert. 436

In Cheimno/Kulmhof diente in den Wochen der erneuten „Inbetriebnahme“ eine Kirche als ${ }_{\text {r }}$ Zwischenlager “ für die aus Lódź herangebrachten Juden - der zuvor verwendete Palast war nach dem Ende der ersten Vernichtungsphase im April 1943 gesprengt worden. Zwischen 7000 und $10000^{437}$ Juden wurden 1944 hier ermordet, wobei die Leichen in Krematorien verbrannt und deren Asche nachts in den Fluß geschüttet wurde. ${ }^{438}$ Anfang 1945 wurde auch das örtliche Häftlingskommando nach einem Ausbruchversuch erschossen. 439

Nach einer zweiwöchigen Unterbrechung der Transporte wurde am 1. August 1944 (an diesem Tag brach in Warschau der große Aufstand aus) verkündet, daß das ganze Lódźer Ghetto nverlagert" würde. Nachdem wegen des schnellen Vorstoßes der Roten Armee die Vernichtung in Chelmno/Kulmhof eingestellt worden war, gedachte man jedoch nicht etwa, die restlichen Juden am Leben zu lassen. Die Freude, die lt. Dobroszycki über den sowjetischen Vormarsch im Ghetto herrschte, war verfrüht. Die Tatsache, daß die sowjetischen Truppen kaum 150 km von Lódź entfernt waren, war

134 Vgl. Dąbrowska, Zaglada, S. $152 \mathrm{f}$.

435 Abdruck des Textes in: Chronicle, S. 503.

436 Lucjan Dobroszycki, in: Chronicle, S. LXIII: 7196; vgl. Dąbrowska, Zagtada, S. 153.

437 Vgl. Serwański, Obóz, S. 56. - Die Differenz zur Zahl der aus Lódź/Litzmannstadt Deportierten ergibt aus der gleichzeitigen Ermordung von zahlenmäßig nicht näher effaßten Opfem von Selektionen in Arbeitslagern. Daher ist die im Bonner Kulmhof-Prozeß nach den Lódźer Listen erstellte Zahl von 7176 Juden (Rücker, Vernichtungslager, S. 292 f.) um einen nicht genau zu bestimmenden Satz anzuheben.

438 Vgl. Serwański, Obóz, S. 56.

439 Vgl. ebenda, S. 61. 
bekannt - daß der Aufstand in Warschau zu einem Aufschub des weiteren Vormarsches führen würde, hatte man nicht erwartet. Daher ist es verständlich, daß die neuerlichen Aufrufe der Deutschen und Rumkowskis, man solle sich zur "Verlagerung“ melden, diesmal nicht befolgt wurden. Die Ghettobewohner rechneten mit ihrer baldigen Befreiung und wollten sich nicht (wie es hieB) in das Reich abtransportieren lassen. Dies war allerdings auch nicht die Absicht der Deutschen gewesen. Vom 9. August 1944 an durchkāmmte die deutsche Polizei unter Mitwirkung der jüdischen Ghetto-Polizei die Hāuser und trieb die Menschen zu den Sammelplātzen. Den Bahnhof Radegast/Radogoszcz verließen Züge, deren Ziel die Vernichtungsstātte Auschwitz-Birkenau war. Mit dem Transport vom 28. August 1944 verließen die letzten „privilegierten“ Juden Lódź, darunter der „Älteste ${ }^{“}$ Rumkowski mit seiner Familie. Auch sie kamen wie die meisten anderen in Auschwitz um. In Lódź verblieben etwa 800 Juden, die bei der Aufräumung des ehemaligen Ghetto-Gebiets eingesetzt wurden. Zusammen mit den Versteckten zählte man bei der Befreiung durch die Rote Armee am 18. Januar 1945 noch 877 Juden in Lódź. 440

Der Warschauer Aufstand selber ${ }^{411}$ hatte nur geringe Bedeutung für die Judenvernichtung, die in Warschau ein Jahr zuvor abgeschlossen worden war. Abgesehen von den Versteckten gab es nur wenige Juden im „Konzentrationslager Warschau“, mit deren Hilfe das ehemalige Ghettogebiet abgeräumt wurde, und einige halbtote Hāftlinge im berüchtigten Gefängnis Pawiak. Die Aufständischen konnten 348 Juden kurz nach Ausbruch des Aufstandes befreien - die Mehrzahl stammte aus nicht-polnischen Gebieten -, ein Untergrundbericht handelt von 89 befreiten polnischen Juden. ${ }^{442}$ Die meisten von ihnen kamen bei der Niederschlagung des Aufstandes ums Leben. Nur einer ganz kleinen jüdischen Gruppe (200 von ursprünglich 500) gelang es, in den Ruinen der auf Hitlers Befehl planmäßig dem Erdboden gleichgemachten Stadt bis zur Befreiung durch die Rote Armee im Januar 1945 auszuharren.443 Eine frühe Schätzung nimmt für den Mai 1944 etwa 15000 in Warschau auf, arischer “ Seite versteckte Juden an - von ihnen heißt es, viele von ihnen seien während des Aufstandes "besonders durch die Hānde der NSZ [ = Narodowe Sily Zbrojne, nationaldemokratische Untergrundarmee] umgekommen. ${ }^{444}$ Jedenfalls haben nicht alle die der planmāBigen Schleifung der Stadt vorangehende Evakuierung der verbliebenen Einwohner überstanden, ohne weiter aufzufallen.

440 Vgl. Dąbrowska, Zagtada, S. 154; Dobroszycki, in: Chronicle, S. LXVI. - Nach Eisenbach (Polityka, S. 570) wurden einige hundert Lódżer Juden nach Ravensbrück und Königswusterhausen zur Zwangsarbeit verschleppt.

441 Vgl. u. Janusz K Zawodny, Nothing but Honour. The Story of the Warsaw Uprising 1944, London 1978.

442 Vgl. Berenstein/Rutkowski, Ob6z $\neq$ Warszawie, S. 19; Whadyslaw Bartoszewski, Uns eint vergossenes Blut, Frankfurt 2M. 1987, S. 253.

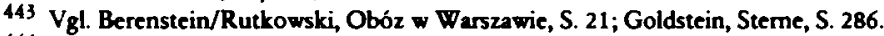

444 Brustin-Berenstein, Deportacje, S. 100. - Bereits vor dem Aufstand, im Juni 1944 berichtete der pro-kommunistische Untergrund nach Moskau: „Auf dem Gebiet Polens häufen sich immer stärker die Fälle, daß Juden nicht nur durch die Gestapo, die Gendarmerie oder die SS ermordet werden, sondern auch durch ,polnische' Banden der Narodowe Siły Zbrojne! ... Eine der schrecklichsten Plagen für gerettete und versteckte Juden sind Erpresser und Denunzianten, durch die in Warschau und anderen Städten täglich -zig Juden in die Hānde der Gestapo gelangen und umkommen. ... In letzter Zeit werden Juden immer hāufiger in den Wäldern und Dörfern gemondet. In den Bezirken Radom und Kielce haben die Banditen von den NSZ über 200 Juden ermordet. (Bericht des Referats für jüdische Angelegenheiten des Landesnationalrats an den Verband Polnischer Patrioten in der UdSSR, 15.6.1944, nach Mark, Do dziejow, S. 10) 
Ähnliches berichtet Filip Friedman aus Lemberg, wo es nach der Ghettoliquidierung ebenfalls einer Anzahl von Juden gelungen war, bei ,arischen“ Freunden oder gegen Entgelt in Verstecken unterzukommen. Friedman berichtet über $n$ Jugendliche und Kinder, die, nachdem sie auf der Straße eine Person mit ,verdāchtigem‘ Äußeren entdeckt hatten, so lange Jude', Jüdin' schreiend hinter ihr herliefen, bis diese verfolgte Person in die Hānde der Polizei fiel“ ${ }^{445}$ Als Lemberg am 27. Juli 1944 befreit worden war, konnten 823 überlebende Juden registriert werden. 446

Die Welt der Arbeitslager befand sich auch die ganze Restzeit des Krieges über in dauerndem Fluß, wobei die organisatorischen Erwägungen der jeweiligen „Arbeitgeber" ${ }^{\prime}$, der Kriegsverlauf, aber auch einfache Willkür als Ursachen für die zahlreichen Verlegungen zu sehen sind. "Verlegungen“ klingt harmlos - sie waren es nicht. Die Transportbedingungen im besetzten Polen waren im letzten Kriegsjahr keineswegs besser geworden; daneben lauerten an vielen der angelaufenen Stationen Einrichtungen, deren einziger Zweck die Ermordung der dauernd von Selektionen bedrohten "Passagiere" war.447

Als Beispiel mag das nunmehr nur als „Arbeitslager “ fungierende Lager Majdanek bei Lublin gelten, wo nach dem Massenmord vom November 1943 nicht mehr als etwa 600 Juden am Leben geblieben waren. Am 17. Dezember 1943 trafen 60 Häftlinge aus Auschwitz ein, im Februar 194480 jüdische Handwerker aus dem Lager Budzyń. Ende Februar kamen weitere 250 aus Auschwitz an, die sofort in Majdanek vergast wurden. Bis Ende Juni wurden laufend kleinere Gruppen aus Budzyń eingeliefert, die zunāchst am Leben blieben. Anfang Juli 1944 schließlich erreichten Majdanek noch 53 Frauen, die zuvor in Trawniki Frondienste geleistet hatten. Parallel dazu - am 16. April 1944 - wurden jedoch auch 600 Personen aus Majdanek NACH Auschwitz geschickt, von denen nur die Mānner zunächst am Leben blieben. Etwa die Hälfte Frauen und zwei Kinder - wurden sofort nach der Ankunft umgebracht. Eine nicht genauer feststellbare Anzahl von Juden verließ im April 1944 Majdanek mit dem Ziel Arbeitslager Plaszów bei Krakau. 56 Handwerker brachte man im April auf das Lubliner Schloß und die Hälfte von ihnen wiederum im Juli 1944 weiter nach Radom. Die Dagebliebenen wurden auf dem Lubliner Schloß kurz vor dem Eintreffen der sowjetischen Truppen erschossen. Die etwa 500 in Majdanek verbliebenen Juden wurden vor dem Eintreffen der Befreier auf einen Todesmarsch nach Auschwitz geschickt. Von den etwa 1000 Juden, die aus verschiedenen Arbeitslagem in der Lubliner Gegend losmarschierten, erreichten am 28. Juli 1944 nur etwa 600 das wenig attraktive Ziel Auschwitz-Birkenau. 448

Ein ähnliches Bild gilt generell auch für die anderen Arbeitslager. Solange sich die militārische Situation einigermaßen stabil gestaltete, fanden Verlegungen zwischen den Lagern statt. Sobald die Front in unmittelbare Nähe rückte, wurde einerseits versucht, möglichst viele der inzwischen wertvoller gewordenen Arbeitskräfte nach We-

145 Friedman, Zaglada, S. 30.

446 Vgl. ebende, S. 31.

447 Uber die Evakuierung und Befreiung der Lager erschien eine Arbeit von Zygmunt Zonik, Anus Belli, Warszawa 1988.

448 Alle Angaben nach Berenstein/Rutkowski, Zydzi, S. 43-48; neuere Zahlen finden wir bei Zofia Leszczyńska (Kronika obozu na Majdanku), aber auch hier werden von Zonik (Anus, S. 128 f.) große Abweichungen festgestellt 
sten, bis ins Reichsgebiet hinein zu verlegen. Diese Verlegungen forderten aufgrund der Rücksichtslosigkeit, mit der sje durchgeführt wurden, unverhältnismäßige Opfer. Wo sie nicht mehr gelangen oder wo die davon potentiell Betroffenen nicht mehr ausreichend transportfähig schienen, wurden sie an Ort und Stelle umgebracht - letztlich entspricht diese Verhaltensweise in etwa der Praxis bei den "Aussiedlungen“ der Ghettos in den Jahren 1942/43. Für den 14. April 1945 ist ein Befehl Himmlers nachweisbar, daß (auf Dachau und Flossenbürg bezogen) „kein Häftling lebendig in die Hānde des Feindes kommen" darf. ${ }^{449}$ Implizit dürfte āhnliches vorher ebenfalls gegolten haben, jedenfalls sah so hāufig die Praxis aus. Erst gegen Ende des Krieges ließ der Wille der fliehenden Lagerwachen ein wenig nach, alle Mitwisser ihrer Taten vor der Befreiung umzubringen.

Am 24. Juli 1944 wurden die letzten ca. 460 Juden des Arbeitslagers Pustków bei Dębica nach Auschwitz und von dort in verschiedene Lager in Deutschland gebracht. 450 In Stalowa Wola arbeitete ein Juden-Arbeitslager an der Produktion von Panzerblech. Es wurde am 23. Juli 1944 nach Plaszów bei Krakau evakuiert, das sich als Sammelpunkt für den Süden des Generalgouvernements herausbildete. Von den 416 auf den Marsch gebrachten Insassen - die zu dieser Zeit alle als arbeitsfähig galten - trafen nur 210 in Plaszów ein: 90 gelang unterwegs die Flucht - mit ungewissem Ausgang; etwa 100 wurden von den Marschbegleitungen erschossen. ${ }^{451}$ Plaszów verdient hier besondere Beachtung, weil es kürzlich zum Objekt einer monographischen Forschungsarbeit geworden ist und so belegt, wie wichtig eine minutiöse Aufarbeitung jener Zeit ist - die in der deutschen Historiographie bis heute vernachlässigt wurde.452 Seinen ersten „Hōhepunkt" hatte das Lager im Mārz 1943, als bei der Liquidierung des Krakauer Ghettos die etwa $\mathbf{8 0 0 0}$ arbeitsfāhigen Juden Krakaus hier zur Zwangsarbeit eingeliefert wurden. Damals lebten etwa 10000 Juden in Plasz6w. ${ }^{453}$ Als das Lager Szebnie kurze Zeit darauf eingerichtet wurde, verlegte man einige Fachkräfte dorthin. 454

Hervorzuheben ist für Plaszów die Tätigkeit des deutschen Fabrikanten Oscar Schindler, der in Krakau-Podgórze an der Zablocie-Straße eine Emailwarenfabrik eingerichtet hatte und laufend Juden aus Plaszów für seine Werke anforderte - er ist als einziger Deutscher im besetzten Polen dafür bekannt geworden, die Juden, die bei

449 Vgl. Jan Zulawiński, Eksterminacja wiçźniów w czasie ewakuacji obozu Gross-Rosen i jego filii, in: Studia i Materialy z Dziejów Slęska 12 (1973), S. 434. Zonik (Anus, S. 356 ) nimmt für alle evakuierten Lager (einschlieflich der reichsdeutschen) eine Gesamtzahl von 215000 im Zuge von Evakuierung und Liquidierung umgekommenen Menschen an.

$450 \mathrm{Vgl}$. Zabierowski, Pustków, S. 55.

$451 \mathrm{Vgl}$. Podhorizer-Sandel, O zagladzie, S. 103. Die Weitertransporte von Auschwitz ins Reich sind zwar zahlenmäßig erfafbar, aber nicht nach Nationalitäten aufzugliedem (vgl. Zonik, Anus, S. 131 ff.).

$452 V_{g l}$. Magdalena Kurzycka-Wyrzykowska, Kalendarium obozu plaszowskiego 1942-1945, in: Biuletyn GKBZHwP 31 (1982), S. 52-84; eine umfassende Beschreibung bietet auch Bieberstein, Zagtade $S$. $100-146$.

$453 \mathrm{Vgl}$. Kurzycka-Wyrzykowska, Kalendarium, S. $60 \mathrm{t}$.

454 Uber die Geschichte des polnisch-jüdischen gemischten Arbeitslagers in Szebnie ist ebenfalls eine Monographie erschienen (St. Zabierowski, Szebnie, Rzeszów 1985). Danach gab es bei der Errichtung des Lagers im April 1943 dort bereits 250 Juden, die aus Jasto, Plaszów, Rzeszów und Krakau in das neue Lager gebracht worden waren (S. 63). Im August/September 1943 trafen dann nach Tausenden zählende Judentransporte in Szebnie cin (S. 64). Zu den Quantifizierungsschwierigkeiten bezüglich der einzelnen Transporte vgl. S. $68 \mathrm{f}$. 
ihm arbeiteten, gezielt vor der drohenden Vernichtung zu bewahren. ${ }^{455}$ Im September 1943 kamen nach der Liquidierung des Ghettos von Tarnów 2000 Juden nach Plaszów - spāter folgte ein Teil der noch in Tarnów verbliebenen sog. Säuberungskolonne. 456 Vom November 1943 an wurden gemāß Hans Franks Anweisung die Judenlager im Krakauer Distrikt liquidiert und die Insassen entweder nach Auschwitz oder in das Zwangsarbeitslager Płaszów deportiert. In Plaszów fanden von September 1943 an regelmäßig drei- bis viermal die Woche Massenexekutionen statt. 457

Das Zwangsarbeitslager wurde Anfang 1944 in ein „normales “ Konzentrationslager umgewandelt. Nachdem das Arbeitslager Szebnie aufgelöst worden war, gelangten etwa 230 polnische Juden, von denen wiederum 150 zuvor in Krosno gewesen waren, im Februar 1944 von dort nach Plaszów. 458 Im Mārz gab das nun nicht mehr „produktive“ Lager Plaszów etwa 2000 jüdische Häftlinge an die Munitionsfirma „Hasag“ (Hugo Schneider AG) in Skarżysko-Kamienna ab. Im April 1944 wiederum trafen 1100 Juden aus dem inzwischen von den Sowjets bedrohten und daher liquidierten Zwangsarbeitslager Drohobycz in Plaszów ein. ${ }^{459}$ Nach einer als „Gesundheitsappell“ ausgegebenen Selektion wurden am 14. Mai 1944 alle Schwachen, Kranken und Kinder (insgesamt 1400) nach Auschwitz zur „Sonderbehandlung“ geschickt - in den Gastod.460 Etwa gleichzeitig trafen in Plaszów ungarische Jüdinnen aus Auschwitz zum Ameitseinsatz ein. ${ }^{461}$

$455 \mathrm{Vgl}$. Bieberstein, Zaglada, S. 143, 147-155; Thomas Keneally hat das Werk Schindlers auf der Basis von Gesprächen mit 50 ,überlebenden Schindlerjuden" (so der Verfasser) romanhaft dargestellt (Schindler's List, New York 1982; dt. Schindlers Liste, München 1983) - Zweimal besuchte Schindler Budapest, wo bis zum Frühjahr 1944 noch keine drastische Judenverfolgung herrschte und von wo aus eine Ausreise zu arrangieren versucht worden sein mag. Zu den Kontakten Schindlers mit ungarischen Hilfsorganisationen vgl. Asher Cohen, The Halutz Resistance in Hungary 1942-1944, Boulder 1986, S. 38. Schindler stört eine weitverbreitete polnisch-nationale Schwarz-Weiß-Malerei. Czeslaw Madajczyk (Sprawy polskie w Atlas of Holocaust, in: Dzieje Najnowsze 18 (1986), S. 287) hält seine Aktivitäten für "nicht eindeutig und verleumdet ihn, gestützt auf polnische Untergrundquellen, als „Prasser, der Alkohol, Frauen liebte, unerhōrt gewitzt" war. Was ergäbe sich wohl, wenn wir die Askese als höchsten Wert setzten? Weiter: „Es besteht weiter der Verdacht, er habe seit 1938 für die Abwehr gegen Polen gewirkt" (ebenda) und mit dem Kommandanten des Lagers Plaszów ${ }_{n}$ nach einigen Berichten “ ${ }_{n}$ in engen Beziehungen “ gestanden. Alles mōglich, aber ,nicht zum Thema'; als Widerstandskämpfer und Deutschenfeind hätte Schindler niemanden gerettet. Und daß Madajczyk in diesem Zusammenhang in einem Brief ausführt, Polen, die Juden verborgen und gerettet hätten, seien ein ungleich größeres Risiko als Schindler eingegangen, ist gleichfalls korrekt aber entwertet es Schindlers Handeln? Sein Verhalten muß man mit dem anderer deutscher Unternehmer im Osten vergleichen - so wie er hat sich für seine Juden "' sonst keiner eingesetzt.

456 Vgl. Kurzycka-Wyrzykowska, Kalendarium, S. 64; Bieberstein, Zaglada, S. 43 f.

$457 \mathrm{~V}$ gl. ebenda, S. 140.

458 Aus Szebnie kamen 2800 Juden am 4.11.1943 nach Auschwitz, weitere 120 am 8.11.1943 in das Arbeitslager Pustków, das dem SS-Truppenübungsplatz unterstand (Vgl. Zabierowski, Szebnie, S. 71). Die Zahl der Szebnier Juden, die nach Auschwitz kamen, wird auch mit 3898 angegeben (Danuta Czech, Kalendarz wydarzeń w obozie koncentracyjnym Oświęcim-Brzezinka, in: Zeszyty Oświęcimskie 4 (1960)). Zabierowski zweifelt diese Zahl aufgrund einer Befragung an (Zabierowski, Szebnie, S. 110). - Nach seinen Ermittlungen waren insgesamt bis zu 5000 Juden gleichzeitig in Szebnie. In Dobnucowa bei Szebnie wurden am 23./24.9.1943 etwa 700 Juden erschossen (vgl. ebenda); am 8.11.1943 ermordete man dort weitere 500 (S. 166), im Lager blieben 86 Juden zurück. Im Januar 1944 erhōhte sich ihre Zahl durch 150 Juden aus dem Unterlager auf dem Flugplatz Krosno (S. 174). Diese etwa 230 Juden gelangten am 2.2.1944 nach Plaszów (ebenda). - Nach Kurzycka-Wyrzykowska (Kalendarium, S. 67) und Bieberstein (Zagłada, S. 144) kamen jedoch nur 100 Juden aus Szebnie nach Płaszów.

459 Vgl. Kurzycka-Wyrzykowska, Kalendarium, S. 67

$460 \mathrm{~V}$ gl. ebenda, S. 68.

461 Bieberstein (Zaglada, S. 183) stellt zwischen den beiden Vorgängen den Zusammenhang folgendermaßen her: Der Lagerleiter Amon Goeth habe sich zur durchgangsweisen Aufnahme ungarischer Juden nur unter der Bedingung bereit erklärt, daß etwa 1500 Plaszówer Juden , sonderbehandelt“ würden. 
Im Sommer 1944 richtete man in Płaszów einige Baracken als Durchgangslager ein, um die durchziehenden Juden aus den weiter östlich gelegenen Gebieten auf ihrem Weg ins Reich zeitweise unterbringen zu können. - 300 Juden aus Stalowa Wola etwa passierten Płaszów ebenso wie 500 aus dem „Zwangsarbeitslager für Juden beim Flugmotorenwerk Reichshof (Rzeszów) ${ }^{4462}, 1000$ aus Pustków und 2000 aus Mielec. 463 Danach wurde die Zahl der Häftlinge drastisch reduziert: 6-8000 deportierte man Anfang August 1944 nach Auschwitz, 5000 nach Mauthausen, ca. 4600 nach Flossenbürg, etwa 4-5000 ungarische Jüdinnen über Auschwitz nach Stutthof bei Danzig. Im August wurde auch das Schindler-Außenlager geschlossen - die Insassen kamen nach einem Zwischenaufenthalt in Plaszów nach Groß-Rosen. 4641200 weitere Insassen brachte man nach Skarżysko-Kamienna in die ausgebauten „Hasag“-Lager. Im September 1944 waren noch etwa 2200 Menschen in Plaszów. Am 15. Oktober wurden 1500 von ihnen nach Groß-Rosen, einige andere nach Buchenwald in Marsch gesetzt. 465 Anfang 1945 waren noch 636 Hāftlinge in Plaszów nachweisbar ${ }^{466}$; sie wurden am 14. Januar 1945 vor den heranrückenden Sowjets zu Fuß nach Auschwitz geführt. 467

Letztlich kann allein eine komplette Aufarbeitung aller Einzeldarstellungen von Lagergeschichten einen auch nur annähernden Aufschluß über das Schicksal der in den Arbeitslagern vegetierenden Juden geben - schon für das noch recht gut dokumentierte Plaszów ist darüber hinaus auch die staatliche Zugehörigkeit nicht durchgāngig nachweisbar, so daß eine auch nur ansatzweise daran orientierte Aufstellung auf unüberwindbare Schwierigkeiten stößt. Eine āhnliche Abfolge von Transporten von Lager zu Lager läßt sich auch für den Distrikt Radom belegen. Hier entstand bei den Hasag - Rüstungswerken in Skarżysko-Kamienna ein großes Arbeitslager, in das bereits 1942 Juden aus Kielce (2000), Chęciny (500) und anderen Orten des Distrikts eingeliefert wurden. Im Mārz und November 1943 trafen Transporte aus Płaszów ein, weiter dann etwa 1900 Häftlinge aus Majdanek. Anfang Mārz 1944 kamen etwa 1600 Bewohner des Ghettos Litzmannstadt nach Skarżysko-Kamienna. Bemerkenswert und in der Literatur bisher nur ungenügend beachtet ist, daß in Skarzysko-Kamienna mittels Lkw-Abgasen auch ein „kleinerer" Tötungsbetrieb angesiedelt war - eine polnische Arbeit gibt die Gesamtzahl von 35000 Ermordeten an, wobei es sich nicht nur um polnische Juden gehandelt haben soll.468 10000 Juden sollen darüber hinaus an Ort und Stelle nach Selektionen erschossen worden sein. Im März 1944 wurden alle im Arbeitslager lebenden Kinder ermordet, einer Gruppe von 250 Juden gelang die Flucht, die meisten wurden jedoch durch ausgesandte Lagerwachen eingefangen und umgebracht. Im Juli 1944 wurde Hasag/Skarżysko-Kamienna evakuiert. 4000 Juden

462 Vgl. Kurzycka-Wyrzykowska, Kalendarium, S. 69.

463 Vgl. Bieberstein, Zeglada, S. 144.

464 Vgl. Kurzycka-Wyrzykowska, Kalendarium, S. 70.

465 Vgl. ebenda, S. 71 . - Bieberstein, der selber an diesem Transport teilnahm, schreibt von 4500 Häftlingen möglicherweise handelt es sich um einen Druckfehler (Zagłada, S. 145).

466 Vgl. Kurzycka-Wyrzykowska, Kalendarium, S. 72; nach Bieberstein 706 Häftlinge (Zaglada, S. 145).

467 V 1 . Kurzycka-Wyrzykowske, Kalendarium, S. 72; nach Bieberstein marschierten die Häftinge am 15.1.1945 (Zaglada, S. 145).

$468 \mathrm{Vgl}$. Adam Rutkowski, Hitlerowskie obozy pracy dla Żydów w dystrykcie radomskim, in: BZIH 17/18 (1956), S. 120. 
wurden zur Hasag-Zentrale nach Leipzig gebracht, etwa 3000 in die Hasag-Werke des weiter westlich gelegenen $\mathrm{Częstochowa/Tschenstochau.}{ }^{469}$

Ähnlich sah es in der Sprengmittelfabrik von Pionki aus, in deren Arbeitslager Juden aus Radom, Kielce, Skarżysko, Żarki, Piotrków/Petrikau, Plaszów und anderen Orten gefangengehalten wurden. Ende Juli 1944 zählte man etwa 3000 Insassen. ${ }^{470}$ Die Desorganisation beim Herannahen der Roten Armee ermōglichte 500 Juden die Flucht, von den restlichen wurden 2000 nach Auschwitz gebracht, etwa 300 zunächst bei der Demontage des Betriebs beschäftigt und Ende August 1944 nach Częstochowa/Tschenstochau transportiert. ${ }^{471}$ Die zwei Arbeitslager von Piotrków/Petrikau wurden Ende November 1944 liquidiert, die Insassen nach Buchenwald und Ravensbrück deportiert (1700 Personen). Aus Radom transportierte man am 26. Juli 1944 ca. 3000 Juden, aus Blizzyn am 30. Juli 1944 ca. 4000 Juden zur Ermordung nach Auschwitz. 472

Befreien konnte die Rote Armee einen Teil der Juden der Arbeitslager von Częstochowa/Tschenstochau, die nach den „Aussiedlungen " vom Oktober $1942 \mathrm{mit}$ zunāchst 5000 Insassen übriggeblieben waren. ${ }^{473}$ Durch Mordaktionen und Flucht reduzierte sich die Häftlingszahl bis Ende 1943 auf etwa 4000474, die bei den Hasag-Betrieben eingesetzt wurden. Ab Juli 1944 trafen nun in Częstochowa/Tschenstochau die Juden aus den Lagem von Plaszów und Skarżysko-Kamienna sowie aus dem Lódźer Ghetto ein. Im Juli 1944 gab es hier demnach ca. 11000 Juden. ${ }^{475}$

Am 14. Dezember 1944 wurden die noch bestehenden Lager aus der „privatwirtschaftlichen" Verwaltung herausgenommen und der SS-Zentrale in Auschwitz unterstellt. Die Situation der Hätlinge soll sich dadurch noch weiter verschlimmert haben. ${ }^{476}$ Schon der nächste Monat brachte jedoch die emeut zur Offensive angetretene Rote Armee nach Częstochowa/Tschenstochau. Die Deutschen versuchten noch, eine möglichst große Zahl von Arbeitern ins Reich zu deportieren. Die Obstruktion der jüdischen Häftlinge, die mehrheitlich nicht zu den angesetzten Abtransportterminen erschienen und vom Werkschutz zwangsweise eingeladen werden mußten, bewirkte, daß nur etwas über 5000 Juden nach Buchenwald, in die Harz-Lager Dora-Mittelbau und nach Groß-Rosen gebracht werden konnten, wo ihr weiteres Schicksal ungewiß ist. Etwa 5200 Juden konnten die einmarschierenden sowjetischen Truppen befreien. ${ }^{477}$ Von diesen waren nach der Registrierung 1518 aus Częstochowa selber. ${ }^{478}$

Bis Oktober 1944 wurde das Vernichtungslager Auschwitz-Birkenau als Mordanlage für Juden aus den aufgelōsten Arbeitslagern verwendet. Aber auch hier machte man sich bereits frühzeitig Gedanken, wie die Massenmorde getarnt werden konnten.

\footnotetext{
$469 \mathrm{Vgl}$. ebenda, S. $120 \mathrm{ff}$.

$470 \mathrm{Vgl}$. ebenda, S. 122.

471 Vgl. ebenda, S. 123.

472 Vgl. ebenda, S. 124-127.

473 Vgl. ebenda, S. 124.

$474 \mathrm{Vgl}$. Brener, O pracy, S. 54.

475 Vgl. ebenda, S. 58; nach Pietrzykowski (W obliczu, S. 80) ca. 10000. Eine genauere Zählung liegt nur für einen Teil der Lager für den 28.6.1944 vor: demnach waren bei der Hasag-Apparatebau 3861, beim HasagWarthewerk 916, bei der Hasag-Eisenhütte 339 und beim Reinhardt-Zahnradwerk-Ost 280 Juden beschäftigt, zusammen also 5216 Juden (Pietrzykowski, Hitlerowcy w Częstochowie, S. 194).

$475 \mathrm{Vgl}$. Brener, O pracy, S. 59.

477 Vgl. ebenda, S. 60; Pietrzykowski, Hitlerowcy w Częstochowie, S. 195; Pietrzykowski, W obliczu, S. 82.

$478 \mathrm{Vgl}$. Pietrzykowski, Hitlerowcy w Częstochowie, S. 195.
} 
Durch Bepflanzung und Beseitigung (Verbrennung nach Exhumierung) der Leichen war zuvor bereits einiges unternommen worden, um die Vernichtungsstätte vor späteren Besuchem zu tarnen. Während die umliegende Bevölkerung selbstverstāndlich über die Vorgānge in den Lagern informiert war (Landsmanns Film „Shoa“ hat dies recht eindrucksvoll festgehalten), sollten sachliche Nachweismöglichkeiten möglichst gering gehalten werden.

Im August 1944 exhumierte man in Plaszów die Opfer der Exekutionen und verbrannte die Leichen mit Hilfe von Benzin auf Holzstößen.479 Im Mai 1944 hatte man bereits in Auschwitz ein Krematorium in eine Luftschutzanlage umgebaut, ein weiteres Krematorium brannte beim Aufstand des „Sonderkommandos“ jüdischer Krematoriumsarbeiter nieder. Im November 1944 wurden die verbliebenen Krematoriumsanlagen in Auschwitz-Birkenau auseinandergenommen, um nach Groß-Rosen abtransportiert zu werden, wo man offenbar vorhatte, die Judenmorde fortzusetzen. 480 Dies gelang nicht mehr - am Tag der Evakuierung des Lagers vor der heranrückenden Roten Armee wurden daraufhin die Anlagen gesprengt - die Ruinen sind bis auf den heutigen Tag sichtbar.

Am 18. Januar 1945 evakuierte man die überlebenden Auschwitzer Häftlinge aus allen Ländern Europas - es waren etwa 58 000; ca. 7000 Kranke ließ man zurück. Es gelang nicht mehr, diese Zeugen zu töten; die Rote Armee konnte sie befreien. Die Bilder der ausgemergelten Gestalten, von denen viele auch nach der Befreiung an den Folgen der Unteremāhrung und der unmenschlichen Behandlung starben, gingen um die Welt.

Allein in Auschwitz, wo ca. $\mathbf{4 0 0 0 0 0 ~ R e g i s t r i e r u n g s n u m m e r n ~ a u s g e g e b e n ~ w o r d e n ~}$ waren und etwas über 60000 Häftlinge aller Nationalitāten das Kriegsende überlebten ${ }^{481}$, sind weit über 1000000 Menschen umgebracht worden. Angesichts dieser unfaßbbaren Zahlen entziehen sich die Dimensionen der Mordtaten menschlicher Vorstellungsfāhigkeit. Sie entziehen die Morde aber auch gleichzeitig der Möglichkeit, sie in Einzelschicksalen nachzuvollziehen. Dadurch entsteht auch ein Eindruck von Unmenschlichkeit, mit der der Historiker vorgehen muß: Vor den ungeheuren Zahlen des industrialisierten Massenmordes verblassen Einzelexekutionen, aber auch „kleinere ${ }^{\star}$ Mordaktionen, deren Opfer in die Hunderte gehen mögen. Und doch ging es auch hier um Einzelschicksale, von denen jedes normal scheinende Vorstellungen Nicht-Krimineller übersteigt.

\section{Die Überlebenden}

Die Ermittlung der Zahl der Juden, die die deutsche Schreckensherrschaft über die Gebiete, die einst den polnischen Staat bildeten, überlebt haben, ist nicht einfach. Es reicht nämlich nicht aus, sich auf Schātzungen und unsystematische Registrierungen zu verlassen; die geschilderten Deportationen, Umsiedlungen und Flüchtlingsbewe-

479 Vgl. Bieberstein, Zagtada, S. 140.

480 Vgl. Jan Sehn, Obóz koncentracyjny Oświęcim-Brzezinka (Auschwitz-Birkenau), Warszawa 1956, S. 126.

$481 \mathrm{Zu}$ den Uberlebenden gehörten nicht in erster Linie Juden, sondern die Insassen des Polenlagers (Auschwitz I) und die nicht-jüdischen Insassen von Birkenau. 
gungen, verbunden mit ganz inkohärenten Mordaktionen und Arbeitseinsātzen, führten zu einer breiten Streuung der überlebenden jüdischen Bevölkerung. Die „Konzentrierungsmaßnahmen “ hatten eher einen gegenteiligen Effekt. Es gab eine Fluchtbewegung in die UdSSR, aus der für einen Teil der polnischen Juden ein Ausweg im Beitritt zu den beiden polnischen Armeen (Anders-Armee und Kościuszko-Division) bestand. Die Deutschen verteilten die Juden auf zahlreiche Arbeitslager, aus denen manche gegen Ende des Krieges bis in das Zentrum des Deutschen Reiches verlagert wurden. Die zunehmende Verfolgung trieb Juden mit ,arischen“ Papieren in Verstecke, in eine scheinlegale Existenz auf der Basis neuer Unterlagen oder auch zu den Partisanen. Da der Antisemitismus in Polen vor dem Krieg keineswegs eine unbeachtliche Größe war und auch nach dem Ende des Krieges nicht nur dort virulent war, wo bis zum Ende der 1940er Jahre noch ukrainische Nationalisten und polnische Antikommunisten sich Gefechte mit den neuen Machthabem lieferten, zogen es nicht wenige polnische Juden vor, mit ihren „arischen “ Papieren weiterzuleben, um sich nicht länger antisemitischen Benachteiligungen und Attacken ausgesetzt zu sehen.

Alle kolportierten Zahlenangaben müssen daher mit det nōtigen Vorsicht behandelt werden. Zwischen Apologeten der polnischen Untergrundbewegung der Kriegszeit und Personen, denen antijüdische Aktivitāten der Heimatarmee (AK) und der zeitweise mit ihnen verbundenen Nationalen Streitkräfte (NSZ) der Nationaldemokraten noch in guter Erinnerung sind, besteht ein langwieriger Streit, den man mangels geeigneter Maßstābe auch nicht schlichten kann, ob und in welchem Maße die nichtjüdischen Polen das Überleben von Juden gefördert haben. So entbrannte auf der wissenschaftlichen Konferenz zum 30. Jahrestag des Ghetto-Aufstandes, die vom Historischen Institut der Polnischen Akademie der Wissenschaften und dem Jüdischen Historischen Institut in Warschau veranstaltet wurde, eine Kontroverse $z$ wischen Tadeusz Bednarczyk, einem ehemaligen AK-Aktivisten, und Wladyslaw Bartoszewski von der Katholischen Universität Lublin. Während Bednarczyk meinte, in Polen seien 300000 Juden versteckt worden, wollte Bartoszewski höchstens 100000 tatsächlich Errettete anerkennen und führte zu recht aus, daß das „Operieren mit deutlich überhöhten und stark übertriebenen Zahlen das Vertrauen selbst zu überprüften und unbezweifelbaren Daten erschüttere ${ }^{\mu} .482$ Israelische Wissenschaftler wiederum warfen Bartoszewski, der einen Band über die Rettung von Juden durch Polen veröffentlicht hat ${ }^{483}$, vor, auch seine Zahlen seien überhōht, die Denunziation von Juden an die Gestapo sei durchaus typischer gewesen als Rettungsversuche. Die Literatur zu polnischen Rettungs- und Versteckversuchen ist verhāltnismäßig zahlreich ${ }^{\mathbf{4 8 4}}$, es gibt jedoch keine verlāßlichen quantifizierenden Ergebnisse. Man muß deutlich unterscheiden zwischen Versteckern, die allein aus Profitsucht gegen Geld halfen - und bei dessen Erschöpfung ihre „Kunden“ nicht selten der Gestapo auslieferten -, und aus

482 Ryszard Nazarewicz, Sesja naukowa o powstaniu w getcie warszawskim, in: Z Pola Walki 16 (1973), S. $1092 \mathrm{t}$.

483 Zusammen mit Zofia Lewinówna, ... ten jest z ojczyzny mojej, Kraków 1969 (engl.: Righteous among $\mathrm{Na}$ tions, London 1969; The Samaritans. Heroes of the Holocaust, New York 1970).

$484 \mathrm{Vgl}$. Tatiana Berenstein/Adam Rutkowski, Assistance to the Jews in Poland, Warszawa 1963; Philip Friedman, Their Brothers' Keepers, New York 1978; Kazimierz Iranek-Osmecki, He Who Saves One Life, New York 1971; Szymon Datner, Las sprawiedliwych, Warszawa 1968; Marek Arczyński/Wieslaw Balcerak, Kryptonim Zegota', Warszawa 1979; Teresa Prekerowa, Konspiracyjna Rada Pomocy Zydom w Warszawie 1942-1945, Warszawa 1982. - Gutman nennt die Hilfe knapp pa classic instance of too little too late* (Polish and Jewish historiography, S. 189). 
Überzeugung handelnden Rettern. Aber auch die umfassende und neueste sorgfältige Arbeit von Nechama Tec, in der erstmals versucht wird, die Persönlichkeit der Helfer zu umreißen, hilft bei der Quantifizierung nicht weiter. Tec gelangt auf der Basis von Archivalien und Interviews jedoch immerhin so weit, Retter von Juden als „independent individualists“ zu charakterisieren, wobei die Angehōrigen der Mehrheitsgruppen (Bauern, „Sanacja“-, Nationaldernokratie-Anhänger) prozentual unterrepräsentiert waren. ${ }^{485}$ Rettungsversuche waren demnach nichts "Typisches“.

Die Zahl von 100000 außerhalb von Lagem und Ghettos Uberlebenden entspricht den Schātzungen, die einer der bekanntesten polnischen Erforscher der NS-Zeit, Szymon Datner, angestellt und erstmals 1968 - dann nochmals 1970 - publiziert hat. 486 Die Addition konkreter Einzelangaben ergibt dagegen geringere Werte. So erhöhte sich zwar die Zahl der im Juli 1944 in Lemberg befreiten Juden im Laufe der Zeit von $823^{487}$ auf „über $2000^{\star 488}$, die aus Verstecken auf der ,arischen Seite ${ }^{\mu}$ und den umliegenden Gebieten in die Stadt kamen, aber auch eine Berücksichtigung der Filip Friedman bekannt gewordenen Zahlen aus Ostgalizien (jeweils einige 100 für Borysław, Thuste und Drohobycz, 200 für Stanislau und kleinere Gruppen für Tarnopol und Brody) ${ }^{489}$ ergibt nicht mehr als etwa $1-2 \%$ der ursprünglichen jüdischen Bevölkerung und damit in der Hochrechnung deutlich weniger als die oben angesetzten 100000 . Shmuel Krakowski rechnet mit $\mathbf{8 0 0 0 0}$ Uberlebenden, diese Zahl schließt jedoch neben den "Illegalen" auch die Uberlebenden der Lager ein. 490

Von der polnischen Hilfsorganisation für die Juden "Żegota“ wird die Zahl von 20000 in Warschau auf ,arischer ${ }^{\mu}$ Seite Versteckten angegeben. ${ }^{491}$ Doch wie viele haben den Aufstand und die Räumung der Stadt überstanden? Die geringen gesicherten Werte aus zahlreichen polnischen Gebieten ${ }^{\mathbf{4 9 2}}$ ergeben keine Berechtigung, einen derart hohen Wert anzunehmen. Schon eine Zahl um 50000 dürfte recht großzügig sein. Pospieszalski493 operiert mit 45-60000, was durchaus im Rahmen des Möglichen liegt. Gleichfalls unklar ist die Zahl der Uberlebenden unter den vor den Deutschen auf sowjetisches Gebiet Geflüchteten. Bis 1946 kehrten etwa 130000 aus der UdSSR nach Volkspolen zurück.494 Für sie fehlt jedoch eine ordentliche Bezugsgröße, denn außer in der Anders-Armee, in der nur wenige Juden u.a. nach Palästina gelangen

485 Vgl. Nechama Tec, When Light Pierced the Darkness. Christian Rescue of Jews in Nazi-Occupied Poland, New York 1986, S. 184-193.

486 Szymon Datner, Zbrodnie hitlerowskie na Żydach zbiegtych z gett, in: BZIH 75 (1970), S. 29; in diesem Zusammenhang sei die Schätrung des exilpolnischen Außenministers Edward Raczyński erwähnt, der von 60-120000 Versteckten ausging.

487 Vgl. Friedman. Zagtada, S. 31.

488 Fridman, Umkum, S. 13.

489 Ebenda

490 Krakowski, Avedot, S. 232.

491 Hier nach Levin, Holocaust, S. 359; nach Bartoszewski (Uns eint, S. 114) betreute, Zegota‘ allein 4000 von ihnen.

492 Etwa das Uberleben einer 1200 Mann starken jüdischen Partisanengruppe bei Nowogródek (vgl. Levin, Holocaust, S. 275) die 600 Juden, die in der Kanalisation von Wilna ihre Befreiung erwarten konnten (ebenda, S. 380) etwa 100, die die Kovpak-Partisanen in Skalat oder polnische Partisanen unter J6zef "Maks" Sobiesiak in Wolhynien retteten (vgl. Datner, Zbrojne, S. 19; Emanuel Brand, The Forest Ablaze: A Jewish Partisan Group in the Kovpak Division, in: Yad Vashem Bulletin 2 (Dezember 1957), S. 16) oder die 1500 Personen, die nach Krakowski aus dem Ghetto Biatystok fliehen und überteben konnten (Krakowski, Avedot, S. 235).

493 Pospieszalski, Prawo, S. 532.

494 Bieberstein (Zagtada, S. 13), der nach dem Krieg in der polnischen Verwaltung arbeitete, gibt die Gesamtzahl der jüdischen Rückkehrer mit ca 100000 an - etwa 25000 seien außerhalb Polens geblieben. 
konnten ${ }^{495}$, tauchten Juden auch in der auf sowjetischer Seite kämpfenden Kościuszko-Division und den zivilen Organisationen des Verbandes Polnischer Patrioten auf, ohne als Juden ausgewiesen zu sein. Die auf die Werbung von Polen und „Freiwilligen unter den früheren polnischen Staatsbürgern nicht-polnischer Nationalitāt “ für die Kościuszko-Division vom 7. Mai 1943496 folgenden Beitritte von Juden lassen sich nur ansatzweise quantifizieren: Der Verband Polnischer Patrioten registrierte unter seinen Mitgliedern 1944 mit 98071 Juden einen Anteil von 43,8\% an der Gesamtzahl von 223806. Die meisten ehemals polnischen Juden lebten damals in Zentralasien, wohin sie nach der Amnestie für die 1940-1941 zu Zwangsarbeit Verurteilten (12. August 1941) gestrōmt waren.497 Anfang 1945 ergab die VPP (ZPP)-Zählung 177604 Juden, d.h. einen Anteil von $56 \%$ an der Mitgliederzahl.498 Diese Zahlen erfassen zum einen aber nur die Verbandsmitglieder, zum anderen bestand keine Veranlassung, sich als Jude auszuweisen - angesichts des bekannten Antisemitismus muß der Anteil der ursprünglich jüdischen Mitglieder noch höher angesetzt werden. 499

Kersten geht in ihrer Schätzung 500 bis $60 \%$. Das Organisationskomitee der polnischen Juden in der UdSSR meldete im Juni 1945 der Weltkonföderation polnischer Juden in New York 250000 polnische Juden - im August 1945 gab dasselbe Gremium jedoch nur noch 150000 an. Ende 1945 waren es laut einer Mitteilung über Repatriierungswillige wieder 200000 . Tatsāchlich kamen im Zuge der offiziellen Repatriierung 136550 Juden nach Polen. ${ }^{501} \mathrm{Da}$ es auch informelle Rückreisen und den Anteil nicht als Juden ausgewiesener Repatrianten gab, ist dieser Wert nur als Mindestzahl anzusehen. Mitte 1946 werden durch das Zentralkomitee der Juden in Polen 157420 Rückkehrer namhaft gemacht, dazu zählt Hornowa etwa 10000 im Herbst 1945 demobilisierte Soldaten und "mindestens ${ }^{4} 3000$ jüdische Offiziere und Soldaten, die im aktiven Dienst blieben. 502

Sodann bleiben noch die Zahlen der in den Lagern Uberlebenden. Auch hier weichen Schätzwerte voneinander ab - für Deutschland, wo die Insassen noch eine Zeitlang in DP-Camps interniert wurden, bevor sie entweder nach Polen zurückkehrten

495 Insgesamt verließen mit Anders etwa 70000 Soldaten und 44000 Zivilisten die UdSSR, davon etwa 4000 Juden (Vgl. Homowa, Powrót, S. 109). - Der Grund für den geringen jüdischen Anteil ist darin zu suchen, daß die UdSSR autgrund einer Vereinbarung mit der polnischen Exilregierung vom 1.12.1941 nur Personen polnischer Nationalität, die vor dem 1.11.1939 als Polen gemeldet waren, als Polen und damit als für die Anders-Amee eligibel ansah. Seitens der Polen sind Einsprüche dagegen nicht bekannt. Die Sowjetunion trat von dieser Diskriminierung am 16.1.1943 zurück und versah von Juni 1944 an alle mit polnischen Papieren, die dies wünschten. Bestātigt wurde dies im polnisch-sowjetischen Abkommen vom 6.7.1945, das die Repatriierung einieitete.

496 Vgl. Zbigniew Kumos, Związek Patriotów Polskich, Warszawa 1983, S. 65

497 Nora Levin (The Jews in the Soviet Union since 1917. Bd. 1, New York 1988, S. 372 f.) gibt gestützt auf die New Yorker Dissertation von Shimon Redlich (The Jews under Soviet Rule During World War II, New York University 1968) ihre Zahl mit "possibly as many as $200000^{4}$ an.

$498 \mathrm{Vgl}$. Hornowa, Powrót, S. 109; Kersten, Repatriacja, S. 42.

499 Szyja Bronsztejn (Uwagi o ludności żydowskiej na Dolnym Sląsku w pierwszych latach po wyzwoleniu, in: BZIH 75 (1970), S. 35 f.) gibt z.B. für Niederschlesien neben ca. 85000 jüdischen Repatrianten ,etwa 5000 Personen jüdischer Herkunft, die mit der jüdischen Gemeinschaft keine Kontakte unterhielten“, an. Er stützt sich dabei auf einen Bericht des Regierungskommissars für die Produktivienung der jüdischen Bevölkerung in Niederschlesien für Dezember 1946 und Januar 1947 (Stdadnica akt Komitetu Wojewódzkiego PZPR Wroclew, 1/N/37).

500 Vgl. Kersten, Repatriacja, S. 36.

501 Vgl. Homowa, Powrót, S. 112.

502 Vgl. ebenda, S. 113. - Am Rande sei erwähnt, daß es 1956-57 zu einer weiteren Repatriierungswelle (ca. 20000) kam. 
oder in Emigrationslānder auswanderten (zu einem geringen Teil auch in Deutschland blieben), fehlen noch eindeutig aufgeschlüsselte Werte. Nach Schlesien kamen 1945 etwa 4000 Juden aus den Lagern im „Westen “. 503 Ebenso schwierig ist es, die exakten Zahlen für die Überlebenden der Arbeits- und Konzentrationslager zu ermitteln. In Częstochowa waren es 5200 , in Auschwitz etwa 7000 Häftlinge (vornehmlich Kranke) aller mōglichen Nationalitāten, in Lódź 877 Personen aus dem Aufrāumungskommando. In Niederschlesien wurden mindestens 15000 Juden aus Arbeitslagem befreit, von denen nach der Abreise westeuropäischer Juden etwa 7000 in Schlesien blieben. ${ }^{504}$ Man geht sicher nicht fehl, die Zahl der in Polen aus den Lagem Befreiten mit 20-25000 anzugeben. Undeutlich bleibt der Anteil nicht-polnischer Juden. Das ergābe etwa 200000 als Mindestwert, etwa 300000 als Maximalwert. Lucy Dawidowicz $^{505}$ rechnet mit 50-70000 polnischen Juden in Polen, der polnischen Armee und in Deutschland. 506 Die Zahl der aus der UdSSR Repatriierten gibt sie mit 180000507 an. Rechnet man hierzu eine unbestimmte Anzahl von polnischen Juden, die in der UdSSR (sei es in den ehemaligen polnischen Ostgebieten oder in den Aussiedlungsgebieten in Sibirien, Kern-Rußland oder Zentralasien) blieben, ergibt sich eine Uberlebensrate, die etwas über 300000 liegt. Krystyna Kersten, die mit einer Arbeit über die Repatriierung der Polen nach dem Zweiten Weltkrieg einschlägig ausgewiesen ist, nennt für das Jahr 1945 vor dem Beginn der Repatriierung aus der UdSSR (nach einer Schätzung des Zentralkomitees Polnischer Juden) 100000 Juden in Polen; bis Juli 1946 sei die Zahl dann auf ca. 245000 angestiegen, was eine Zahl von Repatriierten ansetzt, die jedenfalls über 170000 liegt, weil Kersten richtig schreibt, daß gleichzeitig eine starke Emigration eingesetzt habe. ${ }^{508}$ Für 1945 setzt Kersten die jüdische Auswanderung aus Polen mit 30000 an. 509 Von April 1946 bis Hertst 1948 war in Polen

503 Vgl. Homowa, Powrót, S. 117.

504 Vgl. ebenda

505 War, S. 397.

506 Proudfoot (Refugees, S. 341) nennt 80000 nech dem American Jewish Year Book 1947/48.

507 Bei Proudfoot (Refugees, S. 341) erscheint die Zahl 140000; unter Einschluß der Ameeangehörigen und der Spätrepatrianten von 1957-59 nennen Gutmen/Krakowski 229000 (Unequal, S. 363).

$508 \mathrm{Vg}$. Krystyna Kersten, Narodziny systemu wadzy, Paris 1986, S. 169. Diese Emigration beziffert Proudfoot (Refugees, S. 341) auf 120000 . Auch nach dieser Emigrationswelle hätten noch 100000 Juden in Polen gelebt Nach den Notierungen eines Nev Yorker statistischen Jahrbuchs für 1947, das Jacob Lestschinsky (Crisis, Catastrophe, and Survival. A Jewish Balance Sheet 1914-1948, New York 1948, S. 97) anführ, lebten 1947 in zehn großen polnischen Städten gerade 27348 Juden, die meisten in Lodź mit 13000 , gefolgt von Krakau mit 6000 und Warschau mit 5000 Juden. Da diese Daten nach den Anfordenungen für Mazot ermittelt wurden, hält Lestschinsky sie für greatly exaggerated, since every farnily sought to obtain a larger quota of matzoth and often registered the children expected to be born in the family" (Ebenda). Andererseits gab es für nicht-religiöse Juden, insbesondere wenn sie mit der Partei in Verbindung standen, Gründe, sich nicht um die Zuteilung der rituell vorgeschriebenen Pesah-Speise zu bemühen, so daß diese Werte letztlich nicht aussagefahig sind.

$509 \mathrm{Vgl}$. Kersten, Narodziny, S. 132. Zur Anzahl polnischer Juden in der Sowjetunion liegen stark voneinander abweichende Zahlen vor. Ende 1945 hatten sich 125000 polnische Juden für die Repatriierung registrieren lassen - viele Tausende kehrten jedoch auch individuell nach Polen zurück, während eine nicht näher bestimmbare Anzahl östlich der neuen polnischen Grenze verblieb. Im Juni 1945 meldete das Organisationskomitee Polnischer Juden in der UdSSR (nach seinem Bulletin Nr. 6) der Weltkonferenz der Föderation Polnischer Juden in New York 250000 polnische Juden in der Sowjetunion. Im Protokoll Nr. 11 der Sitzung des Prāsidiums des Zentralkomitees Polnischer Juden (in Polen) war am 20. Februar 1946 von 160000 die Rede, während die Zeitschrift des Verbandes Polnischer Patrioten (Wolna Polska 8-9/144/45 vom 7.3.1946) in der UdSSR die Zahl 170000 verbreitete. Michal Grynberg (Organizacja powrotu ludności żydowskiej z ZSRR do Polski po Il wojnie światowej, Folks-Sztyme 27/6.7.1974), der auch die obigen Angaben vorstellt, hält es für gerechdfertigt, von insgesamt etwa 200000 in der Sowjetunion geretteten polnischen Juden zu sprechen. 
ganz offiziell ein Emigrationsbüro der Jewish Agency tātig, das die jüdische Auswanderung nach Palästina/Israel organisierte. ${ }^{510}$ Danach darf eine Zahl von mehr als 280000 überlebenden polnischen Juden angenommen werden. $\$ 11$

Wie schon angedeutet, handelt es sich dabei keineswegs um Angehörige der jüdischen Religionsgemeinschaft - die Klassifizierung erfolgte vielmehr auf einer Mischbasis aus "nationalem“ Selbstverstāndnis, Glaubensbekenntnis und Fremddefinition (etwa auch durch Antisemiten, die bis in die Gegenwart hinein nicht müde werden, eine "Verjudung ${ }^{\star}$ von Personen zu diagnostizieren, die sich in jeder erdenklichen Hinsicht von Kriterien abgesetzt haben, die eine Zuordnung zu einer ,jüdischen“ Gruppe rechtfertigten). Trotz der Fragwürdigkeit dieses Ordnungsverfahrens muß daher zum Zwecke der Erschließung von entsprechenden Größen auch für die Nachkriegszeit die Zuordnung zur ,jüdischen Gruppe“ auf der Basis der Kriterien der polnischen und deutschen Antisemiten beibehalten werden.

Bereits vor Kriegsende, im Februar 1945 hatte das Ministerium für öffentliche Verwaltung die jüdischen Bekenntnisgemeinden mit ihrer geistlichen und weltichen Mischfunktion durch ein Doppelsystem ersetzt: Bekenntnis-Kongregationen bekümmerten sich auf freiwilliger Basis um den religiösen Bereich, wāhrend Jüdische Komitees (auch atheistische) kulturelle Aufgaben hatten. Nach einer Schätzung gab es im Jahre 1947 in den Kongregationen 80000 jüdische Glāubige. Es gab 38 tätige Synagogen und drei Talmudschulen. Man hatte 25 Rabbiner - im Vergleich dazu gab es 1939 2500 Rabbiner. $\$ 12$ Diese Zahlen sind jedoch für die Ermittlung der Anzahl der Überlebenden von geringer Bedeutung.

Bezogen auf den Zensus-Mittelwert von 3350000 Juden im Jahre 1939 ergibt sich in der einfachen Subtraktion (ohne Rücksicht auf die jeweilige territoriale Ausdehnung des Staates) eine Zahl von ca. 3000000 ermordeten polnischen Juden. Auf diesen Wert kommen Hilberg ${ }^{513}$, Krakowski 514 und Gilbert. ${ }^{515}$ Er dürfte jedoch überhöht sein. Das gilt umsomehr für die ersten Schätzungen nach dem Krieg, die bis zu 3271000 gingen. 516 In einem ersten wissenschaftlichen Versuch nimmt Reitlinger eine Bandbreite von 2350000 bis 2600000 an, wobei er betont, daß es sich nur um „annāhemde Schātzungen " handelt. ${ }^{517}$ Wir sind eher geneigh, die 300000 Heimkehrer von denjenigen zu subtrahieren, die bis 1941 in deutsche Gewalt gerieten (s.S. 443: $3000000)$. 2770000 Opfer unter den polnischen Juden nehmen auch Gerald Fleming 518 und Czeslaw Madajczyk ${ }^{519}$ an. Da letzterer von 110000 polnischen Juden in

510 Kersten, Narodziny, S. 169.

511 Nach den fehlerhaften Angaben von Ginesy (Guerre, S. 58) sollen es 330000 gewesen sein, Gilbert (Endlösung, S. 242) schātzt die Zahl aut 225000.

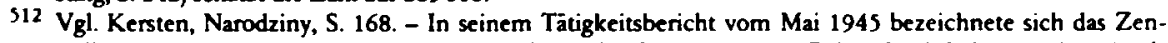
tralkomitee Polnischer Juden als Vertretung folgender Organisationen: Polnische Arbeiterpartei (1942 als Nachfolger der KPP gegründet), Allgemeine Zionisten, Bund, Poale Zion - Linke, Poale Zion, Verband jüdischer Partisanen, Jüdische Kampforganisation (ŻOB), HaShomer HaZair, HeHaluz (Dos naie Lebn, Lódź 6/31.5.1945, nach Mark, Do dziejów, S. 16).

513 Vernichtung, S. 812 .

514 Avedot, S. 232.

515 Endlösung, S. 244. Ein wenig geringer liegt mit 2900000 der Ansatz bei Jacob Lestschinsky, wo jedoch keine genaueren Quellen angegeben werden (Crisis, S. 60).

516 Vgl. Gerald Reitlinger, Die Endlösung, Berlin 1956, S. 573; die Quelle ist hier eine anglo-amerikanische Schātzung aus dem Jahre 1946 (s. Anm. 14).

517 Reitlinger, Endlōsung, S. 573; eigene Schātzung Reitlingers.

518 Gerald Fleming, Hitler und die Endlösung, Wiesbaden 1982, S. 207

519 Madajczyk, Polityka, Bd. 2, S. 328. 
DP Camps im übrigen Europa ausgeht, und nach Reitlinger auf weitere ca. 500000 in der UdSSR kommt, geht Madajczyk von 890000 überlebenden polnischen Juden aus. 520 Auf die Fragwürdigkeit der UdSSR-Schātzwerte war bereits hingewiesen worden.

Die Addition der realistischen Mindestzahlen der polnisch-jüdischen Opfer der Vernichtungsstātten ergibt:

$\begin{array}{lc}\text { Kulmhof, 1. Phase } & 215000 \\ \text { Sobibór } & 80000 \\ \text { Bełżec } & 390000 \\ \text { Treblinka } & 974000^{521} \\ \text { Auschwitz } & 300000 \\ \text { Majdanek } & 50000 \\ \text { Kulmhof, 2. Phase } & 10000 \\ & 2019000\end{array}$

Diesen Orten weist Madajczyk 2000000 nach. Er vermutet aber etwa 700000 weitere Tote aus Ghettos, Arbeitslagern und infolge unmittelbaren Mordes (Einsatzgruppen, Exekutionen, Willkür 1939). ${ }^{522}$ Diesen letzteren Wert solide zu verifizieren erscheint bis jetzt kaum möglich.

Unter Berücksichtigung der Bevölkerungsdifferenz und der Addition der Minimalziffem der nachweislichen Morde kann jedoch der angeführte Wert von 2700000 als durchaus realistisch gelten, eine Korrektur dürfte jedenfalls eher nach oben als nach unten berechtigt sein.

Mit den Morden durch die deutschen Nationalsozialisten ist der Schaden, der der jüdischen Bevölkerung zugefügt wurde, jedoch nur unvollständig umrissen. Dem polnischen Judentum als lebendiger Menschengemeinschaft wurde der Todesstoß versetzt. Die demographische Regeneration wurde dramatisch unterbrochen. In der unnatürlichen Lebensweise der polnischen Juden ist einer der Gründe dafür zu sehen, daß die Geburtenziffern in den Ghettos drastisch fielen und schon bald einen gegen null tendierenden Wert erreichten. Die Abweichung der Geburtenrate vom Normalzustand verhinderte bis auf den heutigen Tag die normale Regeneration der europäischen Juden nach dem Zweiten Weltkrieg - die Uberlebenden, von denen nicht alle nach den erlittenen Qualen und medizinischen Experimenten noch zur Kinderzeugung fähig waren, bildeten eine überalterte Population; darin ist Polen keine Ausnahme.

Die Zahl von 300000 Uberlebenden erscheint in bezug auf die in den Grenzen des polnischen Staates nach 1945 lebenden Juden nach allem Abwägen realistisch. Aber

320 Ebenda - Die hierzu erforderlichen ca 3500000 Juden Ausgangsbevölkerung erhālt Madajczyk durch die Anhebung der Zensuszahlen um die. sog. Ressejuden nach nationalsozialistischer Definition, die auch christlicher Konfession und polnischer Muttersprache sein konnten.

521 Wir glauben, hier ausnahmsweise eine höhere Zahl ansetzen zu können als diejenige Wolfgang Schefflers, dessen Wert $(90000)$ Wolfgang Benz in der Einleitung dieses Bandes benutzt Zum einen ist die "Feier" des millionsten Häflings etwes Markantes, zum anderen ist die sich ergebende Diskrepanz nicht so grof, daß sich signifikante Unterschiede ergïben. Andererseits wird so illustriert, auf welch vagen Indikatoren quantitative Festlegungen basieren.

522 Madajczyk, Polityka, Bd. 2, S. 328. 
das Leben dieser Menschen war auch danach keineswegs sicher. Polens erste Nachkriegsjahre waren von Bürgerkrieg, politischen Machtkämpfen und den Versuchen geprägt, die Kriegsfolgen zu überwinden. Und dennoch kam es nicht etwa zu einem Ende des Antisemitismus in dem befreiten Land. Nicht wenige Polen hatten von der deutschen Judenverfolgung materiell profitiert und bemühten sich um eine Sicherung ihres Besitzes. „Goldgräber " strömten an die Stätten der Lager und gruben nach versteckten Wertsachen der Insassen. 523 Abstruse Ritualmordvorwürfe lebten wieder auf, und eine in rechten Kreisen angenommene Interessenidentität von Juden und Kommunisten vergiftete die Atmosphāre. Im Zuge des polnischen Bürgerkriegs, aber auch durch den Pogrom von Krakau am 11. August 1945 und denjenigen von Kielce vom 4. Juli 1946 (ca. 40 Tote) sowie in zahlreichen anderen Fällen, bei denen es u.a. um die Rückgabe von durch die Nationalsozialisten den Polen übergebenen Wohnraums ging, kamen nochmals in Polen Juden gewaltsam ums Leben. ${ }^{524}$

Der Rest wurde in den darauffolgenden Jahrzehnten vertrieben. Nach dem Zweiten Weltkrieg war einige Jahre lang eine geregelte Emigration nach Israel ${ }^{525}$ bzw. in andere Emigrationsländer (USA, Australien) möglich. Nach 1957 konnten einige Juden Polen im Zuge der Familienzusammenführung für Deutsche verlassen, die mit der Bundesrepublik Deutschland vereinbart worden war. Fast alle restlichen polnischen

523 Zu Treblinka vgl. Donat, Treblinka, S. 265. - Zur Anomalitāt der demographischen Struktur der polnischen Juden vgl. Michal Grynberg, Struktura spoleczna repatriantów oraz szacunek liczby ludności iy. dowskiej w Polsce w pierwszych latach po II wojnie światowej, Folks-Sztyme 29/27.7.1974. Grynberg vergleicht die allgemeinen Zensusdaten von 1946 mit den spezifischen Angaben zu den jüdischen Repatrianten aus der UdSSR und den Juden in Lódź, dem einzigen Ort, an dern statistische Erhebungen gemacht wurden:

$\begin{array}{llll} & \text { Zensus } 1946 & \text { jüd. Repatrianten } & \text { Juden in Lódź } \\ \text { Verhältnis Männer/Frauen } & 10083 & 45: 54 & - \\ \text { Unter } 18 \text { Jahren (in \%) } & 36,7 & 25 & 14 \\ \text { Uber } 59 \text { Jahren (in \%) } & 8,9 & 3 & 1\end{array}$

524 Vgl. Gutman/Knakowski, Unequal, S. 370. Gesichert scheint die Zahl von 353 Toten zu sein (Julius H. Schoeps, Unbequeme Erinnerungen, in: Die ZEIT 42/9.10.1987, S. 23), Gilbert (Endlōsung, S. 241) gibe 1000 Opfer an. Im Mai 1945 formulierte eine Resolution der Londesberatung von Aktivisten der PPR (Polnische Arbeiterpartei) im jüdischen Milieu: „Die Bentung verurteilt auf das schärfste die verbrecherische Tätigkeit von reaktionären Elementen der NSZ, die die Hitlerexzesse in bezug auf die gerettete jüdische Bevölkerung fortsetzen und sogar jüdische Frauen und Kinder morden.“ (nach Mark, Do dziejów, S. 15). - Vgl. ue S. L. Shneiderman, Between Fear and Hope, New York 1947; Goldstein, Sterne, S. 287 : „Die große Mehrzahl der Polen stand den Juden feindlich gegenüber. Dauemd konnte man hören: ,Was, noch so viele Juden! Wo kommen die alle her? Antisemitismus zeigte sich überall. Den zurückkehrenden Juden wurde bedeutet, daß sie überflüssig waren, daß jedes Stück Brot, das sie in den Mund steckten, einem besseren Menschen als ihnen weggenommen wünde! ... Unsere Beschwerden wurden von unseren polnischen Freunden verständnisvoll hingenommen, aber keine Aktion gegen die antijüdische Welle wurde eingeleitet. Es gab zu viel anderes zu tun "s - 1947 versuchte in einem von der Gesamtpolnischen Liga für den Kampf mit dem Rassismus herausgegebenen Buch Michał Borwicz (Organizowanie wścieJosci, Warszawa 1947) die Methode zu dokumentieren, mit der die Deutschen polnischen Antisemitismus gefördert hätten, und so den Antisemitismus in Polen zu bekämpfen. Vgl. auch Martwa fala Zbiór artyęulów o antysemityźmie, Warszawa 1947. - Daß es such ohne antisemitischen Kontext jüdische Opfer von Bürgerkrieg und normaler Kriminalität gab, wie Madajczyk (Sprawy, S. 291) betont, ergibt keinen Widerspruch. Eine Trennung zwischen beiden Kategorien ist nur in einzelnen Fällen möglich, da nur mehr selten die Motive der Tater ergründbar sind. Gutman/Krakowski (Unequal, S. 366) betonen, daß es niche die Kommunisten waren, die für die antisemitischen Hetzkampagnen verantwortich waren. Sie schreiben: -One thing can be asserted without hesitation: the surfeit of Nazi anti-semitism that had created the Holocaust had also infected the Polish public." (S. 369)

525 Zwischen 1946 und 1948 gelangten 17000 polnische Juden nach Palästina, zwischen 1948 und 1951 weitere 106000 nach Israel (Proudfoot, Refugees, S. 356, 359). 
Juden wurden im Zuge der "antizionistischen ", in Polen in Wirklichkeit antisemitischen Hetzkampagnen 1968 aus dem Lande getrieben. Es blieben etwa 5000 - in der überwiegenden Mehrzahl handelte es sich um kranke und alte Menschen, so daß der Tag abzusehen ist, da Polen ein Land ohne Staatsbürger jüdischer Herkunft sein wird. 
